Check for updates

Cite this: Mater. Chem. Front. 2019, 3, 2326

Received 30th July 2019,

Accepted 28th August 2019

DOI: $10.1039 / c 9 q m 00492 k$

rsc.li/frontiers-materials

\section{Ligand functionalized copper nanoclusters for versatile applications in catalysis, sensing, bioimaging, and optoelectronics}

\author{
Shayan Shahsavari, (D) $\dagger^{\mathrm{ab}}$ Samaneh Hadian-Ghazvini, $\uparrow^{\mathrm{c}}$ Fahimeh Hooriabad Saboor, $\uparrow^{\mathrm{d}}$

 \\ Andrey L. Rogach iD *ij
}

\begin{abstract}
Copper nanoclusters (Cu NCs) have emerged as a valuable member of the family of ligand-protected few-atomic metal nanoparticles and show fascinating properties of color-controlled light emission, combined with the advantages of versatile solution-based chemical synthesis at low cost. Synthetic methods of $\mathrm{Cu}$ NCs using various types of functional ligands and scaffolds allow tuning their emission wavelength and improving their environmental stability. Depending on the method of preparation and the ligands used, Cu NCs have already been applied for a wide variety of applications in catalysis, sensing, bioimaging, theranostics, and optoelectronics. This review highlights the potential of Cu NCs and links synthetic procedures and functionalization with different ligands with their properties and applications.
\end{abstract}

\section{Introduction}

Functional nanomaterials have undergone an impressive development and are now starting to impact diverse aspects of human life. An important class of nanomaterials is metal nanoparticles (NPs) with chemical, electrical, magnetic, and optical properties often different from their bulk phases, ${ }^{1}$ which have made them applicable for a wide range of applications. A recent development in the synthesis of metal NPs is the fabrication of sub-nanometer structures which are composed of a few or few tens of atoms.

\footnotetext{
${ }^{a}$ Department of Chemistry, Sharif University of Technology, Tehran, Iran

${ }^{b}$ Nanoclub Elites Association, Tehran, Iran

${ }^{c}$ Institute of Biochemistry and Biophysics, University of Tehran, Tehran, Iran

${ }^{d}$ Department of Chemical Engineering, University of Mohaghegh Ardabili, Ardabil, Iran

${ }^{e}$ School of Medicine, Tehran University of Medical Sciences, Tehran, Iran

${ }^{f}$ Department of Chemical and Petroleum Engineering, Sharif University of Technology, Tehran, Iran

${ }^{g}$ Department of Materials Science and Engineering, Sharif University of Technology, P.O. Box 11365-9466, 14588 Tehran, Iran.E-mail: simchi@sharif.edu; Fax: +98 (21) 6600 5717; Tel: +98 (21) 66165226

${ }^{h}$ Institute for Nanoscience and Nanotechnology, Sharif University of Technology, P.O. Box 11365-9466, 14588 Tehran, Iran

${ }^{i}$ Department of Materials Science and Engineering, and Centre for Functional Photonics, City University of Hong Kong, 83 Tat Chee Avenue, Kowloon,

Hong Kong S.A.R. E-mail: andrey.rogach@cityu.edu.hk

${ }^{j}$ Shenzhen Research Institute, City University of Hong Kong, Shenzhen, 518057, China

$\dagger$ These authors contributed equally to this work.
}

These so-called metal nanoclusters (MNCs) provide a link between larger, plasmonic metal NPs and molecular-like compounds. Their sizes are close to the Fermi wavelength of electrons, so that they exhibit discrete electronic states and show fluorescence emission. ${ }^{1-3}$ In recent years, many studies have been devoted to gold and silver NCs. ${ }^{4}$ In spite of the lower cost and ready availability of copper, $\mathrm{Cu}$ NCs were more difficult to synthesize, while their photoluminescence quantum yields (PLQY) tended to be lower. ${ }^{2}$ At the same time, the photostability of $\mathrm{Cu}$ NCs is better than that of organic dyes. In comparison with many II-VI and IV-VI semiconductor quantum dots with high PLQY, toxicity issues of Cu NCs are fewer, ${ }^{4}$ while their cellular uptake could be easier, due to the smaller size. ${ }^{5}$ Due to the useful chemical, optical and electrical properties of $\mathrm{Cu}$ NCs, efforts on broadening their applicability in various fields such as catalysts, chemical sensors, biological imaging agents, and electronic devices have increased in recent years. $^{2,3,6-8}$

The aim of this article is to present a comprehensive review on the application-related aspects of $\mathrm{Cu}$ NCs (summarized in Table 1), which were not so much in the focus of other reviews. Recent advances in the synthetic protocols with an emphasis on their advantages and shortcomings are considered, and properties of $\mathrm{Cu}$ NCs related to several possible applications (Scheme 1) such as catalysis, detection and sensing, biological imaging, theranostics, and light emitting devices (LEDs) are discussed. The review concludes with the future trends and outlooks for the further development of the $\mathrm{Cu}$ NC field. 


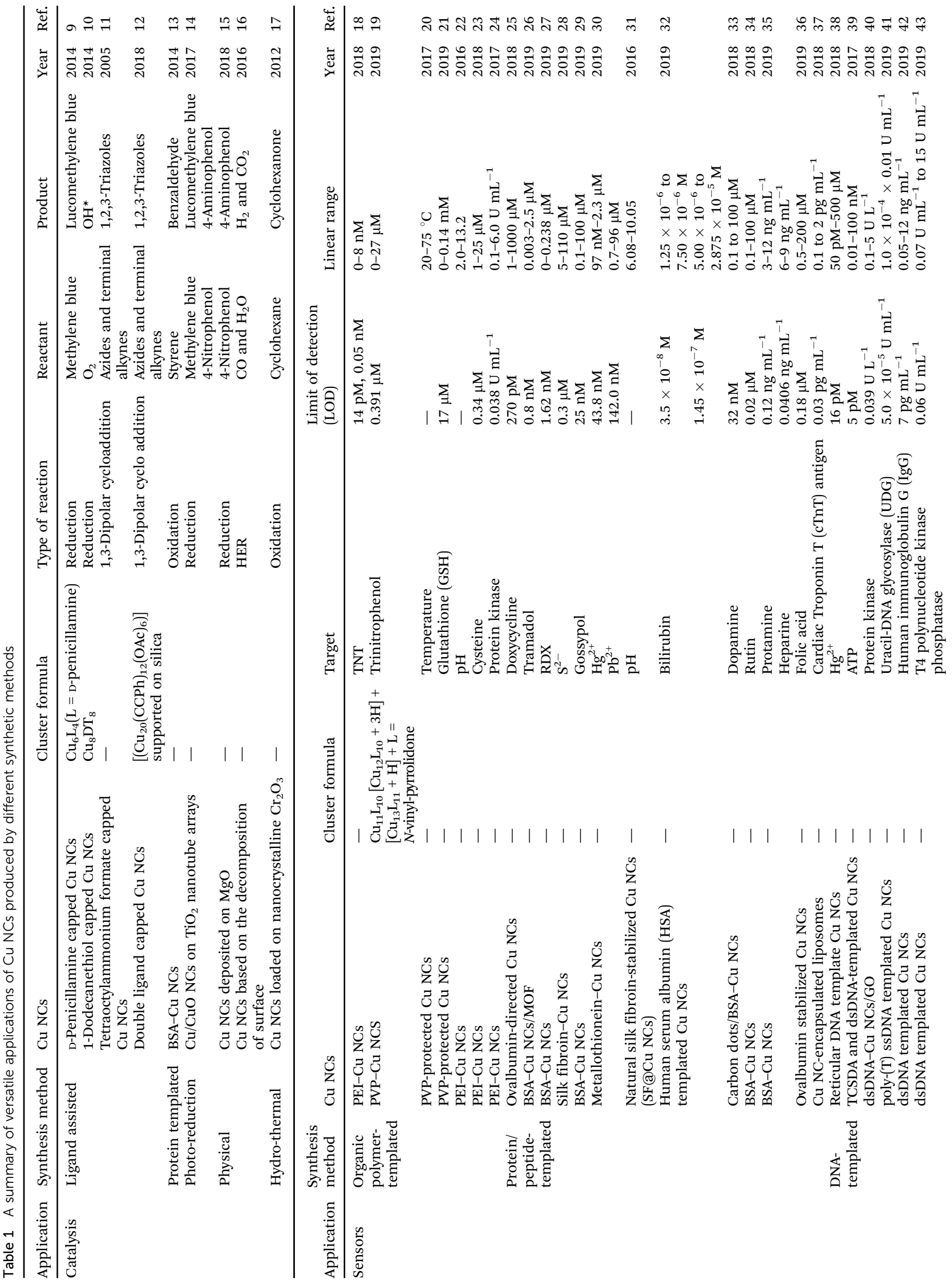




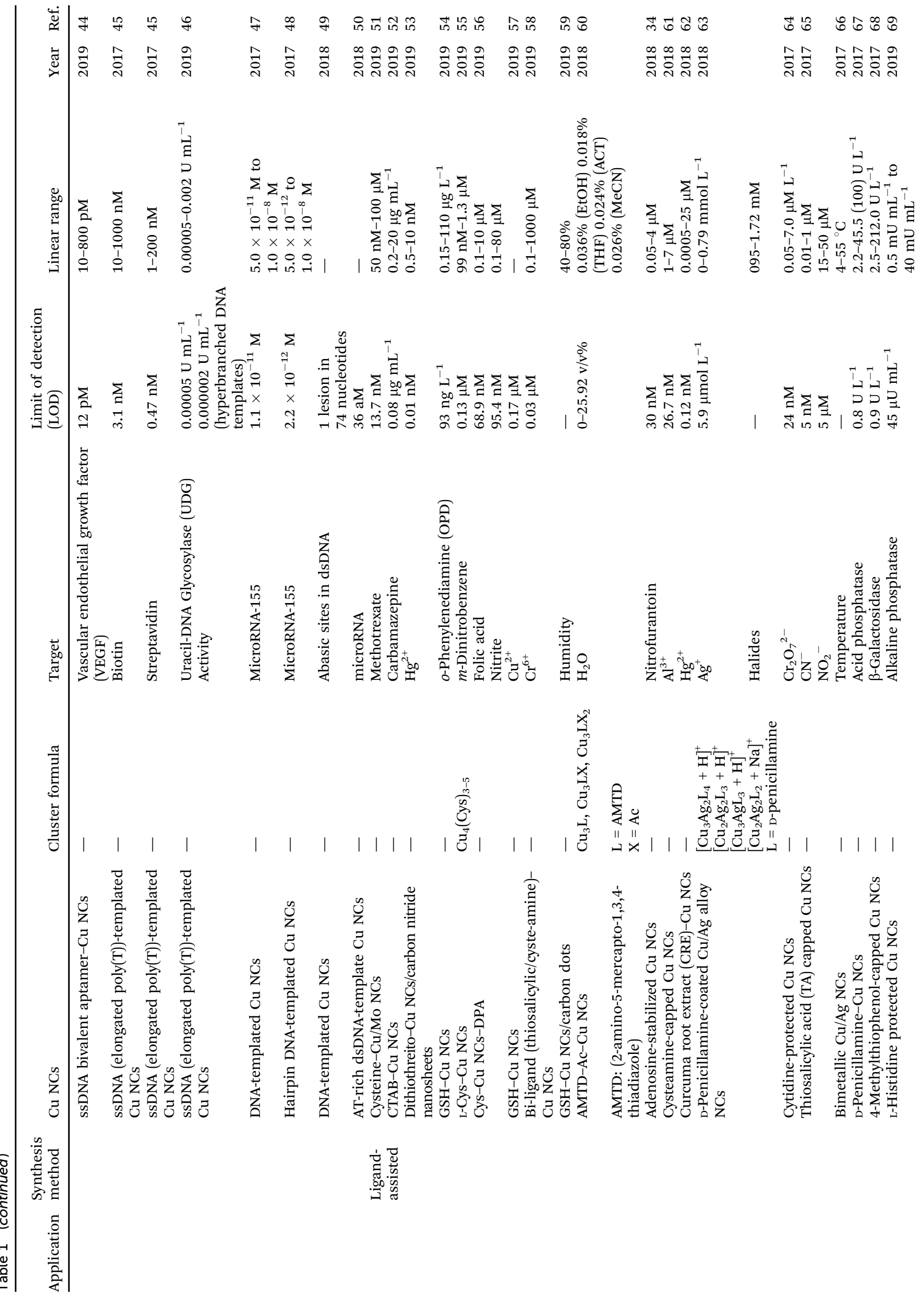




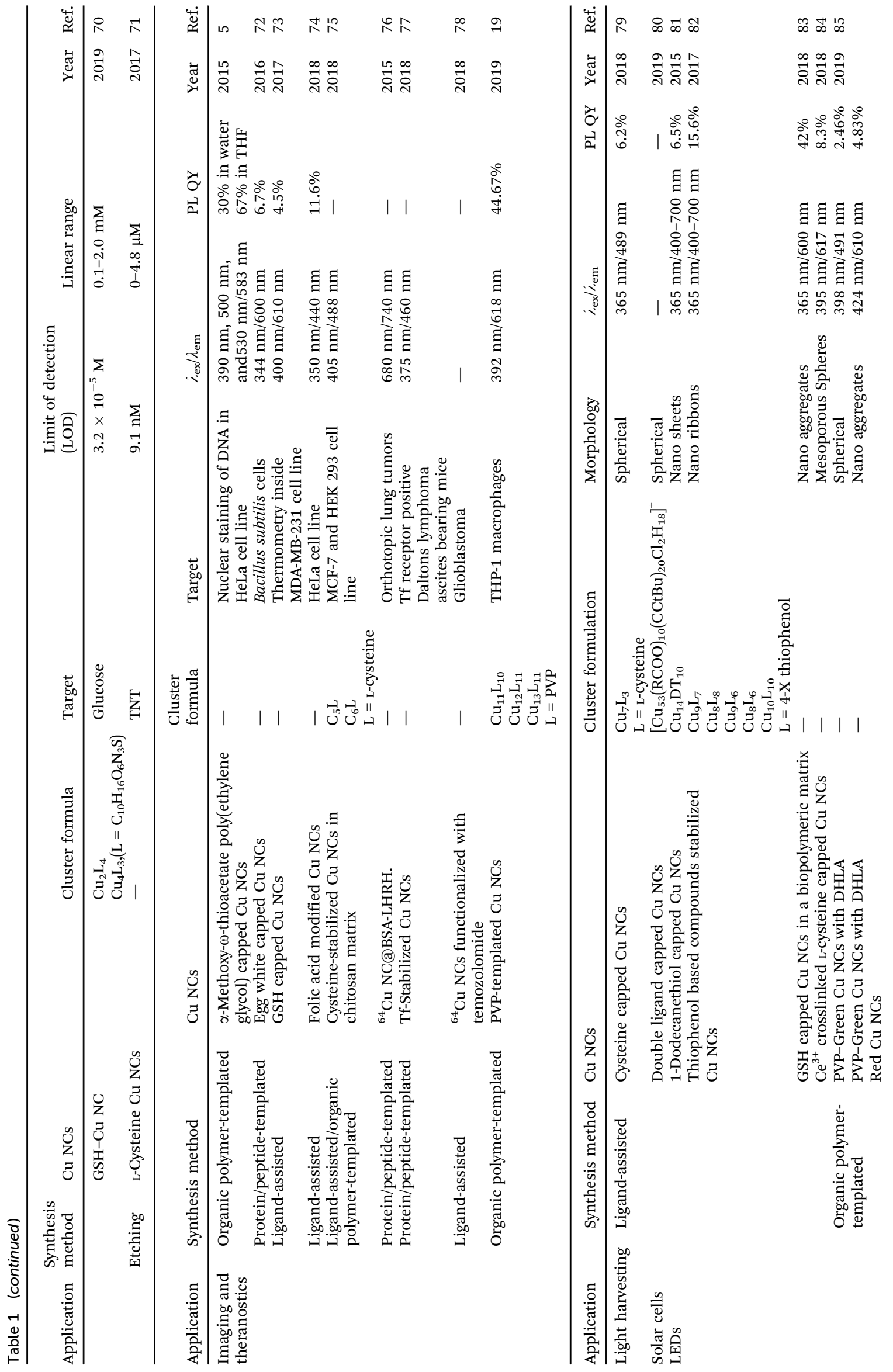




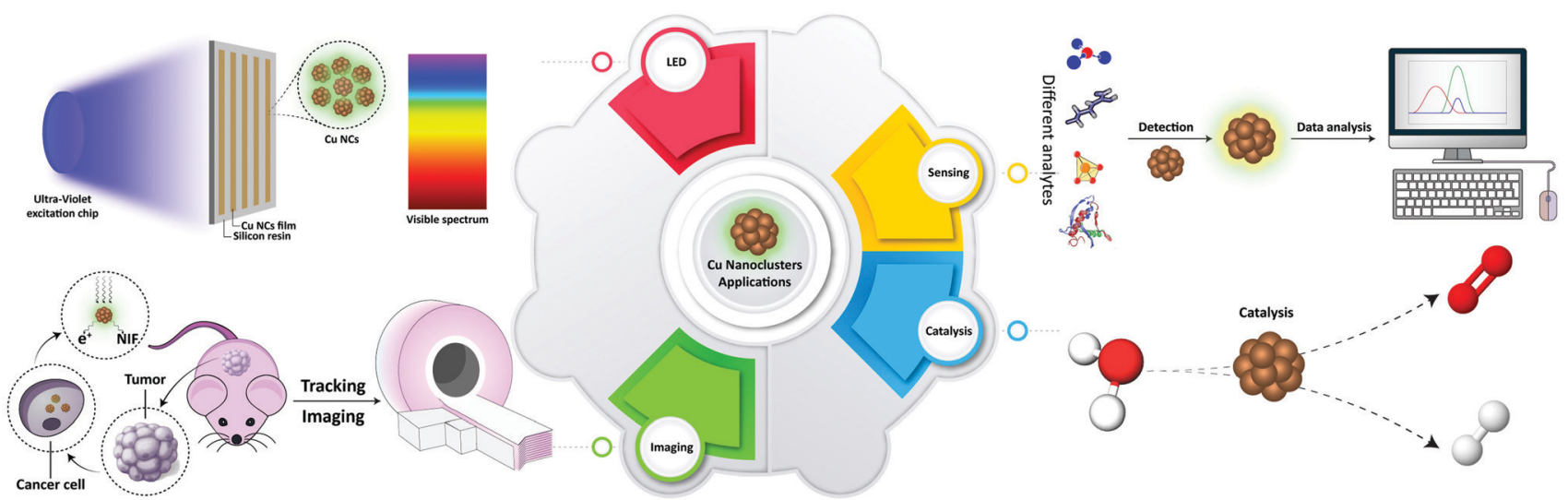

Scheme 1 Schematic depiction of different possible applications of copper nanoclusters.

\section{Optical properties of metal NCs and their aggregation/assembly induced emission}

The ultrafine size (usually less than $2 \mathrm{~nm}$ ) of metal NCs induce electronic transitions between separated energy levels giving rise to light absorption at a given wavelength and emission with a longer wavelength. ${ }^{2,86,87}$ Bornacelli and coworkers ${ }^{88}$ synthesized bare Pt, Ag and Au NCs by ion-implantation in sapphire plates, and employed the Jellium model, $E_{\mathrm{Fermi}} / N^{1 / 3}$, to simulate their emission spectra. They concluded that the optical emission of these clusters can be explained based on the quantum confinement effects. Hovewer, the Jellium model would not work for ligand-functionalized NCs such as the thiolate-protected ones, because it does not take into account the contribution of ligands towards the electronic structure and the optical transitions of such structures. The PL origin of ligand-protected metal NCs and relevant parameters that contribute to their emission have been summarized by Xie and co-workers in a recent book, ${ }^{89}$ pointing out the effect of varying core sizes and the type of ligands. ${ }^{90}$ Ligand exchange further confirmed their effects on the PL of metal NCs. ${ }^{91}$ Besides the effects of the ligands and the metal core, there are some other variables such as the thiol-to-metal ratio and the oxidation state of the metal core that affect the PL response of metal NCs. ${ }^{89}$

It has been demonstrated in a plenty of studies that the emission of the metal NCs can be significantly improved as a result of their aggregation. The aggregation-induced emission (AIE) phenomenon which was discovered for molecular dyes in 2001 by Tang and coauthors is also valid for the metal NCs, so far. ${ }^{89,92}$ AIE characteristics of the metal NCs include sufficiently high PL QYs (typically in the range of 10-50\%), large Stokes shift, and long excited state lifetimes. ${ }^{89,93}$ Among the different ligand stabilized metal NCs, those capped with glutathione, 1-dodecanethiol, penicillamine, and cysteine are the most often reported ones with AIE. The AIE effect in metal NCs can be conveniently triggered by post-synthetic treatment, when changes of the solvent polarity, $\mathrm{pH}$, and/or addition of some ions induce their self-assembly and aggregation. ${ }^{89,92}$ Although the exact mechanism of AIE in metal NCs still requires further studies, it has been generally stated that

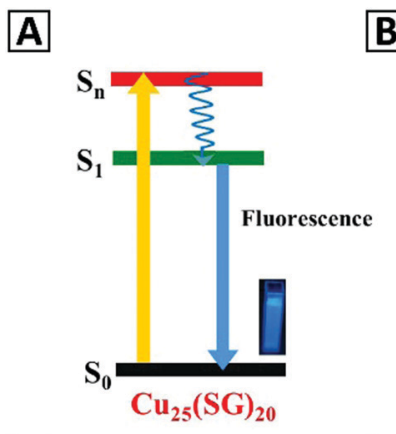

C

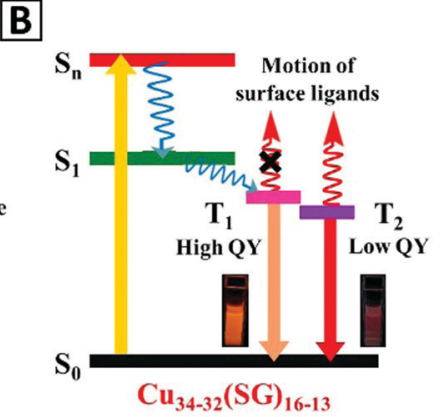

D

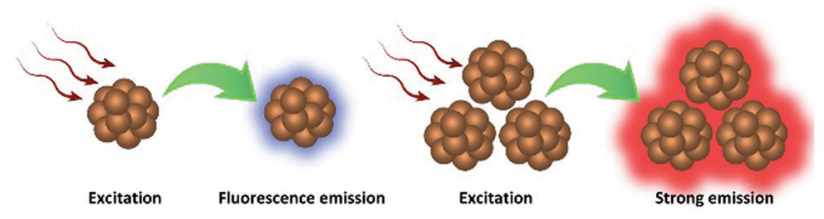

Fig. 1 Schematics of the energy levels and excitation/emission processes in (A) isolated $\mathrm{Cu}_{25}(\mathrm{SG})_{20} \mathrm{NCs}$ and $(\mathrm{B})$ aggregated $\mathrm{Cu}_{34-32}(\mathrm{SG})_{16-13} \mathrm{NCs}$. Adapted with permission from ref. 92, Copyright 2019, ACS. (C and D) Give a schematic representation of the emission from the isolated metal NCs and the aggregated clusters, respectively.

restriction in molecular rotational and vibrational motions of the capping ligands after aggregation blocks non-radiative pathways and opens radiative ones, and thus subsequently leads to PL enhancement. As illustrated in Fig. 1, the emission of isolated metal NCs relies on the $S_{1}$ to $S_{0}$ transition (fluorescence), while aggregated ones emit based on the $T_{1}$ to $S_{0}$ transition (phosphorescence). ${ }^{89,92,94}$ An additional advantage of the AIE of aggregated metal NCs is that their emission color often appears in the red and near-infrared spectral regions, which means they can be employed for biosensing, with little interference with the autofluorescence of biological materials. ${ }^{94}$

\section{Synthesis of copper NCs}

Fig. 2A and Table 1 summarize the main chemical and physical preparation methods that have been utilized for the synthesis 


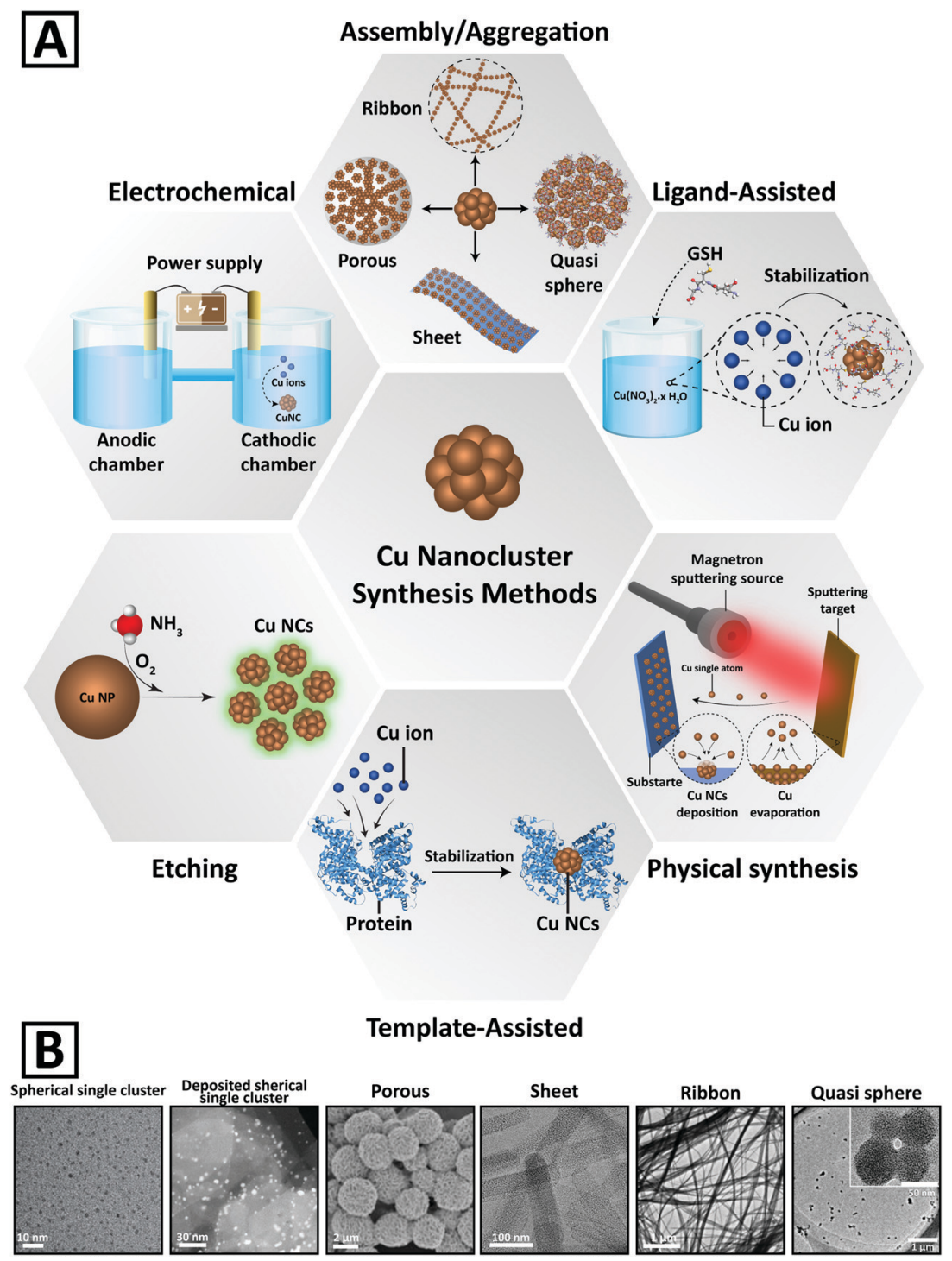

Fig. 2 (A) Schematic representation of different chemical and physical methods developed for the synthesis of Cu NCs. (B) Representative electron microscopy images of Cu NCs with different morphologies. Adapted with permission from ref. 15, 82, 84 and 100-102, Copyrights 2016-2018, Wiley$\mathrm{VCH}, \mathrm{RSC}$, and ACS.

of $\mathrm{Cu}$ NCs so far. The synthetic procedures can be categorized into 6 groups, including ligand assisted, template-assisted, electrochemical, etching, and physical methods, and assembly and aggregation. ${ }^{64}$ Chemical methods rely on the reduction of $\mathrm{Cu}^{2+}$ ions into $\mathrm{Cu}$ atoms in a solution phase. ${ }^{95,96}$ Ligands and templates are often employed to stabilize the clusters and to protect them from aggregation and oxidation; ${ }^{2,5,97,98}$ therefore, assembly and aggregation are considered as a subset of the ligand assisted method, which results in two- and three-dimensional cluster morphologies. Representative electron microscopy images of $\mathrm{Cu}$ NCs with different morphologies are presented in Fig. 2B.

Several characterization protocols of $\mathrm{Cu}$ NCs are in place to confirm different aspects of their structure. NMR spectroscopy and X-ray absorption spectroscopy are often used, as are chromatographic methods to assess their purity. ${ }^{99} \mathrm{X}$-ray photoelectron spectroscopy (XPS) is applied to study the oxidation states of the metallic core of $\mathrm{Cu}$ NCs, while it has to be noted that the unambiguous recognition between $\mathrm{Cu}(0)$ and $\mathrm{Cu}(\mathrm{I})$ states is challenging. ${ }^{79}$ Absorption and steady-state/time-resolved PL spectroscopy are routine while essential measurements to provide basic optical characterization of NCs, and for the determination of their PLQY. ${ }^{92}$

\subsection{Ligand assisted synthesis of $\mathrm{Cu}$ NCs}

During the synthesis and formation of $\mathrm{Cu}$ NCs, there is a high tendency of aggregation in order to decrease the surface energy, and ligands can prevent this by steric effects which rely on nonbonding interactions. Ligands can also influence the reactivity of precursor ions and molecules, which determines the final size and shape of NCs. ${ }^{103}$ Controlling the kinetics of $\mathrm{Cu}^{2+}$ reduction in the presence of ligands is crucial to attain monodisperse Cu NCs. Different parameters such as ligand concentration, reducing agent 
concentration, the $\mathrm{pH}$ of solution, the temperature, and the reaction time can affect the formation of desirable products. Choosing different ligands not only affects the PL intensity and the catalytic activity of ligand functionalized $\mathrm{Cu}$ NCs, but also plays a role in sensitivity to various environments. ${ }^{104}$ Ligands with thiol and carboxyl groups are the two most important organic molecules which have widely been utilized for the synthesis of $\mathrm{Cu}$ NCs, ${ }^{64}$ as will be presented below.

3.1.1. Thiolate ligands. Many research groups have employed glutathione (GSH) as a ligand for the synthesis of Cu NCs. Huang et $a .^{105}$ synthesized GSH-capped $\mathrm{Cu}$ NCs which had a red luminescence under UV irradiation at $365 \mathrm{~nm}$. Wang et al. ${ }^{98,106}$ used GSH as both protecting and reducing agents, mixing GSH and $\mathrm{Cu}^{2+}$ with a molar ratio of $4: 1$ which resulted in $\mathrm{Cu}$ NCs with a red emission at $600 \mathrm{~nm}$. Mukherjee and co-workers ${ }^{107}$ mixed $\mathrm{Cu}^{2+}$ and GSH with a molar ratio of $1: 1$ and prepared $\mathrm{Cu}$ NCs $\left(\mathrm{Cu}_{15}(\mathrm{GSH})_{4}\right)$ having a blue emission under UV irradiation. Through a similar approach, Huang et al. ${ }^{108}$ synthesized $\mathrm{Cu}$ NCs with an intense blue fluorescence under $365 \mathrm{~nm}$ UV irradiation. They added ascorbic acid (AA) to a solution of $\mathrm{Cu}^{2+}$ and $\mathrm{GSH}$ and stirred the mixture for $4 \mathrm{~h}$ at $65{ }^{\circ} \mathrm{C} / \mathrm{pH}=6$. Cu NCs with a red emission at $620 \mathrm{~nm}$ under UV excitation ( $365 \mathrm{~nm}$ ) were also prepared by mixing $\mathrm{GSH}$ and $\mathrm{Cu}^{2+}$ at a molar ratio of $5: 1$. The maximum PLQY (24\%) was attained at $\mathrm{pH}=5 .{ }^{101,109}$

More recent advances are the synthesis of $\mathrm{GSH}$-capped $\mathrm{Cu}$ NCs with different sizes by heating the solution (up to $80{ }^{\circ} \mathrm{C}$ ) under $\mathrm{N}_{2}$ flow, followed by separation of clusters through gel electrophoresis, capillary electrophoresis, and liquid chromatography. The resulting $\mathrm{Cu}$ NCs had a composition of $\mathrm{Cu}_{5}(\mathrm{GSH})_{6}$, $\mathrm{Cu}_{6}(\mathrm{GSH})_{6}, \mathrm{Cu}_{7}(\mathrm{GSH})_{6}, \mathrm{Cu}_{8}(\mathrm{GSH})_{6}$, and $\mathrm{Cu}_{9}(\mathrm{GSH})_{6}$. We note that some of these $\mathrm{Cu}$ NCs have larger sizes than $\mathrm{Au}_{25}(\mathrm{GSH})_{18}$ prepared by gel electrophoresis. ${ }^{110}$ Han et al. ${ }^{111}$ developed a one-pot synthesis protocol to prepare GSH-protected Cu NCs encapsulated in metal-organic frameworks (MOFs). To obtain $\mathrm{Cu}$ NCs@GSH/MOF-5, 1,4-benzene dicarboxylic acid and Zn $\left(\mathrm{NO}_{3}\right)_{2} \cdot 6 \mathrm{H}_{2} \mathrm{O}$ were dissolved in DMF, and under stirring $\mathrm{Cu}^{2+}$ salt and GSH solutions were introduced. Through adjusting $\mathrm{pH}$ to 5 , a white turbid solution was attained after $24 \mathrm{~h}$ at room temperature (RT). The fluorescence intensity of $\mathrm{Cu}$ NCs in the composite nanostructure was enhanced 35-fold, while the stability improved from 3 days to 3 months.

Another approach utilizes thiolates as ligands for an organic-phase synthesis of GSH stabilized $\mathrm{Cu}$ NCs with a red PL emission under UV irradiation. Huang et al. ${ }^{112}$ prepared $\mathrm{Cu}$ NCs in DMF by a simple mixing method and used them for sensitive detection of water in organic solvents. GSH capped $\mathrm{Cu}$ NCs were synthesized by injection of a saturated GSH aqueous solution into a solution of $\mathrm{Cu}^{2+}$ in $\mathrm{EtOH}$, and the aggregation was triggered by supersaturation of GSH in EtOH as a poor solvent. The PL QY was $48 \%$ in the solid state, which exceeded the value reported for Zn-coordinated GSH-capped Au NCs. ${ }^{93,113}$

Zhao and co-workers ${ }^{67}$ used D-penicillamine as a suitable ligand for the synthesis of $\mathrm{Cu}$ NCs. They obtained $\mathrm{Cu}$ NCs with a bright red luminescence at $37^{\circ} \mathrm{C}$ and at an incubation time of $4 \mathrm{~min}$. Other groups also used penicillamine as a protecting ligand for the synthesis of $\mathrm{Cu}$ NCs. ${ }^{9,114-116}$ Chen and co-workers ${ }^{96}$ used 2-mercapto-5- $n$-polypyrimidine as a ligand and $\mathrm{NaBH}_{4}$ as a reducing agent. They obtained clusters with the composition of $\left[\mathrm{Cu}_{8}\left(\mathrm{C}_{7} \mathrm{H}_{9} \mathrm{~N}_{2} \mathrm{~S}\right)_{4}\right]$ which had PL with dual emissions at $423 \mathrm{~nm}$ and $593 \mathrm{~nm}$ and PLQY of $3.5 \%$ and $0.9 \%$, respectively. Chang's group ${ }^{65}$ has shown that thiosalicylic acid can also be used as a ligand; by mixing it with THF in DMF and then adding $\mathrm{Cu}^{2+}, \mathrm{Cu}$ NCs were obtained. Mercaptosuccinic acid (MSA) was also utilized as a ligand in the presence of $\mathrm{NaBH}_{4}$ as a reducing agent. ${ }^{117}$ Another molecule that has often been used as a ligand is L-cysteine. Borghei et al. ${ }^{118-120}$ have shown that $\mathrm{Cu}$ NCs can rapidly be prepared in the presence of cysteine at $\mathrm{pH}=12$ at $\mathrm{RT}$, which exhibited a PL emission in the range of 410 to $580 \mathrm{~nm}$ depending on the cysteine concentration. Su and Liu ${ }^{121}$ employed L-cysteine with an equal molar ratio with $\mathrm{Cu}^{2+}$ to prepare $\mathrm{Cu}$ NCs with a pale red emission color under UV irradiation (365 nm). Blue emitting $\mathrm{Cu}$ NCs (at $428 \mathrm{~nm}$ ) were prepared with 4,6-diamino-2mercaptopyrimidine (DAMP) as a ligand by Khonkayan et al. ${ }^{122}$ Stable red emissive $\mathrm{Cu}$ NCs were fabricated from $\mathrm{CuCl}_{2}$ using L-cysteine as a capping ligand and a mild reducing agent at RT. ${ }^{121}$ These $\mathrm{pH}$ responsive $\mathrm{Cu}$ NCs were used for producing hybrid nanostructures with bovine serum albumin (BSA), which were soluble in water at $\mathrm{pH}=3.0$ and had PLQY of $6.3 \%$ and $2.1 \%$ in the solid state and aqueous solution, respectively. ${ }^{121}$

The cation cross-linking procedure has been used to fabricate aggregated L-cysteine capped $\mathrm{Cu}$ NCs with a mesoporous morphology and improved PLQY. ${ }^{84}$ For this purpose, $100 \mu \mathrm{L}$ of $0.1 \mathrm{M} \mathrm{CuSO}_{4} \cdot 5 \mathrm{H}_{2} \mathrm{O}$ was added to $2 \mathrm{~mL}$ of $0.1 \mathrm{M}$ L-cysteine in water; the mixture was subjected to vortexing for $10 \mathrm{~min}$, and a suitable amount of $0.1 \mathrm{M} \mathrm{Na}_{2} \mathrm{CO}_{3}$ was added to induce aggregation. Thereafter, different amounts of $\mathrm{Ce}^{3+}$ were titrated to produce crosslinked aggregates; PLQY before and after $\mathrm{Ce}^{3+}$ addition was 3.4\% and $8.3 \%$, respectively. ${ }^{84}$ Yet another strategy for improving the PLQY of Cu NCs is direct metal doping. For example, central doping of $\mathrm{Au}$ as a single atom into dichalcogenolate-protected $\mathrm{Cu}$ NCs led to strong enhancement of their PLQY, which reached 59\% when measured at $77 \mathrm{~K}$ in 2-MeTHF for $\left[\mathrm{Au} @ \mathrm{Cu}_{12}\left(\mathrm{~S}_{2} \mathrm{CN}^{n} \mathrm{Bu}_{2}\right)_{6}(\mathrm{CCPh})_{4}\right]^{+}$ clusters. $^{123}$

Self-assembly of Cu NCs into wires, ribbons, and sheets has been realized by employing 1-dodecanethiol (DT) as a ligand. For the synthesis of ribbons, for example, $30 \mathrm{mg}$ of copper(II) acetylacetonate was dissolved in a mixture of dibenzyl ether $(2 \mathrm{~mL}$ ) and liquid paraffin $(5 \mathrm{~mL})$. Then, $1 \mathrm{~mL}$ DT was introduced, and the mixture was stirred at $120{ }^{\circ} \mathrm{C}$ for $30 \mathrm{~min} .{ }^{10}$

Several other thiolate ligands were also employed for the synthesis of $\mathrm{Cu}$ NCs, namely, cysteamine, ${ }^{124,125}$ phenylethanethiol, ${ }^{114}$ dihydrolipoic acid, ${ }^{126}$ mercaptobenzoic acid, ${ }^{127}$ 3-mercapto-trimethoxy silane, ${ }^{128}$ and 2-mercapto-1-methylimidazole. ${ }^{129}$

3.1.2. Ligands with carboxyl groups. Ligands with carboxyl groups are less frequently used for the synthesis of $\mathrm{Cu}$ NCs. As an example, $\mathrm{Cu}$ NCs were prepared by mixing $\mathrm{Cu}^{2+}$ and sodium cholate at controlled concentrations to form blue hydrogels. The PL spectra displayed the maximum excitation wavelength at $375 \mathrm{~nm}$ and an emission peak at $615 \mathrm{~nm} .{ }^{130}$ Tannic acid as a ligand and AA as a reducing agent have been used to make $\mathrm{Cu}$ NCs exhibiting a blue PL emission at $430 \mathrm{~nm}$ under excitation at $360 \mathrm{~nm} .{ }^{4}$ Zheng et al. ${ }^{131}$ showed that AA itself can serve as a 
protecting ligand upon the synthesis of $\mathrm{Cu}$ NCs when the reaction mixture was kept for $3 \mathrm{~h}$ at $25{ }^{\circ} \mathrm{C}$.

\subsection{Template-assisted synthesis of $\mathrm{Cu}$ NCs}

To prepare $\mathrm{Cu}$ NCs and at the same time avoid their aggregation, templates such as DNA, protein, peptides, and polymers have been widely utilized. $\mathrm{Cu}^{2+}$ ions are able to bind to those templates and are then reduced to form clusters, whose aggregation is prevented by steric hindrance. Different templates can be chosen based on the types of potential application. Parameters such as $\mathrm{pH}$, temperature, ratio of $\mathrm{Cu}^{2+}$ and templates can control the ratio of functional ligand groups and the metal core. For example, in $\mathrm{Cu} \mathrm{NC}$ synthesis utilizing the protein template, the increase of $\mathrm{pH}$ facilitates breaking of disulfide bonds and stabilizes $\mathrm{Cu}$ NCs within the protein scaffold by thiol groups. A recent study has shown that by modifying the synthetic conditions in the template-assisted method, high PLQY exceeding $44 \%$ in water can be achieved. ${ }^{19}$ A brief overview of the resulting $\mathrm{Cu}$ NCs is given below.

3.2.1. DNA templating. DNA templates have widely been employed for the synthesis of $\mathrm{Cu}$ NCs. Borghei et al. ${ }^{48}$ synthesized orange- and green-emitting DNA-Cu NCs using ascorbate as the reducing agent for $\mathrm{Cu}^{2+}$ ions in phosphate buffer saline (PBS) at $\mathrm{pH} \sim 7$. Mokhir's group ${ }^{132}$ utilized AA as the reducing agent and double-stranded DNA (dsDNA) as the template to obtain $\mathrm{Cu}$ NCs with a strong PL emission in the range of 580-600 nm. Similarly, Singh et al. ${ }^{49}$ used two single-stranded DNA (ssDNA) to prepare dsDNA in the presence of AA and employed them to grow $\mathrm{Cu}$ NCs. Han et al. ${ }^{133}$ prepared thymine(T)-template fluorescent $\mathrm{Cu}$ NCs through the reduction by $\mathrm{NH}_{2} \mathrm{OH} \cdot \mathrm{HCl}$ at $\mathrm{pH} 11.5$, which exhibited a strong PL peak at $561 \mathrm{~nm}$ when excited at $354 \mathrm{~nm}$. In a similar study, Cu NCs with a PL emission of $617 \mathrm{~nm}$ (for excitation at $349 \mathrm{~nm}$ ) were prepared using elongated poly $\mathrm{T}$ as a template. ${ }^{45}$ The template was prepared via polymerization of $\mathrm{T}$ with biotin-DNA/folateDNA as the primer, and terminal deoxynucleotidyl transferase (TdT) as the catalyzing enzyme. The mixture was allowed to react in the PCR tube for $4 \mathrm{~h}$ at $37^{\circ} \mathrm{C}$. In another study, ${ }^{134,135}$ Zhou's group showed that DNA with long chains can stabilize $\mathrm{Cu}$ NCs at RT within $2.5 \mathrm{~h}$. Herein, TdT was used to polymerize DNA in the presence of adenine and thymine at a molar ratio of $1: 1$. Examination of different ssDNA templates like random ssDNA, poly A, poly $\mathrm{T}$, poly $\mathrm{C}$ and poly $\mathrm{G}$ at $\mathrm{pH} 7.6$ by 3-morpholinopropane1-sulfonic acid has indicated that only poly $\mathrm{T}$ template yielded luminescent $\mathrm{Cu}$ NCs with a PL peak at $\sim 600 \mathrm{~nm}$ when excited at $340 \mathrm{~nm} .{ }^{97,136}$ The reason for this is that $\mathrm{Cu}^{+}$is an intermediate product of $\mathrm{Cu}^{2+}$ reduction to $\mathrm{Cu}$, and $\mathrm{T}$ has the lowest affinity for binding to $\mathrm{Cu}^{+}$(while $\mathrm{G}$ has the highest affinity for binding to $\mathrm{Cu}^{+}$).

3.2.2. Polymer templating. Polyethyleneimine (PEI) has widely been utilized as a template for the synthesis of $\mathrm{Cu}$ NCs, while hydrazine hydrate ${ }^{137}$ and $\mathrm{AA}^{138}$ were the most popular reducing agents for reduction of $\mathrm{Cu}^{2+}$ to $\mathrm{Cu}$ atoms in combination with PEI. For instance, Cu NCs@PEI with an intense blue emission under excitation at $365 \mathrm{~nm}$ have been prepared by mixing a $\mathrm{Cu}^{2+}$ solution, AA and PEI, followed by microwave irradiation for $20 \mathrm{~s}$ and incubation at $25{ }^{\circ} \mathrm{C}$ for 3 h. ${ }^{18,137}$ Poly(amidoamine) (PAMAM) dendrimers as a template and $\mathrm{NaBH}_{4}$ as the reducing agent have also been utilized to prepare $\mathrm{Cu}$ NCs with different number of $\mathrm{Cu}$ atoms in the core, ranging from 4 to $64 .^{139-141}$ Bologh et al. ${ }^{142}$ employed a polypropylene imine dendrimer modified with diaminobutane, and $\mathrm{NaBH}_{4}$ in methanol as a reducing agent to produce $\mathrm{Cu}$ NCs. Polyvinylpyrrolidone (PVP) was used as the template in the presence of AA and formaldehyde (as the reducing agent) to prepare $\mathrm{Cu}$ NCs with 398-457 nm PL emission under UV irradiation (310 $\mathrm{nm}$ to $390 \mathrm{~nm}) .{ }^{143,144}$ Some reducing agent free methods have also been examined. For instance, poly(methacrylic acid) modified with pentaerythritol tetrakis 3-mercaptopropionate has been used as a template for the synthesis of $\mathrm{Cu}$ NCs via photo-reduction of $\mathrm{Cu}^{2+}$, yielding clusters with a PL emission peak of $630 \mathrm{~nm}$ under excitation at $360 \mathrm{~nm}^{145}$ Polyethylene glycol (PEG) modified with lipoic acid has been used to prepare blue emitting $\mathrm{Cu}$ NCs. ${ }^{5}$ Green emitting water-soluble $\mathrm{Cu}$ NCs with a high PLQY of $\sim 44 \%$ were synthesized through introducing an aqueous solution (10 mL) of $100 \mu \mathrm{L} \mathrm{CuCl}_{2}, 0.2 \mathrm{~g}$ PVP and $300 \mu \mathrm{L}$ AA into Carousel 6 Plus $(100 \mathrm{~mL})$. The mixture was sealed to protect it from possible oxidation, and incubated for $21 \mathrm{~h}$ at $90{ }^{\circ} \mathrm{C}$ under gentle stirring to attain Cu NCs@PVP. ${ }^{19}$

3.2.3. Protein and peptide templating. Proteins and peptides have appropriate functional groups for binding to $\mathrm{Cu}^{2+}$ ions, thus promoting stabilization of $\mathrm{Cu}$ NCs. Some proteins like bovine serum albumin (BSA) can act as both a reducing agent and a stabilizer. BSA in the presence of dithiothreitol (DTT) assisted the reduction of $\mathrm{Cu}^{2+}$ ions. ${ }^{146}$ There are other additives such as $\mathrm{H}_{2} \mathrm{O}_{2}{ }^{147}$ and hydrazine hydrate ${ }^{13}$ which support such a role of BSA. In the presence of $\mathrm{NaOH}$, which decomposes the BSA structure and breaks the disulfide bonds, blue emitting $\mathrm{Cu}$ NCs (410 $\mathrm{nm}$ ) were produced by using BSA without any secondary reductant. ${ }^{148-150}$ Papain is another appropriate protein that has been used as a template for the formation of $\mathrm{Cu}$ NCs. In the presence of hydrazine hydrate as the reducing agent, red emitting $\mathrm{Cu}$ NCs (620 nm) under UV excitation (370 nm) can be synthesized. ${ }^{151}$ Lysozyme, ${ }^{152}$ yeast, ${ }^{153}$ and trypsin ${ }^{13}$ are also good templates for $\mathrm{Cu}$ NC synthesis. Gao et al. ${ }^{154}$ designed a peptide CCYGGPKKKRKVG and applied it as the template to obtain blue emitting $\mathrm{Cu}$ NCs (418 nm). In a similar work, a CLEDNN peptide was used as a template and AA as the reducing agent. ${ }^{155}$ Egg white is an easily available template for the one-pot synthesis of $\mathrm{Cu}$ NCs. Bhamore et al. ${ }^{72}$ mixed egg white with hydrazine hydrate, $\mathrm{NaOH}$, and $\mathrm{CuSO}_{4}$ and heated the mixture inside a microwave at $100 \mathrm{~W}$ for $5 \mathrm{~min}$ to prepare multicolor emitting $\mathrm{Cu}$ NCs. Similarly, Ding et al. and Qiano et al. ${ }^{156,157}$ incubated a mixture of $\mathrm{CuCl}_{2}$, chicken egg white and $\mathrm{NaOH}$ at $55{ }^{\circ} \mathrm{C}$ for $8 \mathrm{~h}$ to prepare $\mathrm{Cu}$ NCs as fluorescent probes.

3.2.4. Other templating methods. In addition to the aforementioned templates, there are other substances that can be used as a scaffold for the preparation of functional $\mathrm{Cu}$ NCs. Biosynthesis of $\mathrm{Cu}$ NCs with strong PL emission (500-650 nm) under $405 \mathrm{~nm}$ excitation by MDA-MB-231 cells in the presence of L-glutathione as the reducing agent was performed by Ye and co-workers. ${ }^{73} \mathrm{Hu}$ et al. $^{158}$ employed DTT as a template to prepare orange-florescent $\mathrm{Cu} \mathrm{NCs}$ for detection of $\mathrm{Al}^{3+}$ ions in food samples. Biswas and co-workers synthesized $\mathrm{Cu}$ NCs of 
diameter 1-4 $\mathrm{nm}$ by employing a millifluidic reactor, ${ }^{159}$ with the reported advantage concerning lower amounts of required reagents and better control over the reaction temperature. The reason for attaining $\mathrm{Cu}$ NCs was the ability to separate the nucleation and growth stages. In a typical procedure, an aqueous solution of $\mathrm{Cu}\left(\mathrm{NO}_{3}\right)_{2}$ and $O$-[2-(3-mercaptopropionylamino)ethyl]-O'methylpolyethylene glycol [MPEG] was pumped into the reactor, and a reducing agent $\left(\mathrm{NaBH}_{4}\right)$ was injected by another pump. $\mathrm{Cu}$ NCs were formed, separated, and collected under a nitrogen atmosphere.

\subsection{Electrochemical synthesis}

Electrochemical synthesis is a method that has widely been used to prepare various metal NPs and NCs. During the process, electrolysis of the copper anode releases $\mathrm{Cu}^{2+}$ ions, which are then reduced and capped at the cathode in the form of $\mathrm{Cu}$ NCs; by controlling the current density, the final size of NCs can easily be adjusted. ${ }^{160}$ The advantages of this procedure are that $\mathrm{Cu}$ NCs can be synthesized at low current densities and without any additional ligands or surfactants. Under optimum conditions, PLQY of such "naked" Cu NCs could be as high as $13 \%$, which favorably compares with many of $\mathrm{Cu}$ NCs prepared by wet chemical methods. ${ }^{161}$ Huseyinova et al. ${ }^{162}$ synthesized stable surfactant-free $\mathrm{Cu}_{5}$ clusters with a blue PL emission (305 nm) under excitation at $224 \mathrm{~nm}$. Vilar-Vidal et al. ${ }^{161}$ produced highly stable ligand-free $\mathrm{Cu}_{13}$ NCs with a blue PL emission (410 nm) by using tetrabutylammonium nitrate as an electrolyte and showed that the number of atoms in the copper core ( $u$ p to $\mathrm{Cu}_{20}$ ) can be regulated by heating these clusters at $80{ }^{\circ} \mathrm{C}$, followed by re-dissolution in acetonitrile. Green fluorescent $\mathrm{Cu}$ NCs with smaller dimensions (down to $\mathrm{Cu}_{5}$ core atoms) have been produced by centrifugation in ethanol through a purification process. ${ }^{163}$

\subsection{Etching methods}

Chemical etching can be considered as a top-down method for the synthesis of MNCs from larger, non-luminescent NPs, often in the presence of suitable excess ligands or excess metal salts. ${ }^{64}$ NCs can be synthesized from poly-disperse NPs through a digestive ripening or core etching mechanism. Using an etching approach for formation of $\mathrm{Au}$ and $\mathrm{Ag}$ NCs has been rather popular, while there are only a few examples in the case of $\mathrm{Cu}$ NC synthesis. ${ }^{92}$ Wang and co-workers ${ }^{22}$ added $\mathrm{Cu}^{2+}$ to oleyl amine (OA) and 1-octadecene (ODE) solution to prepare $\mathrm{OA}-\mathrm{Cu}$ NPs. Etching of $\mathrm{Cu}$ NPs was performed by adding an aqueous solution of polyethyleneimine (PEI) to OA-Cu NPs in chloroform at $50{ }^{\circ} \mathrm{C}$. In another experiment, ${ }^{164} \mathrm{Cu}^{2+}$ and AA (serving as both a reducing agent and a capping agent) were used to prepare $\mathrm{Cu}$ NPs, which were added to GSH aqueous solution to provide the etching process. The resulting $\mathrm{Cu}$ NCs exhibited a strong emission peak at $600 \mathrm{~nm}$. Instead of using GSH for etching, other thiol ligands like cysteine ${ }^{164,165}$ and penicillamine ${ }^{164}$ can also be utilized. Xie et al. ${ }^{166}$ reduced $\mathrm{Cu}^{2+}$ by $\mathrm{NaBH}_{4}$ to attain $\mathrm{Cu}$ NPs protected by GSH, which were transferred to an organic phase through the addition of cetyltrimethylammonium bromide (CTAB), which were incubated for $24 \mathrm{~h}$ to obtain $\mathrm{Cu}$ NCs with a blue PL emission at $438 \mathrm{~nm}$.
Patra's group ${ }^{92}$ synthesized red and blue emitting $\mathrm{Cu}$ NCs through the etching of $\mathrm{Cu}$ NPs by addition of a highly concentrated GSH. The as-synthesized red emitting $\mathrm{Cu}_{34-32}(\mathrm{SG})_{16-13}$ NCs showed a PL peak at $625 \mathrm{~nm}$ with a low PLQY of $0.03 \%$, which could be increased 36-fold via addition of EtOH with $f_{\mathrm{v}}=90 \%$. The as-prepared blue-emitting $\mathrm{Cu}_{25}(\mathrm{SG})_{20}$ NCs showed a PLQY of $9.7 \%$, which could be further enhanced two-fold by addition of EtOH with $f_{\mathrm{v}}=75 \%$. Deng et al. ${ }^{100}$ developed a method to etch $\mathrm{Cu}$ NPs with ammonia $\left(\mathrm{NH}_{3}\right)$; green fluorescent $\mathrm{Cu}$ NCs with a PLQY of $6.6 \%$ were attained after $\sim 15 \mathrm{~min}$.

\subsection{Other methods}

There are few other techniques used for fabrication of $\mathrm{Cu}$ NCs which are somewhat hard to be classified into the above-mentioned groups. Lopez-Quintela and coworkers ${ }^{167}$ employed the water-in-oil micro-emulsion technique to prepare blue emitting $\mathrm{Cu}$ NCs under $\mathrm{UV}$ irradiation, using $\mathrm{Cu}^{2+}$ as an aqueous solution, cyclohexane as an oily phase, $\mathrm{NaBH}_{4}$ as a reducing agent and sodium dodecyl sulfate with isopentanol as a surfactant. Recently, Koninti et al. ${ }^{168}$ synthesized Cu NCs inside the water pool of reverse micelles, which were made of sodium bis(2-ethyl-1-hexyl)-sulfosuccinate or Triton $\mathrm{X}-100$ or CTAB. Quite remarkably, the stability of L-cysteine protected $\mathrm{Cu}$ NCs increased from 40 days in bulk water to 180 days in reverse micelles due to the protection of the as-synthesized clusters from aerial oxidation. Kawazaki et al. ${ }^{169}$ employed a microwave-assisted polyol synthesis to produce oxidation resistant $\mathrm{Cu}$ NCs through in situ ethoxylation reaction of ethylene glycol, without the need for any additional ligands or surfactants. Toh et al. ${ }^{170}$ embedded $\mathrm{Cu}$ NCs in ZnO thin films prepared by the radio frequency magnetron sputtering method to study their magnetic properties. The film deposition was carried out at $170 \mathrm{~K}^{171,172}$ under the gas flow of $\mathrm{Ar}$ and $\mathrm{He}\left(100-200 \mathrm{~cm}^{3} \mathrm{~min}^{-1}\right)$. Then, $\mathrm{Cu}$ NCs were formed on the ZnO film by using nanocluster beam deposition. The clusters had an average size of 8 to $10 \mathrm{~nm}$ while secondary phase nanoclusters $\left(\mathrm{CuO}\right.$ and $\mathrm{Cu}_{2} \mathrm{O}$ ) were also formed. After depositing another $\mathrm{ZnO}$ layer on top of $\mathrm{Cu}$ NCs, improved ferromagnetism at RT was attained through the overlapping of the p-orbital from $\mathrm{O}$ contributed by $\mathrm{ZnO}$ and the d-orbital contributed by $\mathrm{Cu}$. Stable and ligand-free $\mathrm{Cu}$ NCs were synthesized via an anti-replacement method. ${ }^{173}$ A mixture of $3 \mathrm{~mL}$ of $\mathrm{CuCl}_{2}$ solution $\left(20 \mathrm{mg} \mathrm{mL}{ }^{-1}\right)$ and $2 \mathrm{~mL}$ of Au NP solution $\left(0.01 \mathrm{mg} \mathrm{mL}^{-1}\right)$ was irradiated by a pulse laser $(532 \mathrm{~nm})$ for $5 \mathrm{~min}$; Cu NCs with $2.0 \pm 0.4 \mathrm{~nm}$ diameter were formed as a result and were separated by centrifugation, and they emitted at $440 \mathrm{~nm}$ under $350 \mathrm{~nm}$ excitation wavelength. The formation mechanism of $\mathrm{Cu}$ NCs under laser irradiation was ascribed to the generation of "hot electrons" in $\mathrm{Au}$ NPs, which consequently reduced adjacent $\mathrm{Cu}^{2+}$ ions.

\section{Applications of $\mathrm{Cu} \mathrm{NCs}$}

\subsection{Catalysis}

Metal NCs have become quite important from the point of view of their catalytic activity, due to their ultrasmall size and high surface energy, ${ }^{174,175}$ which capitalized on the previously conducted catalytic related studies of larger MNCs. ${ }^{140}$ Although NCs based on 


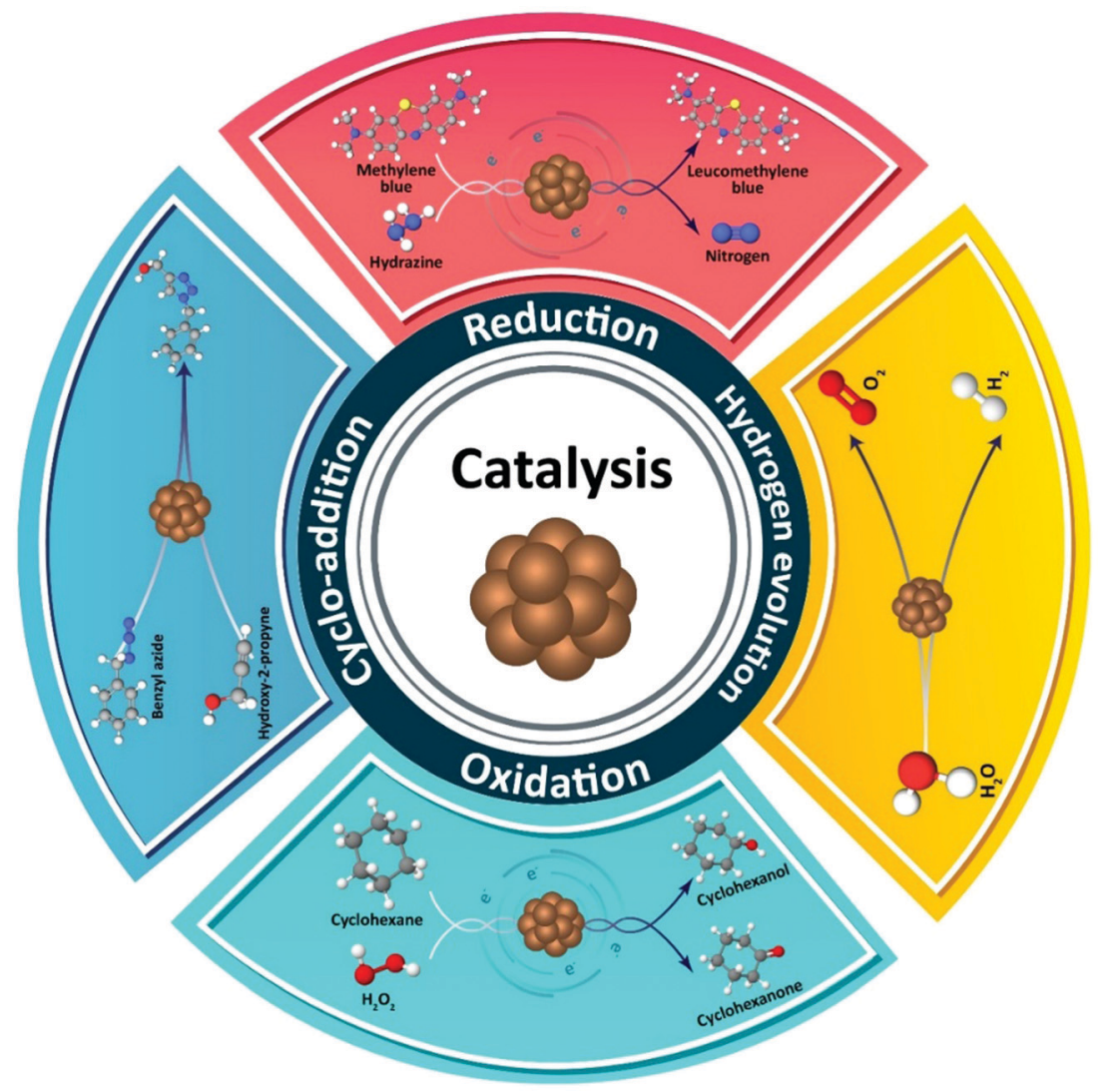

Scheme 2 Schematic representation of four different types of chemical reactions which can be catalyzed by Cu NCs.

noble metals display good catalytic performance, it is highly desirable to offer alternative, less expensive while catalytically active $\mathrm{Cu} \mathrm{NC}$ analogues. Computational aided methods can suggest suitable strategies for developing active catalysts based on Cu NCs. ${ }^{104}$ In that respect, theoretical studies on the surface chemistry of $\mathrm{Cu}$ NCs aimed at the exploration of adsorption steps of different chemical compounds are helpful in the understanding of various types of possible catalytic reactions. For instance, theoretical comparisons between adsorption of $\mathrm{CO}$ and $\mathrm{H}_{2}$ molecules on $\mathrm{Cu}$ NCs by molecular dynamics simulations have shown that $\mathrm{CO}$ is adsorbed more easily than $\mathrm{H}_{2}$, and this has a greater impact on the cluster structure. ${ }^{176}$ As depicted in Scheme 2, catalytic reactions which have been performed so far on $\mathrm{Cu}$ NCs can be classified into four groups, including reduction, oxidation, hydrogen evolution reaction (HER), and 1,3-dipolar cycloaddition. Examples of $\mathrm{Cu}$ NCs used in these kinds of catalytic reactions are outlined below and listed in Table 1.

4.1.1. Reduction. Methylene blue (MB) can be reduced to lucomethylene blue by using hydrazine as a reducing agent. Kinetic studies have shown that in the absence of $\mathrm{Cu}_{13} \mathrm{NCs}$, the optical density of MB was not changed during the reaction; however, in the presence of electrochemically synthesized $\mathrm{Cu}_{13}$ NCs, a fast reduction occurred, and the $\mathrm{Cu}$ NCs retained their catalytic activity for at least 42 cycles. ${ }^{140}$ It was also shown that the increase of concentration of $\mathrm{Cu}_{13} \mathrm{NCs}$ and hydrazine resulted in the enhancement of the rate constant, while the reaction became slower in acidic solutions. It was noted that the size of $\mathrm{Cu}$ NCs is very crucial because larger clusters $\left(e . g . \mathrm{Cu}_{20}\right.$ $\mathrm{NCs}$ ) have not exhibited catalytic activity for this reaction. ${ }^{140}$

Titanium dioxide is a very well-known photocatalyst that has attracted researchers' attention in the last decades. To improve visible light sensitivity of $\mathrm{TiO}_{2}$, Liu et al. ${ }^{177}$ prepared $\mathrm{Cu}(\mathrm{II})$ NC-grafted $\mathrm{Nb}$-doped $\mathrm{TiO}_{2}$. $\mathrm{Nb}$ ions reduced the energy level below the conduction band of $\mathrm{TiO}_{2}$ to be matched with the $E_{\mathrm{Cu}^{2+} / \mathrm{Cu}^{+}}$ (redox potential) of the $\mathrm{Cu}$ (II) $\mathrm{NC}$ complex on the surface of the catalyst. The resulting $\mathrm{Cu}(\mathrm{II})-\mathrm{Nb}_{x} \mathrm{Ti}_{1-x} \mathrm{O}_{2}$ nanocomposite could decompose 2-propanol as an organic compound into $\mathrm{CO}_{2}$ under visible light. A theoretical and experimental study demonstrated that deposition of $\mathrm{Cu}_{5} \mathrm{NCs}$ on the surface of $\mathrm{TiO}_{2} \mathrm{NPs}_{\text {could extend }}$ visible light absorption and lead to the formation of an efficient photocatalyst. ${ }^{178}$

Cai et al. ${ }^{15}$ deposited bimetallic $\mathrm{Cu} / \mathrm{Au} \mathrm{NC}$ catalysts onto a $\mathrm{MgO}$ powder support for the reduction of 4-NP to 4-AP by $\mathrm{NaBH}_{4}$. Cu-rich NCs, Au-rich NCs or Cu/Au-equal NCs formed an alloy structure randomly. The reaction rate constant of $3.49 \times 10^{4} \mathrm{~min}^{-1}$ mole of metal ${ }^{-1}$ was attained from the $\mathrm{Cu} / \mathrm{Au}-$ equal NC catalyst, which was 6.6 (8.9) fold higher than that for the Cu-rich (Au-rich) NCs. Theoretical modeling determined the balancing of the adsorption of 4-NP and desorption of 4-AP, which enhanced the activity of $\mathrm{Cu} / \mathrm{Au}-\mathrm{NC}$ catalysts. It was also found that the activity of $\mathrm{Cu} / \mathrm{Au}$-equal NCs prepared by beam 
deposition was 25 fold higher than that of the catalyst synthesized by wet chemistry.

The first report on the catalytic activity of copper-based structures for reduction of $\mathrm{CO}_{2}$ appeared in 1981. ${ }^{179}$ Tang and co-workers ${ }^{180}$ utilized $\mathrm{Cu}_{32} \mathrm{H}_{20} \mathrm{~L}_{12}$ NCs (L is dithiophosphate ligand) to reduce $\mathrm{CO}_{2}$ to $\mathrm{CO}$ and $\mathrm{HCOOH}$. After adsorption of $\mathrm{CO}_{2}$ on the surface of the catalyst, the main step was where the hydrogen was added: combination of hydrogen with $\mathrm{C}$ would facilitate the reaction to form $\mathrm{HCOOH}$, while addition of hydrogen to $\mathrm{O}$ would produce $\mathrm{CO}$. The turnover number of $\mathrm{Cu}_{13} \mathrm{H}_{20} \mathrm{~L}_{12}$ NCs has been determined as $\sim 1740$ mole $\mathrm{HCOOH}$ per mole of $\mathrm{Cu}_{32} \mathrm{H}_{20} \mathrm{~L}_{12}$.

Although use of the thiolate ligands may become detrimental for achieving high catalytic activity, there have been reports on thiolated $\mathrm{Cu}$ NCs showing decent catalytic performance. ${ }^{181}$ Based on the density functional theory (DFT) simulations, thiolated $\left[\mathrm{Cu}_{25} \mathrm{H}_{10}\left(\mathrm{SPhCl}_{2}\right)_{18}\right]^{3-}$ NCs were introduced as a catalyst for reduction of ketones to alcohols in the presence of hydrogen at RT. ${ }^{182}$ Other studies suggested that the migration of ligands and their partial removal activate catalytic performance of thiolated metal NCs. ${ }^{183,184}$

Even though Au NCs are most popular for electrochemical reduction, ${ }^{185}$ several studies ${ }^{96,186}$ have shown that $\mathrm{Ag}$ and $\mathrm{Cu}$ NCs are also electro-catalytically active. It was reported that $\mathrm{Cu}_{n}$ $(n<9)$ NCs have high catalytic activity for the oxygen reduction reaction (ORR). ${ }^{187}$ Results of electrochemical cyclic voltammetry (CV) also indicated that $\mathrm{Cu}$ NCs with smaller core sizes exhibited higher electro-catalytic activity for oxygen reduction. ${ }^{96,188}$ Ligandfree $\mathrm{Cu}$ NCs were introduced as electrocatalysts for the ORR. ${ }^{173}$ Reduction currents were observed when $\mathrm{Cu}$ NCs were immersed in $0.1 \mathrm{M} \mathrm{KOH}$ solution saturated with either $\mathrm{O}_{2}$ or $\mathrm{N}_{2}$, with respective current density 22 and 1500 times higher than that of $\mathrm{Au}$ NCs and protected Cu NCs of similar size (Fig. 3A). The mass activity of these $\mathrm{Cu}$ NCs was 1.6 and 4.2 fold higher than that of the target set by the U.S. Department of Energy and the commercial Pt catalyst. Such a high electrocatalytic activity was ascribed to the clean surface in the absence of ligands, which greatly facilitated the electron transfer. Interestingly, ligandfree $\mathrm{Cu}$ NCs were also quite durable: The current-time response of $\mathrm{Cu}$ NCs retained $88.1 \%$ of its initial value after $10000 \mathrm{~s}$ (Fig. 3A), which was better than that for the ligand-functionalized $\mathrm{Cu}$ NCs used for comparison.

By employing DFT, the effect of chalcogen (oxygen family elements) doping on the catalytic activity of $\mathrm{Cu}_{4}$ NCs was systemically investigated. ${ }^{189}$ Doped $\mathrm{Cu}$ NCs could electrochemically reduce $\mathrm{CO}_{2}$ to $\mathrm{CH}_{4}$ and $\mathrm{CH}_{3} \mathrm{OH}$. It was also shown that the activation energy barrier for $\mathrm{CO}_{2}$ hydrogenation to $\mathrm{CH}_{4}$ was reduced by $\mathrm{Cu}_{4} \mathrm{~S}$ and $\mathrm{Cu}_{4} \mathrm{O}$ NCs by $0.15 \mathrm{eV}$ and $0.37 \mathrm{eV}$, respectively, and over-potentials for the reaction changed in the order of $\mathrm{Cu}_{4} \mathrm{~S}<\mathrm{Cu}_{4} \mathrm{O}<\mathrm{Cu}_{4} \mathrm{Se}$.

4.1.2. Oxidation. Wang et al. ${ }^{13}$ employed BSA-Cu NCs as a catalyst for styrene oxidation. They showed that in the presence of this catalyst, $70 \%$ of styrene was converted to products with high selectivity (70\% of products was benzaldehyde), while without the catalyst only $7 \%$ of styrene could be converted. Takahashi et al. ${ }^{190}$ used $\mathrm{Cu}_{32} \mathrm{Pt}_{16} \mathrm{Au}_{12}$ multi-metallic nanoclusters (MNCs) for the oxidation of indane to indanone in an oxygen atmosphere (1 atm). It was shown that the catalytic activity of MNCs was 24 times higher than that of commercial Pt catalysts and 5 times higher than that of $\mathrm{Pd}-\mathrm{Au}$. The turn over frequency (TOF) for this catalyst was 1433 (total metal atom $^{-1}$ hour $^{-1}$ ) at $90{ }^{\circ} \mathrm{C}$ under pure oxygen. They also claimed that MNC catalysts could be utilized for other compounds with primary $\mathrm{C}-\mathrm{H}$ bonds, like xylene. He et $a l^{191}$ suggested soluble $\mathrm{Cu}$ NCs as an alternative for alkaline metal alkoxide catalysts in the industrial carbonylation reactions. The high activity of $\mathrm{Cu}$ NCs for green oxidation of methanol to methyl formate with $\mathrm{CO}$ was demonstrated, and complete conversion into this compound under controlled reaction conditions (0.3-3.0 MPa CO, 353-443 K) was shown.

Sarkar and co-workers ${ }^{17}$ synthesized $\mathrm{Cu}$ NCs supported on $\mathrm{Cr}_{2} \mathrm{O}_{3}$ for the oxidation of cyclohexane. $\mathrm{Cr}_{2} \mathrm{O}_{3}-4.4 \mathrm{wt} \% \mathrm{Cu}$ showed the highest selectivity and conversion in comparison to $\mathrm{CuO}$,
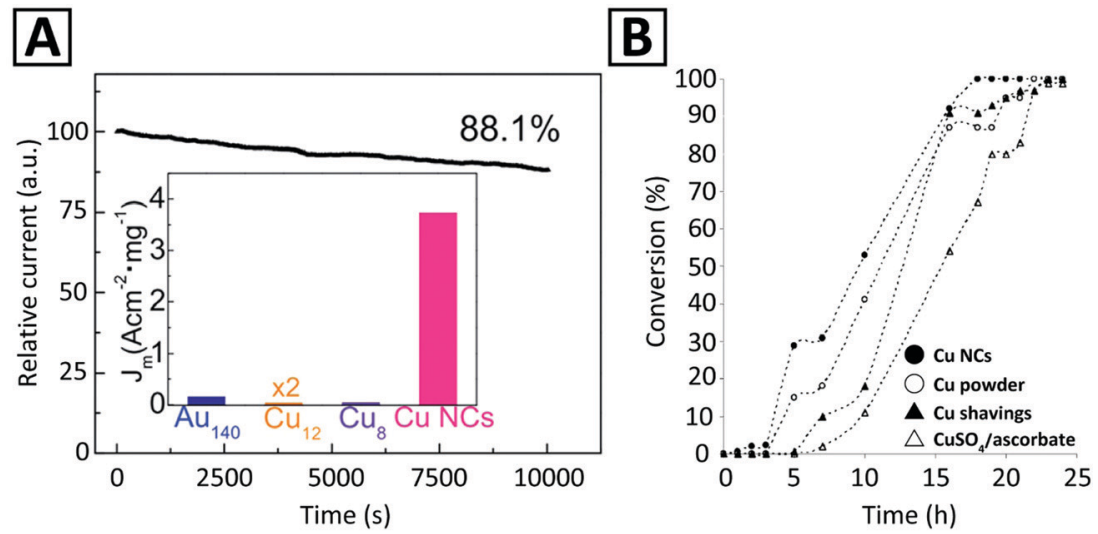

Fig. 3 (A) Time-dependent reduction current (in the $\mathrm{O}_{2}$-saturated solution, at $0.9 \mathrm{~V}$ ) of ligand-free $\mathrm{Cu}$ NCs used as an electrocatalyst for the ORR. The inset compares the current density $\left(\mathrm{J}_{\mathrm{m}}\right)$ per mass unit of the ligand-free $\mathrm{Cu}$ NCs with that of several ligand-functionalized MNCs, namely, $\mathrm{Au}_{140}\left(\mathrm{~S}_{(}\left(\mathrm{CH}_{2}\right)_{5} \mathrm{CH}_{3}\right)_{53}, \mathrm{Cu}_{12} \mathrm{DT}_{8} \mathrm{AC}_{4}$, and $\mathrm{Cu}_{8}\left(\mathrm{C}_{7} \mathrm{H}_{9} \mathrm{~N}_{2} \mathrm{~S}\right)_{4}$. Adapted with permission from ref. 173, Copyright 2018, RSC. (B) Observation of timedependent conversion profiles for the 1,3-cycloaddition of prop-2-yn-1-ol to benzyl azide employing different Cu catalysts. Adapted with permission from ref. 11, Copyright 2005, Wiley-VCH. 
$\mathrm{Cu}_{2} \mathrm{O}$, and other proportions of $\mathrm{Cu}-\mathrm{Cr}_{2} \mathrm{O}_{3}$ catalysts. This catalyst exhibited $86 \%$ conversion to cyclohexanone and cyclohexanol, with $85 \%$ selectivity of formation of cyclohexanone, and its TOF was about 52.5 and did not change after 4 successive runs. In another study, a $0.9 \% \mathrm{Cu} / \mathrm{SiO}_{2}-\mathrm{MnO}_{2}$ catalyst for oxydehydration of glycerol was used, ${ }^{192}$ with the main products being acrylic acid and acrolein. The conversion efficiency of glycerol was $77.1 \%$, while the attained acrylic acid selectivity was $74.7 \%$, and the TOF for this catalyst was $32.9 \mathrm{~h}^{-1}$. Commercial $\mathrm{MnO}_{2}$ showed only $5.5 \%$ conversion of glycerol under the same conditions. Athawale and Bhagwat ${ }^{193}$ used a $\mathrm{Cu}$ NCs/polyaniline composite as a catalyst for a Wacker oxidation reaction, where 1-decene was converted into 2-decanone in the presence of molecular oxygen. Hu et al. ${ }^{194}$ showed that $3,3^{\prime}, 5,5^{\prime}$-tetramethylbenzidine could be oxidized by $\mathrm{H}_{2} \mathrm{O}_{2}$ in the presence of $\mathrm{Cu}$ NCs; the reaction would not proceed without a catalyst. In a theoretical study, Tang et al. ${ }^{195}$ investigated the catalytic action of $\mathrm{Cu}_{55} \mathrm{NCs}$ on the oxidation of $\mathrm{CO}$ to $\mathrm{CO}_{2}$. It was found that the oxidation process is catalyzed by $\mathrm{Cu}$ NCs through two mechanisms: Eley-Rideal (adsorption of oxygen molecules on the cluster surface and then interaction with $\mathrm{CO}$ ) and Langmuir-Hinshelwood (co-adsorption of $\mathrm{O}_{2}$ and $\mathrm{CO}$ ).

4.1.3. Hydrogen evolution reactions and hydrogen dissociation. Hydrogen is considered as a biofriendly fuel gas, and has the largest energy density; therefore, hydrogen evolution reactions (HER) are important in the renewable energy industry. Tang and co-workers ${ }^{180}$ used $\mathrm{Cu}_{32} \mathrm{H}_{20} \mathrm{~L}_{12}$ NCs for the reduction of $\mathrm{CO}_{2}$, as we already discussed above. The HER may occur in competition of the reduction reaction according to $\mathrm{Cu}_{32} \mathrm{H}_{20}+\mathrm{H}^{+}+\mathrm{e}^{-} \rightarrow$ $\mathrm{Cu}_{32} \mathrm{H}_{19}+\mathrm{H}_{2}$ (Heyrovsky mechanism), or $\mathrm{Cu}_{32} \mathrm{H}_{19}+\mathrm{H}^{+}+\mathrm{e}^{-} \rightarrow$ $\mathrm{Cu}_{32} \mathrm{H}_{20}$ (Volmer reaction). At high over-potential, the HER is preferable while at low overpotentials the formation of $\mathrm{HCOOH}$ is more susceptible. Recently, $\left[\mathrm{Cu}_{32}(\mathrm{H})_{20}\left\{\mathrm{~S}_{2} \mathrm{P}\left(\mathrm{O}_{2} \mathrm{Bu}\right)_{2}\right\}_{12}\right]$ and $\left[\mathrm{Cu}_{20} \mathrm{H}_{11}\left\{\mathrm{~S}_{2} \mathrm{P}\left(\mathrm{O}_{2} \mathrm{Bu}\right)_{2}\right\}_{9}\right]$ have been introduced; ${ }^{196}$ although the high molecular weight of supporting $\mathrm{S}$-based ligands utilized in the stabilization of these $\mathrm{Cu}$ NCs did not make them good candidates for $\mathrm{H}_{2}$ storage, they offered a platform to release $\mathrm{H}_{2}$ under extremely mild conditions, which could qualify metal hydrides to become exceptional models for the HER, such as those able to harvest solar energy.

The densest crystallographic plane of copper with the lowest surface energy is the (111) plane. ${ }^{197}$ This surface plane can become unstable under CO exposure ( 0.1 to 100 Torr) at RT to form $\mathrm{Cu} \mathrm{NCs}$, with the edge of $\mathrm{Cu}$ atoms decorated by $\mathrm{CO}$ molecules. ${ }^{16}$ DFT simulations have shown that the energy of $\mathrm{CO}$ binding to low-coordinated $\mathrm{Cu}$ atoms and the weakening of binding of $\mathrm{Cu}$ to neighboring atoms drive this process. $\mathrm{Cu} \mathrm{NC}$ formation could activate the surface for the water dissociation reaction (e.g. $\mathrm{CO}+\mathrm{H}_{2} \mathrm{O} \leftrightarrow \mathrm{CO}_{2}+\mathrm{H}_{2}$ ) leading to the production of $\mathrm{H}_{2}$. It is noteworthy that no clustering was detected on the surface of Pt(111) under CO exposure. ${ }^{16}$ Even though the high surface area of $\mathrm{Cu}$ NCs provides high catalytic selectivity, its kinetic rate for $\mathrm{H}_{2}$ dissociation is very low. ${ }^{198}$ Very recently, Hoyt et al. ${ }^{104}$ employed DFT to explore the mechanism of how $\mathrm{Cu}$ NCs improve the catalytic activity for the HER. They showed that an icosahedral $\mathrm{Cu}_{13} \mathrm{NC}$ has a large magnetic moment, which influences the catalytic behavior. The most capable transition state for $\mathrm{H}_{2}$ dissociation has lower energy of activation than that of single-crystal $\mathrm{Cu}$ surfaces, but needs a magnetization change from 5 to $3 \mu_{\mathrm{B}}$. Fragile spin-orbit coupling delays this change, reducing the kinetic rate of $\mathrm{H}_{2}$ dissociation by a factor of 16. Strategies to aid magnetization change through environmental magnetic stimulus can improve the catalytic efficiency of $\mathrm{Cu}$ NCs.

4.1.4. 1,3-Dipolar cycloaddition. 1,3-Dipolar cycloaddition is a chemical reaction between a 1,3-dipole and a dipolarophile to form five-membered heterocycles and their ring-opened acyclic derivatives, which is sometimes referred to as Huisgen cycloaddition. While this reaction generally does not proceed readily under mild conditions, $\mathrm{Cu}(\mathrm{I})$-catalysts have been able to accomplish it even under physiological conditions (neutral $\mathrm{pH}$, RT and water solution). ${ }^{199}$ Only a few examples are documented in the literature on using $\mathrm{Cu}$ NCs for this reaction. Lee et al. ${ }^{11,200}$ developed a hydride-centered dithiophosphate cluster $\left(\left[\mathrm{Cu}_{8}\left(\mu_{4}\right.\right.\right.$ $\left.\left.\mathrm{H})\left\{\mathrm{S}_{2} \mathrm{P}(\mathrm{OEt})_{2}\right\}_{6}\right]\left(\mathrm{PF}_{6}\right)\right)$ which was able to catalyze the 1,3-dipolar cycloaddition of organic azides and alkynes into substituted triazoles. The required catalyst loading was as low as $0.4 \mathrm{~mole} \%$. The formation of the obligatory $\mathrm{Cu}(\mathrm{I})$ acetylide intermediate was suggested to be facilitated by the abstraction of the terminal hydrogen of alkynes by the hydride released from the central part of the cluster. Pachón et al. ${ }^{11,200}$ have demonstrated that air-stable $\mathrm{Cu}$ NCs are good candidates for the $\mathrm{Cu}(\mathrm{I})$-catalysed "click" cycloaddition of azides. Monitoring the reaction kinetics between prop-2-yn-1-ol and benzyl azide, conversion profiles were obtained for 4 different catalysts, including $\mathrm{Cu} \mathrm{NCs,} \mathrm{Cu}$ powder, Cu shavings, and $\mathrm{CuSO}_{4} /$ ascorbate (Fig. 3B). Significant differences in the reaction kinetics were observed, and it was noted that $\mathrm{Cu}$ NCs did not serve as a $\mathrm{Cu}(\mathrm{I})$ reservoir. $\mathrm{Cu}$ NCs showed the highest activity among the 4 catalysts studied, and achieved 100\% conversion after $18 \mathrm{~h}$ (Fig. 3B).

Other studies suggested that organometallic $\mathrm{Cu}$ NCs are more active than thiolated ones. ${ }^{12}$ The catalytic activity of $\left.\left[\mathrm{Cu}_{20}(\mathrm{CCPh})_{12}(\mathrm{OAc})_{6}\right)\right]$, both in a bare form and immobilized on silica, in the Huisgen cycloaddition was examined. Unsupported $\mathrm{Cu}$ NCs used as a homogeneous catalyst were unstable and dissociated into smaller NCs and/or discrete $\mathrm{Cu}(\mathrm{I})$ cations; on the other hand, silica-supported $\mathrm{Cu}$ NCs displayed comparable yields even after recycling.

\subsection{Sensing}

$\mathrm{Cu}$ NCs have been widely applied in sensing using several strategies, including electrochemical signaling, enzyme mimetic activity, and optical responses. Among these sensing schemes, the detection based on absorption and emission properties has been employed more frequently, and included in situ synthesis of fluorescent $\mathrm{Cu}$ NCs (through the turn on/turn-off mechanism), fluorescent quenching through the inner filter effect (IFE), FRET, and electron transfer, and enhanced fluorescent intensity (mostly due to AIE mechanisms). Accordingly, a lot of studies have recently been conducted on potential applications of $\mathrm{Cu}$ NCs as a fluorescent sensor for detection of various compounds such as anions, namely,

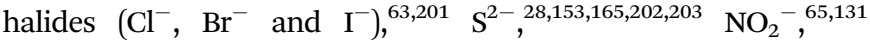
$\mathrm{CN}^{-},{ }^{65} \mathrm{Cr}_{2} \mathrm{O}_{7}{ }^{2-},{ }^{64}$ and phosphate; ${ }^{204}$ cations, such as $\mathrm{Ag}^{+},{ }^{63,205}$ 


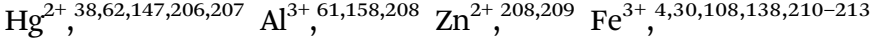
$\mathrm{Au}^{3+},{ }^{214} \mathrm{Mn}^{2+},{ }^{133} \mathrm{~Pb}^{+215}$ chromium(Iv), ${ }^{216} \mathrm{Cr}^{6+},{ }^{217} \mathrm{Cu}^{2+} ;{ }^{218-220}$ various organic compounds; water in organic solvents; ${ }^{60,221}$ and $\mathrm{H}_{2} \mathrm{O}_{2}{ }^{9,117,126,137}$ and $\mathrm{H}_{2} \mathrm{~S}^{156,222,223}$ in aqueous systems. Regarding organic compounds, $\mathrm{Cu}$ NC based sensors have been applied for detection of various medications including tramadol, ${ }^{26}$ methotrexate, ${ }^{51}$ carbamazepine, ${ }^{52}$ nitrofurantoin, ${ }^{42}$ $o$-phenylenediamine, ${ }^{224}$ doxycycline,${ }^{25}$ and tetracycline ${ }^{225}$ biocidal and herbicidal compounds such as thiram and paraquat; ${ }^{72}$ explosive compounds including trinitrotoluene (TNT), ${ }^{71,226,227} \mathrm{~m}$ dinitrobenzene, ${ }^{55}$ nitrofurantoin, ${ }^{34} \mathrm{RDX},{ }^{27}$ and trinitrophenol (TNP) $;^{19,228}$ food additives such as melamine, ${ }^{229}$ folic acid, ${ }^{56}$ quinoline yellow, ${ }^{224}$ gossypol; ${ }^{29}$ humidity and ethanol. ${ }^{59}$ Representative examples are presented in Table 1 and are briefly outlined below.

4.2.1. Organic molecule sensing. Several characteristics of $\mathrm{Cu}$ NCs such as cost-effectiveness, biocompatibility, and attractive emission properties make them promising candidates for detection and quantification of several medications in biological fluids, such as doxycycline, tramadol, carbamazepine, methotrexate, nitrofurantoin (NFT), and so on. Compared with other methods such as capillary electrophoresis, chromatography, ion mobility measurements and electrochemical methods, luminescencebased techniques are simpler, more cost-effective, and highly sensitive for detection of biomolecules. Recently, a high-performance chemiluminescence technique was reported for sensitive quantification of tramadol within a linear concentration range of 0.003-2.5 $\mu \mathrm{M}$ and a limit of detection (LOD) of $0.8 \mathrm{nM}$ using BSA-Cu NCs encapsulated into the nanoporous structure of a flake-like copper-based MOF as a support material. To improve the selectivity toward tramadol, a pre-extraction step has been


solid phase extraction method. ${ }^{26}$ Fluorescent bimetallic NCs composed of copper and other metals such as $\mathrm{Pd}, \mathrm{Au}, \mathrm{Ag}$, and Mo have also been developed. A fluorescence sensor based on $\mathrm{Cu} / \mathrm{Mo}$ bimetallic NCs with a PLQY of $26 \%$ has been used for detection of methotrexate, an anti-neoplastic drug, within a linear range of $50 \mathrm{nM}$ to $100 \mu \mathrm{M}$ and LOD of $13.7 \mathrm{nM}^{230}$ CTAB-coated $\mathrm{Cu}$ NCs were employed for detecting carbamazepine in exhaled breath condensate within a linear range of 0.2 to $20 \mu \mathrm{g} \mathrm{mL}^{-1}$ and LOD of $0.08 \mu \mathrm{g} \mathrm{mL}^{-1} .^{52}$

Orange-fluorescent $\mathrm{Cu}$ NCs $(560 \mathrm{~nm}$ ) with a PLQY of $5.8 \%$ were synthesized using ovalbumin and applied for detecting doxycycline with a linear range from 1 to $1000 \mu \mathrm{M}$, and LOD of $270 \mathrm{nM}^{25}$ This sensing probe was also applicable for detecting doxycycline in urine specimens as a real sample with recoveries over $90 \%$. In the presence of doxycycline, Cu NCs@OVA exhibited a high PL enhancement due to the interaction between doxycycline and ovalbumin that results in the formation of a more compact structure of the nanoclusters. Under UV excitation, a change in the solution color containing a different concentration of doxycycline (from orange to yellow) occurred. Additionally, Cu NCs@OVA showed high selectivity for doxycycline detection compared with other antibiotics such as penicillin, ampicillin, streptomycin, lincomycin, and norfloxacin. It was emphasized that the aqueous solubility of these clusters provided by multiple hydroxyl groups on the surface as well as their low toxicity and biocompatibility features could make them suitable for in vivo applications. ${ }^{25,72}$ They also exhibited good stability in hyper-saline environments (at $40{ }^{\circ} \mathrm{C}$ and under photobleaching conditions) and in the presence of several organic solvents and metal ions. ${ }^{25}$

A label-free, "turn off" analytical strategy using water-soluble adenosine-stabilized $\mathrm{Cu}$ NCs has been developed by Wang et $a l .{ }^{34}$ This fluorescent sensing probe showed fast, sensitive and selective response to nitrofurantoin (NFT) in a wide linear range of $0.05-4.0 \mu \mathrm{M}$ with a detection limit of $30 \mathrm{Nm}$, and has been used for the analysis of lake water samples with a recovery of $96-105 \%$ and relative standard deviation lower than $2 \%$. The emission intensity of the adenosine-stabilized $\mathrm{Cu}$ NCs reduced with a gradual shift towards longer wavelengths at higher NFT concentrations. A small variation in the PL spectra of $\mathrm{Cu}$ NCs in the presence of many other substances such as phenylalanine, proline, isoleucine, valine, alanine, glutamic acid, serine, glycine, lysine, leucine, glutamine, methionine, tyrosine, aspartic acid, asparagine, threonine, arginine, cysteine, glucose, and uric acid (at $1.0 \mu \mathrm{M}$ ) proved the high selectivity of this probe to NFT. The quenching mechanism has been proposed to be based on the IFE between adenosine-stabilized $\mathrm{Cu}$ NCs and NFT, because of the overlap between the absorption band of NFT at 250-430 nm and the excitation and emission of $\mathrm{Cu}$ NCs. A ratiometric sensor based on GSH-stabilized $\mathrm{Cu}$ NCs for the detection of o-phenylenediamine (OPD), as an intermediate in medicine production, has been developed, and exhibited a linear detection range of 0.15 to

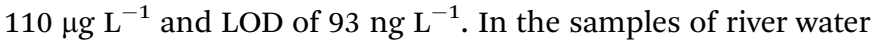
and textile dyeing wastewater, its recovery rate was $96.8 \%$ and $100.3 \%$, respectively. ${ }^{224}$

Quantitative detection of explosive compounds such as nitroaromatics (e.g. trinitrophenol, dinitrobenzene, TNT) and heterocyclic nitramines (e.g. trinitrotriazine, $\mathrm{RDX}$ ) using $\mathrm{Cu}$ NCs as a turn-on/turn-off luminescent probe has been reported. Cysteine-stabilized $\mathrm{Cu}$ NCs were employed for selective sensing of dinitrobenzene and picric acid based on a turn-on fluorescence mechanism. ${ }^{55}$ The sensor exhibited a linear range of $99 \mathrm{nM}$ to 1.3 and LOD of $0.13 \mu \mathrm{M}$. Quantitative detection of RDX with a LOD of $1.62 \mathrm{nM}$ in a linear concentration range of $0 \mu \mathrm{M}$ to $0.238 \mu \mathrm{M}$ was performed using BSA-stabilized $\mathrm{Cu} \mathrm{NCs;} ;{ }^{27}$ it was based on the turn off-on fluorescence mechanism using $\mathrm{Zn}^{2+}$ ions as a modulator. Upon adding RDX, due to the Lewis acid-base interactions between $\mathrm{Zn}^{2+}$ and trinitrotriazine, fast recovery of $\mathrm{Zn}^{2+}$ induced fluorescence quenching of $\mathrm{Cu}$ NCs was realized. A TNT probe based on L-cysteine modified $\mathrm{Cu}$ NCs with a LOD of $9.1 \mathrm{nM},,^{71}$ and a luminescence sensor using a $\mathrm{Cu}$ NCs-ZIF-8 nanocomposite with a LOD of $8.5 \mu \mathrm{M}^{227}$ have been demonstrated. Recently, a fluorescent and colorimetric sensor for selective and sensitive detection of trace amounts of TNT both in solution (LOD = 14 pM) and in the gas phase $(\mathrm{LOD}=0.05 \mathrm{nM}$ ) based on water-soluble PEI-capped $\mathrm{Cu}$ NCs has been developed. ${ }^{18}$ Their high sensitivity arises from selective binding between PEI and an electron deficient molecule such as TNT; it can result in a charge transfer complexing interaction between the aromatic ring of TNT and amino groups of PEI-capped Cu NCs through a photo-induced electron transfer (PET) reaction. In the presence of TNT, the emission of 
NCs was quenched, which could be related to the formation of a Meisenheimer complex through acid base pairing, hydrogen bonding, and electrostatic interactions. The selective sensing performance of the PEI-capped $\mathrm{Cu}$ NCs compared with some organic molecules such as toluene, nitrobenzene (NB), 4-nitrotoluene (4-NT), trinitrophenol (TNP), dinitrophenol (DNP), RDX and 4-nitrophenol (4-NP) could arise from the absence of the Meisenheimer complex. Preparing paper strips of PEI-capped $\mathrm{Cu}$ NCs with storage stability over one month has also been reported, which could be useful for rapid onsite and visual detection of TNT. ${ }^{18}$ These paper strips showed a detection limit of $10 \mathrm{nM}$ within $1 \mathrm{~min}$ for sensing of TNT in vapor form. Green fluorescent PVP-stabilized Cu NCs with a large Stokes shift and a high PLQY ( $>44 \%$ ) were used for detection of trinitrophenol (TNP) with a LOD of $0.391 \mu \mathrm{M}^{19}$

A chemiluminescent sensor based on L-Cys stabilized $\mathrm{Cu}$ NCs-DPA was developed for the detection of folic acid with a linear concentration range of $0.1-10 \mu \mathrm{M}$ and LOD of $69.8 \mathrm{nM}$. A similar sensor based on $\mathrm{Cu}$ NCs-DPA-FA was used for detection of nitrites, and exhibited a linear range of detection within $0.1-80.0 \mu \mathrm{M}$ and LOD of $0.0954 \mu \mathrm{M} .{ }^{56}$ Blue emitting L-Cys stabilized $\mathrm{Cu}$ NCs were used for detection of quinoline yellow as a food colorant, with a linear concentration range from 0.2 to $5.5 \mu \mathrm{M}$ (LOD of $0.11 \mu \mathrm{M}$ ) and high selectivity compared with other yellow colorant additives such as sunset yellow and tartrazine. ${ }^{224}$ Formation of a stable complex between gossypol and BSA in a BSA-Cu NCs has been used in a fluorescence-based probe for detection of gossypol, with a linear range of $0.1-100 \mu \mathrm{M}$ and LOD of $25 \mathrm{nM}$. This sensor was used in real samples (cottonseed meal and oil), and exhibited a selective fluorescent quenching behavior in the presence of interfering compounds such as $\mathrm{Na}^{+}, \mathrm{K}^{+}, \mathrm{Ca}^{2+}, \mathrm{Mg}^{2+}, \mathrm{Zn}^{2+}$, glucose, glycine, and palmitic acid. ${ }^{29}$

4.2.2. $\mathrm{H}_{2} \mathrm{O}$ and $\mathrm{H}_{2} \mathrm{O}_{2}$ sensing. A dual-emitting film composed of GSH-Cu NCs and carbon dots (CDs) has been used by Wen et al. ${ }^{59}$ for the detection of atmospheric humidity in the range of $40-80 \%$. The sensor was prepared through the infiltration of a $\mathrm{CD}$ solution in a filter paper followed by dipping in a $\mathrm{Cu}$ NC solution and then drying under vacuum. An increase in the air humidity induced a color change of the film from red to blue; it could also be used for simultaneous detection of ethanol and water. A nanoswitch of copper nanoclusters (AMTD-Ac-Cu NCs) stabilized by dual ligands 2-amino-5-mercapto-1,3,4-thiadiazol (AMTD) and acetate (Ac-) has been developed by Cheng et al. ${ }^{60}$ for sensitive detection of trace water in organic phases. It operated in a reversible way between two states including "fluorescence off" in the solid form and "fluorescence on" in the presence of water, where the strong hydrogen bonding between water and AMTD/Ac resulted in the aggregation of $\mathrm{Cu}$ NCs. High sensitivity, good reversibility, and a repeatable response have been reported for water sensing with the maximum fluorescence intensity for the water content of $50.0 \%, 35.48 \%, 35.48 \%$, and 39.39\% (MeCN) in EtOH, THF, ACT, and MeCN solvents, respectively. The detection limit was 0.036 for EtOH, 0.018 for THF, 0.024 for ACT, and 0.026 for MeCN. Time-resolved luminescence decay curves exhibited a long lifetime of 3.14 ns, which indicated a type of phosphorescence behavior. Importantly, aqueous solutions of these $\mathrm{Cu}$ NCs had long-term stability for several months.

Detection of $\mathrm{H}_{2} \mathrm{O}_{2}$ in aqueous solutions in a concentration range from $1 \mu \mathrm{M}$ to $1 \mathrm{M}$ by a direct and fast colorimetric sensing probe and without using any chromogenic reagent or expensive instrument has been reported by Du et al. ${ }^{117}$ The sensing probe has been prepared using water-soluble mercaptosuccinic acid stabilized Cu NCs (MSA-capped Cu NCs). The color of a diluted $\mathrm{Cu}$ NC solution exhibited a change from claret-red at low concentrations of $\mathrm{H}_{2} \mathrm{O}_{2}$ (about $0.001 \mathrm{mM}$ ) to saffron yellow at high concentrations (about $1000 \mathrm{mM}$ ) (Fig. 4A-I). With increasing concentration of $\mathrm{H}_{2} \mathrm{O}_{2}$ from 0 to $1 \mathrm{mM}$, the absorption peak at $520 \mathrm{~nm}$ was gradually quenched due to the aggregation and growth of $\mathrm{Cu}$ NPs via the cleavage of $\mathrm{Cu}-\mathrm{S}$ bonds and detachment of MSA from the $\mathrm{Cu}$ NP surface (Fig. 4A-II). By a further increase in the $\mathrm{H}_{2} \mathrm{O}_{2}$ concentration from $1 \mathrm{mM}$ to $1000 \mathrm{mM}$, the absorption peak at $375 \mathrm{~nm}$ was progressively increased because of $\mathrm{Cu}_{2} \mathrm{O}$ formation (Fig. 4A-III). Therefore, the MSA-capped $\mathrm{Cu}$ NCs could be applied as a colorimetric $\mathrm{H}_{2} \mathrm{O}_{2}$ sensor in a wide range of $0.001 \mathrm{mM}$ to $1000 \mathrm{mM}$. These Cu NCs also revealed a desirable selectivity and salt tolerance capability for $\mathrm{H}_{2} \mathrm{O}_{2}$ sensing in real water samples with recoveries in the range of $96.7 \%$ to $104.1 \%$ and a relative standard deviation lower than $4 \%$. They also demonstrated a fast kinetics reaction of about $60 \mathrm{~s}$, a slight influence of temperature $\left(20-40{ }^{\circ} \mathrm{C}\right)$ on the absorption response, and storage stability of the purified and freeze-dried $\mathrm{Cu}$ NCs for 10 months (under dark conditions).

4.2.3. Ion sensing. Trace detection of heavy metal ions such as $\mathrm{Hg}^{2+}, \mathrm{Pb}^{2+}, \mathrm{Cr}^{6+}$, and $\mathrm{Cr}^{3+}$ based on $\mathrm{Cu}$ NCs has been extensively reported in the literature. Bi-ligand stabilized $\mathrm{Cu}$ NCs composed of thiosalicylic acid and cysteamine at different ratios showed a PLQY of up to $34 \%$ and were used for $\mathrm{Cr}^{+6}$ detection in a linear range of $0.1-1000 \mu \mathrm{M}$ with a LOD of $0.03 \mu \mathrm{M}^{217}$ The PL quenching in the presence of $\mathrm{Cr}^{6+}$ ions was related to the IFE mechanism because of a large overlap between the $\mathrm{Cu}$ NC excitation and $\mathrm{Cr}^{6+}$ absorption spectrum. In a real sample examination (mineral water), a high recovery in the range of 98.3-105.0\% was attained. Li et al. ${ }^{38}$ presented a sensor based on reticular DNA templated-Cu NCs aggregates for sensitive and selective detection of $\mathrm{Hg}^{2+}$ in real water samples (lake water), with high recovery (98 to102\%) and low relative standard deviation (1.6-4.6\%). The rigid nature of the reticular DNA as a template led to the formation of $\mathrm{Cu} \mathrm{NC}$ aggregates with greatly enhanced emission compared with singlestranded DNA-templated $\mathrm{Cu}$ NCs. The dual-function of DNA manipulation including $\mathrm{Hg}^{2+}$ induced fluorescence enhancement and $\mathrm{Hg}^{2+}$-induced enzyme restraint resulted in the fabrication of $\mathrm{a} \mathrm{Hg}^{2+}$ biosensor with a remarkably enlarged signal-to-noise ratio (from 2.2 to 56.1), which made it possible to quantify $\mathrm{Hg}^{2+}$ in the range of $50 \mathrm{pM}$ up to $500 \mu \mathrm{M}$ with an ultra-low detection limit of $16 \mathrm{pM}$ (Fig. 4B). Due to the specificity of $\mathrm{T}-\mathrm{Hg}^{2+}$ interaction, the fluorescence intensity at $650 \mathrm{~nm}$ was not significantly affected by replacing $\mathrm{Hg}^{2+}$ with other metal ions such as $\mathrm{Na}^{+}, \mathrm{K}^{+}, \mathrm{Li}^{+}, \mathrm{Mg}^{2+}$, $\mathrm{Ca}^{2+}, \mathrm{Co}^{2+}, \mathrm{Ba}^{2+}$ and $\mathrm{Ni}^{2+}$ ions, which indicated the selectivity of the sensor. Bhamore et $a .^{62}$ used Curcuma root extract 


\section{A}

(I)

Concentration of $\mathrm{H}_{2} \mathrm{O}_{2}(\mathrm{mM})$

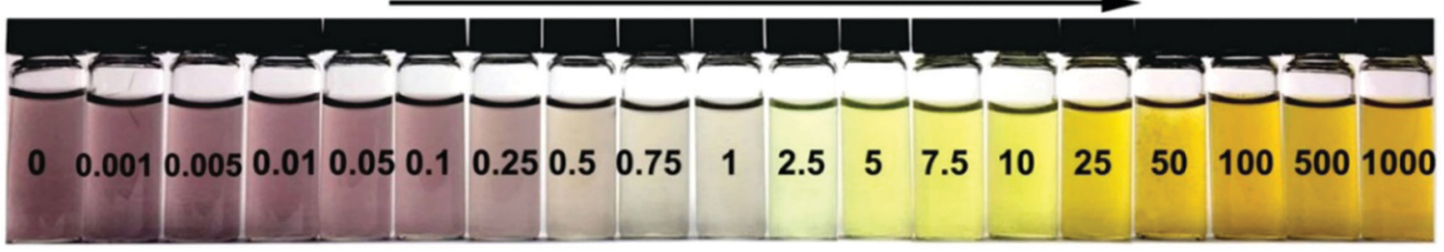

(II)

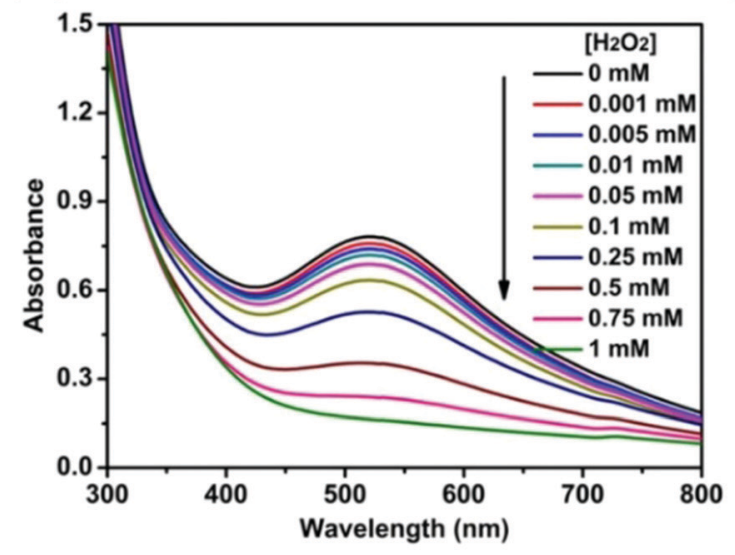

(III)

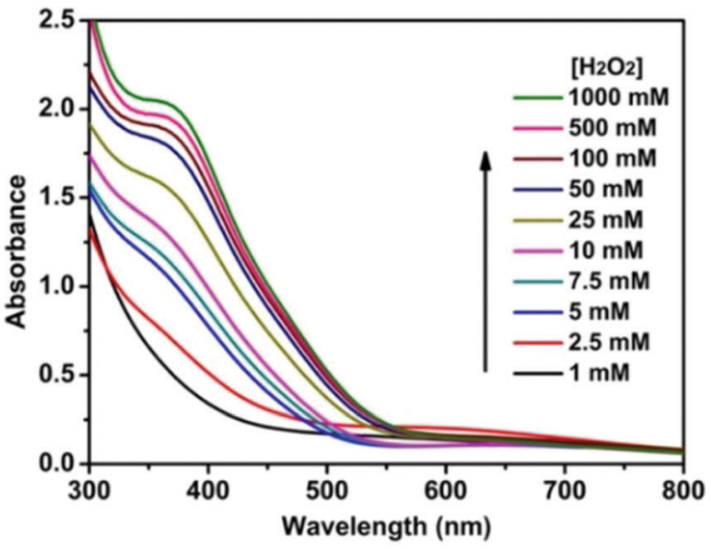

B

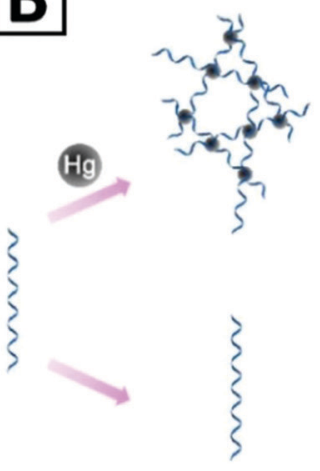

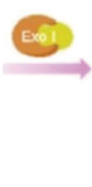

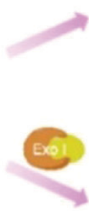

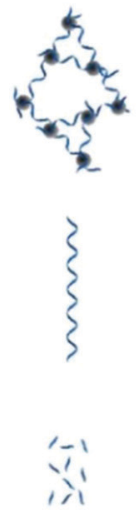
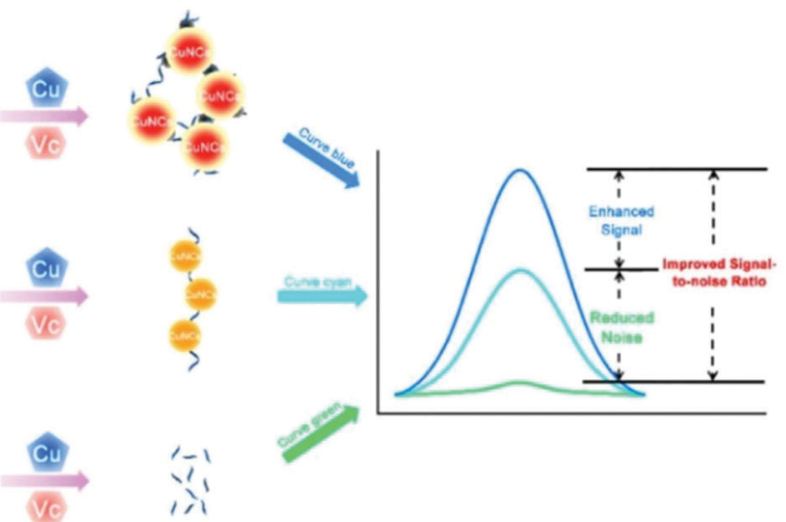

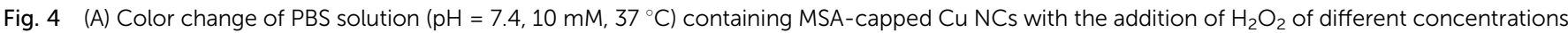

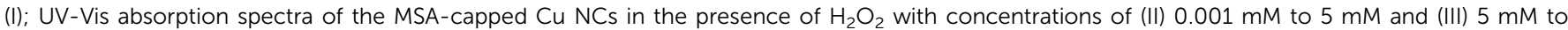

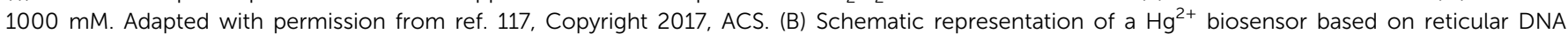
templated-Cu NC aggregates. Adapted with permission from ref. 38, Copyright 2018, ACS.

templated-Cu NCs with a PLQY of $7.2 \%$ for detecting $\mathrm{Hg}^{2+}$, with a LOD of $0.12 \mathrm{nM}$ and a linear range of $0.0005-25 \mu \mathrm{M}$. Liu et $a .^{232}$ presented metallothionein-stabilized $\mathrm{Cu}$ NCs for visual detection of heavy metal ions. The colorimetric sensor utilized the effect of $\mathrm{Hg}^{2+}$ and $\mathrm{Pb}^{2+}$ on the enzyme-like activity of MT-Cu NCs via changing it from the catalase-like activity to the peroxidase-like one. The linear range of detection for $\mathrm{Pb}^{2+}$ was $0.7-96 \mu \mathrm{M}$, and for $\mathrm{Hg}^{2+}$ it was $97 \mathrm{nM}-2.3 \mu \mathrm{M}$ and 3.1-15.6 $\mu \mathrm{M}$. LODs were $142 \mathrm{nM}$ and $43.8 \mathrm{nM}$ for $\mathrm{Pb}^{2+}$ and $\mathrm{Hg}^{2+}$, respectively.
A fluorescent chemodosimeter for sensitive and selective detection of $\mathrm{Al}^{3+}$ in real water samples with a recovery of $92-101 \%$ and a relative standard deviation of less than $4 \%$ has been reported by Boonmee et al. ${ }^{61}$ using cysteamine-Cu NCs as a sensing probe. This sensor worked in a concentration range of 1-7 $\mu \mathrm{M}$ with a low detection limit of $26.7 \mathrm{nM}$. The $\mathrm{Cu}$ NCs were synthesized by a ligand-assisted method in which cysteamine (Cys), a weak base containing $-\mathrm{NH}_{2}$ and $-\mathrm{SH}$ moieties, was applied as both a capping agent and a reducing agent. The -SH moiety attached to the surface of $\mathrm{Cu}$ NCs through 
$\mathrm{Cu}-\mathrm{S}$ bonding, and the $-\mathrm{NH}_{2}$ moiety acted as a receptor interacting with metal ions through different interactions such as electrostatic interactions under acidic conditions. $\mathrm{Al}^{3+}$ ions could interact with $-\mathrm{NH}_{2}$ moieties on the surface of $\mathrm{Cu}$ NCs resulting in the aggregation of the NCs and subsequently an enhancement of the fluorescence intensity depending on the concentration of $\mathrm{Al}^{3+}$. According to the aggregation-induced emission (AIE) mechanism, the fluorescent intensity of $\mathrm{Cys}-\mathrm{Cu}$ $\mathrm{NCs}$ at $380 \mathrm{~nm}$ linearly increased with $\mathrm{Al}^{3+}$ concentration.

D-Penicillamine capped-bimetallic AuCu NCs have been used as a fluorescent probe for $\mathrm{Fe}^{3+}$ detection in rain and river water, as well as in human blood serum. ${ }^{213}$ A high selectivity in the presence of various anions and cations especially $\mathrm{Fe}^{2+}$ has been demonstrated. Quenching of the PL intensity in the presence of $\mathrm{Fe}$ ions occurred through the IFE mechanism because of the overlap between the $\mathrm{Fe}^{3+}$ absorption peak and excitation peak of bimetallic AuCu NCs located at around $275 \mathrm{~nm}$. The sensor exhibited a linear detection range of 0.5$7.0 \mu \mathrm{M}$ and $7.0 \mu \mathrm{M}-0.1 \mathrm{mM}$, and a LOD of $0.1 \mu \mathrm{M}$. Synthesis of water-soluble L-histidine-capped Cu NCs, stable against photobleaching and with long-term storage stability for sensitive and selective detection of $\mathrm{Fe}^{3+}$ has been performed by Lin et al. ${ }^{210}$ The LOD of this sensor was $82 \mathrm{nM}$ in a concentration range of 0.10 to $20 \mu \mathrm{M}$. High quenching efficiency and stable sensing conditions were achieved at $\mathrm{pH}=4.1$. The sensing mechanism was based on a fluorescence "turn off-on" mechanism in which the fluorescence intensity of the L-His-Cu NCs was quenched due to the aggregation of the particles through bonding between $\mathrm{Fe}^{3+}$ ions with amine groups of L-histidine. The fluorescence intensity increased after adding ethylenediaminetetraacetate (EDTA) into the mixture of L-His-Cu NPs with $\mathrm{Fe}^{3+}$. This chemosensor was employed to detect $\mathrm{Fe}^{3+}$ in real water samples, including tap water and river water with recoveries in the range of 82.8-107.4\%. L-Histidine-capped $\mathrm{Cu}$ CNs exhibited a selective sensing performance towards $\mathrm{Fe}^{3+}$ compared with various interfering ions such as $\mathrm{Na}^{+}, \mathrm{K}^{+}, \mathrm{Li}^{+}, \mathrm{Ca}^{2+}, \mathrm{Mg}^{2+}, \mathrm{Co}^{2+}, \mathrm{Ni}^{2+}, \mathrm{Pb}^{2+}$, $\mathrm{Zn}^{2+}, \mathrm{Mn}^{2+}, \mathrm{Cu}^{2+}, \mathrm{Hg}^{2+}, \mathrm{Cd}^{2+}, \mathrm{Al}^{3+}$, and $\mathrm{Fe}^{2+}$, as well as some common anions such as $\mathrm{F}^{-}, \mathrm{Cl}^{-}, \mathrm{Br}^{-}, \mathrm{I}^{-}, \mathrm{Ac}^{-}, \mathrm{NO}_{3}{ }^{2-}, \mathrm{PO}_{4}{ }^{3-}$, $\mathrm{CO}_{3}{ }^{2-}, \mathrm{SO}_{4}{ }^{2-}$, and $\mathrm{SO}_{3}{ }^{2-}$.

A turn-on PL sensor based on silk fibroin (SF) protected-Cu NCs (SF@Cu NCs) has been developed by Zhang et al. ${ }^{203}$ It was used to detect $\mathrm{S}^{2-}$ in aqueous solutions with a LOD of $\sim 0.3 \mu \mathrm{M}$ and a linear range of 5-110 $\mu \mathrm{M}$. The working mechanism of the sensor was ascribed to the assembly induced emission enhancement (AIEE). In the presence of $\mathrm{S}^{2-}$ ions, SF@Cu NCs aggregated to larger, rod-shaped nanoparticles, which led to an increase of the PLQY from $1.6 \%$ to $4.9 \%$. High selectivity was observed towards $\mathrm{S}^{2-}$ in the presence of different interfering ions and macromolecules, and in particular sulfur-containing ions such as $\mathrm{SO}_{3}{ }^{2-}, \mathrm{SO}_{4}{ }^{2-}, \mathrm{S}_{2} \mathrm{O}_{4}{ }^{2-}$ and $\mathrm{SCN}^{-}$. A DNA templated$\mathrm{Cu} / \mathrm{Ag}$ NC fluorescent probe was developed by Ding et al. ${ }^{156}$ to detect $\mathrm{S}^{2-}$ with a LOD of $3.75 \mathrm{pM}$ and a wide linear concentration range from $10 \mathrm{pM}$ to $1 \mathrm{mM}$. This sensor worked due to the PL quenching of DNA-Cu/Ag NCs in the presence of sulfide; application for measuring sulfide amount in mouse blood $\left(\mathrm{H}_{2} \mathrm{~S}\right.$ poisoned blood sample) was demonstrated. Sulfide ion detection using water-soluble Zn-modified $\mathrm{Cu}$ NCs based on a protein/ peptide templated method has been reported by Li et al. ${ }^{202}$ As compared with bare $\mathrm{Cu}$ NCs, Zn-modified $\mathrm{Cu}$ NCs exhibited an enhanced fluorescence intensity (by about 3.5-fold), and their PLQY reached $6.2 \%$. Due to the degradation of the copper shell and change in conformation of proteins, as well as the formation of $\mathrm{Zn}(\mathrm{OH})_{x}$ at high $\mathrm{pH}$ values $(>8)$, the optimum $\mathrm{pH}$ ranged from 6 to $8 . \mathrm{CuS}_{x}$ is an insoluble salt of copper and due to high oxidation/decomposition stability of Zn-modified $\mathrm{Cu}$ NCs in water, this sensor could be used for sensitive detection of sulfide ions by fluorescence quenching at $663 \mathrm{~nm}$. The recovery of this ratiometric sensor in real water samples such as lake and tap water containing $20-80 \mu \mathrm{M} \mathrm{S}^{2-}$ was found to be 101-109.9\%. This sensing system also showed a selective sensing performance for $\mathrm{S}^{2-}$ detection in water samples containing other common species.

Shen et al. ${ }^{220}$ employed in situ synthesized Cu NCs for the detection of $\mathrm{Cu}^{2+}$ through an AIE phenomenon. Rapid reduction of $\mathrm{Cu}^{2+}$ ions in solution, and cluster formation using thiol-containing glutathione as both reducing and stabilizing agents occurred when THF, acetonitrile, and DMF were added. Aggregation of NCs induced a bright emission which increased through addition of more copper ions.

4.2.4. Detection of biomacromolecules and small biomolecules. Electrochemiluminescence (ECL) of metal NCs has been widely utilized in sensing and biosensing applications. ${ }^{233}$ ECL efficacy of protein-templated metal NCs is restricted because of the IFE due to the tight arrangement of NCs that prevents the activation of internal emitters. Therefore, the realization of proper molecular arrangements through the controlled spatial distribution of NCs is of crucial importance, and DNA-templated NCs often show advantages over proteintemplated NCs. ${ }^{50,234}$ DNA structures have been employed for ECL detection of miRNA155. ${ }^{50}$ Zhou et al. ${ }^{50}$ prepared a DNA nanocrane structure with a manipulator on a glassy carbon electrode (GCE) through DNA hybridization and binding. Due to the tetrahedral structure of the nanocrane and the sequence of the manipulator, lateral and longitudinal separation of $\mathrm{Cu}$ NCs became possible. A strand displacement reaction, $\mathrm{Mn}^{2+}$ DNAzyme-assisted target recycling, and autonomous DNA walking created AT-rich dsDNA sequences on this structure (Fig. 5A). This strategy gave rise to ECL detection of miRNA155 on GCE in the presence of $\mathrm{S}_{2} \mathrm{O}_{8}{ }^{2-}$ with a LOD of 36 attomolar (aM). In another study, ${ }^{49}$ abasic sites of a dsDNA sequence were detected by DNAtemplated $\mathrm{Cu}$ NCs. The NCs were formed from $\mathrm{Cu}^{2+}$ cations in the presence of AA and interacted with dsDNA. The chemically or enzymatically created DNA abasic sites impeded $\mathrm{Cu}$ NC formation, leading to an increase in the amount of unreacted $\mathrm{Cu}^{2+}$ cations, which in turn quenched the fluorescence intensity of carbon dots. This method could detect one or two abasic sites in a 35 bps DNA oligonucleotide. Borghei et al. ${ }^{47}$ employed the DNA templating technique to detect miRNA155 having two different sequences; the first one had a 15-thymine-base and loop forming sequence, and the second had a poly thymine tail at one end. By measuring changes in the fluorescence intensity of $\mathrm{Cu}$ NCs, they detected miRNA with a lowest LOD of $2.2 \mathrm{pM}$ in the linear range of $50 \mathrm{pM}$ to $10 \mathrm{nM}^{48}$ 
A


(III)
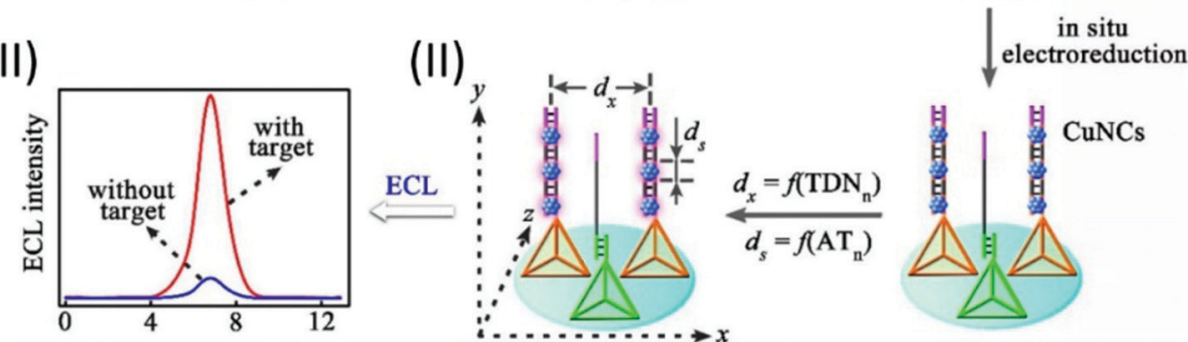

B
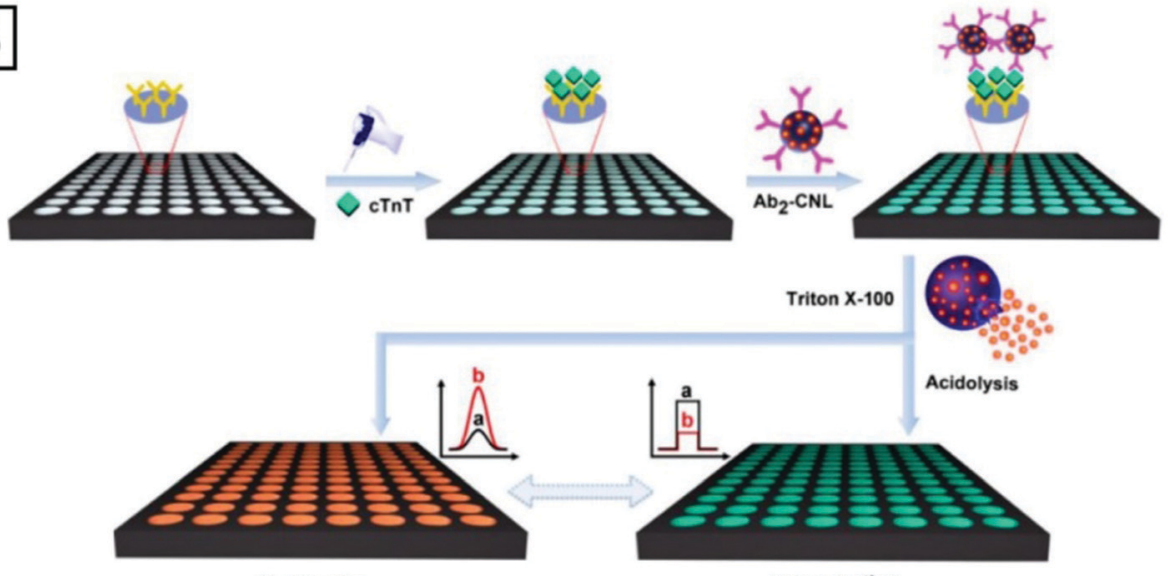

FL detection

PEC detection

Fig. 5 (A) Schematic representation of miRNA155 detection based on nanocrane-like DNA structures. (I) Strand displacement by the target molecule leads to amplified production of DNA oligonucleotide containing an ATP binding sequence (Apt1). (II) Tetrahedral DNA nanostructures (TDN) modulate the efficiency of the ECL signal of Cu NCs which are formed by in situ electroreduction via programming the lateral spacing (dx) and size controlling (ds) through an AT periodic sequence. (III) ECL signal in the presence and absence of the target. Adapted with permission from ref. 50, Copyright 2018, ACS. (B) Representation of two complementary detection strategies (photoelectrochemical and fluorescent) for an immunoassay with Cu NC-encapsulated liposomes as signal generators. Adapted with permission from ref. 37, Copyright 2018, ACS.

$\mathrm{Cu}$ NCs were also used for protein detection. An immunoprobe was prepared by blocking unreacted sites of antibody-immobilized Pt NPs by BSA-Cu NCs. ${ }^{235}$ The immunosensor could detect prostate specific antigen through a sandwich assay with a LOD of $145.69 \mathrm{fg} \mathrm{mL}^{-1}$ with a linear range from $0.5 \mathrm{pg} \mathrm{mL} \mathrm{m}^{-1}$ to $100 \mathrm{ng} \mathrm{mL}^{-1}$. In another study, ${ }^{37}$ an immunosensor was developed for detection of cardiac Troponin $\mathrm{T}$
(cTnT) antigen based on photoelectrochemical (PEC) signals generated after lysis treatment of secondary antibody-bonded liposomes. As illustrated in Fig. 5B, the secondary antibody was bonded to the external surface of $\mathrm{Cu}$ NC-encapsulated liposomes. This immunosensor could sensitively detect cTnT by a signal-off method through the PEC mechanism, with a LOD of $0.03 \mathrm{pg} \mathrm{mL}^{-1}$. 
A

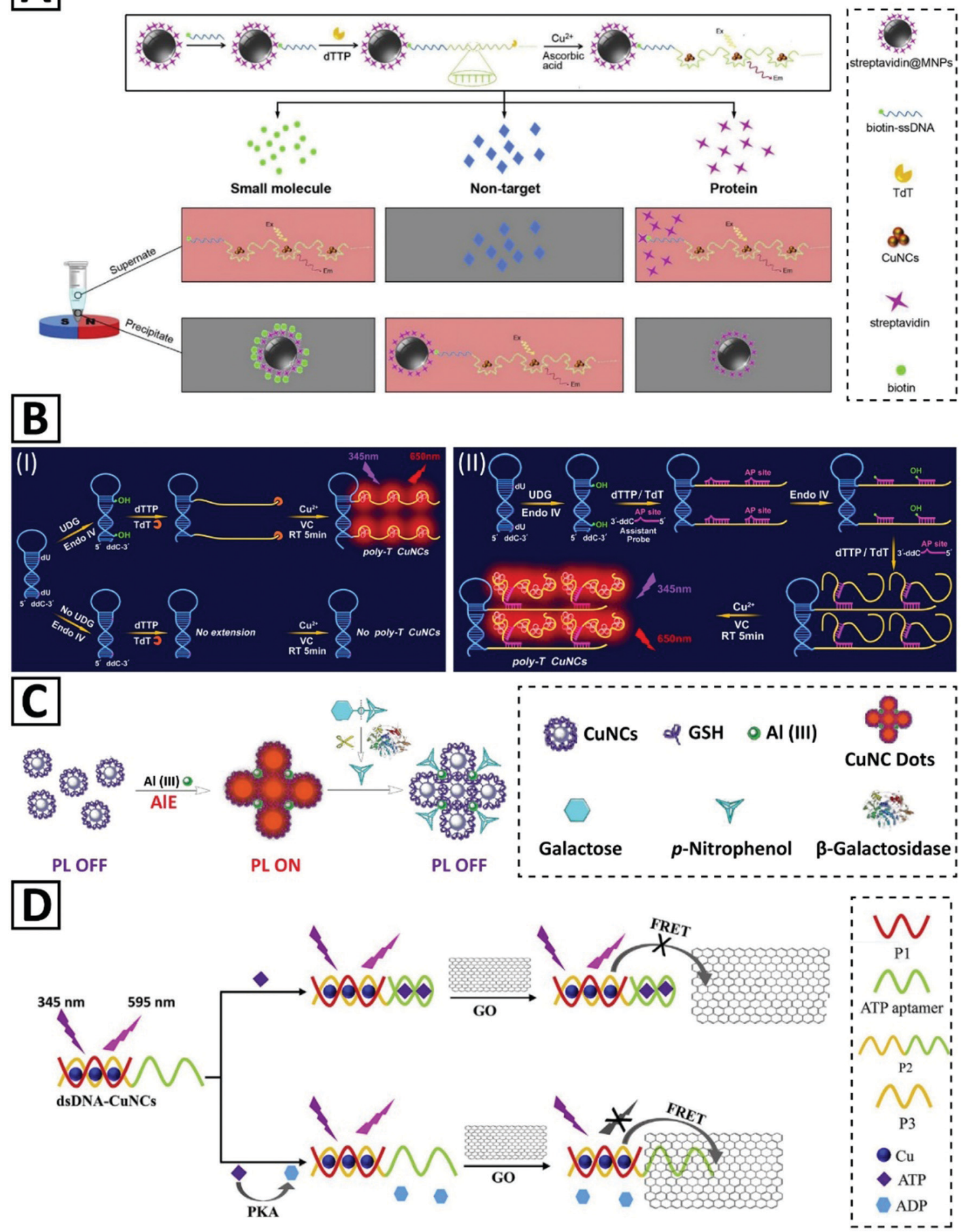

Fig. 6 (A) Representation of the detection strategy for small molecules and proteins relying on magnetic separation and opposite fluorescent signaling in the presence of $\mathrm{Cu}$ NCs. Adapted with permission from ref. 45, Copyright 2017, Elsevier. (B) Schematic illustration of (I) the proposed UDG assay principles and the roles of TdT and endonuclease IV in Cu NC template formation. (II) Hyperbranched extension of the Cu NC template helped by the assistant probe. Adapted with permission from ref. 46, Copyright 2019, Elsevier. (C) Schematic illustration of $\beta$-galactosidase activity measurement via emission quenching of aluminum-assisted self-assembled Cu NCs. Adapted with permission from ref. 105, Copyright 2017, RSC. (D) Schematic illustration of the PKA activity detection via a FRET-based fluorescent biosensor. Adapted with permission from ref. 40, Copyright 2018, Elsevier.

Cao et al. ${ }^{45}$ presented a strategy for detecting a small molecule and its interacting protein, using streptavidin and biotin as a model (Fig. 6A). Protein molecules immobilized on magnetic nanoparticles (MNPs) were one part, and ssDNA oligonucleotides 
with a small molecule at their $5^{\prime}$-end were another part of the detection system. The signal was generated via the formation of $\mathrm{Cu}$ NCs which were synthesized by a polythymin templating method. Supernatant or precipitant location of the generated signals determined the interacting proteins. This biosensor enabled detection of streptavidin and biotin in the linear range of 1-200 nM and 10-1000 nM, with LOD of $0.47 \mathrm{nM}$ and $3.1 \mathrm{nM}$, respectively.

Hybrid nanostructures of $\mathrm{Cu}$ NCs and glucose oxidase (GOx) enzyme were employed for glucose sensing. ${ }^{121}$ Enzymatic oxidation of glucose led to $\mathrm{H}_{2} \mathrm{O}_{2}$ production that would quench the emission of $\mathrm{Cu}$ NCs. The $\mathrm{GO}_{x} / \mathrm{Cu} \mathrm{NC}$ assembly selectively measured glucose with a LOD of $1.5 \mu \mathrm{M}$ in a linear range of 5-100 $\mu \mathrm{M}$. Another kind of biosensor for glucose via the turn-off fluorescence strategy has been designed based on lysozyme-stabilized $\mathrm{Cu}$ NCs (Lys-CCs). ${ }^{236}$ A glucose biosensor using a pH-responsive fluorescent solution, a mixture of luminescent $\mathrm{Cu}$ NCs and $\mathrm{CaCO}_{3}$ nanoparticles, and alginate, has been reported. ${ }^{70}$ In the presence of glucose, the produced $\mathrm{H}^{+}$could release $\mathrm{Ca}^{2+}$ from $\mathrm{CaCO}_{3}$ nanoparticles, which turned the solution into a gelated phase with an enhanced emission. This AIE-based sensor could detect glucose with a linear range of 0.1 to $2.0 \mathrm{mM}$ and LOD of $3.2 \times 10^{-5} \mathrm{M}$. Zhang et al. ${ }^{237}$ employed OVA@Cu NCs for L-lysine (L-Lys) detection with a LOD of $5.5 \mu \mathrm{M}$ and a linear range of $10 \mu \mathrm{M}-1 \mathrm{mM}$. They showed that OVA@Cu NCs could selectively detect L-Lys among many other amino acids and cations based on the PL enhancement via coordination of copper by L-Lys functional groups and surface electron density increment on $\mathrm{Cu}$ NCs. Yang and co-workers ${ }^{25}$ employed OVA@Cu NCs to detect Vitamin B1 (VB1) and doxycycline based on turn-off and turn-on PL strategies. VB1 quenched PL of OVA@Cu NCs through aggregation, while doxycycline enhanced the emission due to its strong interaction with OVA, and making a more compact structure. OVA-Cu NCs with a red emission at $625 \mathrm{~nm}$ and a PLQY of $3.95 \%$ were used for folic acid detection with a LOD of $0.18 \mu \mathrm{M}$. Evaluation of FA absorption (360 $\mathrm{nm}$ ) and OVA-Cu NC excitation spectra (348 nm) as well as fluorescence lifetimes of $\mathrm{Cu}$ NCs in the presence and absence of FA indicated that the detection mechanisms should be the static quenching and the IFE. ${ }^{36}$ Quenching of BSA-Cu NCs by rutin (a kind of flavonoid) through hydrogen bonding and electrostatic interactions between BSA and rutin was used for naked eye fluorescent detection in aqueous solution as well as on a paper filter. ${ }^{34}$ Via the same mechanism, detection of mangiferin, a kind of flavonoid, was performed in real samples by BSA-Cu NCs. ${ }^{238}$ In another biosensing method, Kojic acid, a fungal metabolite, was measured through Cu NCs FL quenching. ${ }^{239}$ The fluorescence of BSA-Cu NCs was diminished due to its binding to copper ions and the formation of copper Kojate on the surface of $\mathrm{Cu}$ NCs.

Quenched fluorescence of NCs triggered by electron transfer of metal ions can be recovered by strong interactions between analytes and those ions. ${ }^{240}$ The turn-on fluorescence of PEI-Cu NCs was employed for detecting biothiols (e.g. cysteine and $\mathrm{GSH}) .{ }^{23}$ Herein, $-\mathrm{SH}$ functional groups interacted strongly with $\mathrm{Cu}^{2+}$ (introduced into the reaction mixture) as a quencher.
Acetylcholinesterase (AChE), which is capable of hydrolyzing acetylthiocholine into thiocholine, has a strong tendency in forming a complex with $\mathrm{Cu}^{2+}$; hence, it could be assayed by

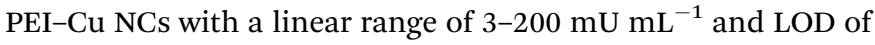
$1.38 \mathrm{mU} \mathrm{mL} \mathrm{m}^{-1} .^{23}$ This approach was also used for detecting an AChE typical inhibitor, tacrine. ${ }^{23}$ In another study, a dualemitting nanohybrid was prepared based on blue emitting carbon dots modified with 3-aminophenyl boronic acid (APBA-CDs) and BSA-Cu NCs for the detection of dopamine. ${ }^{33}$ Red-emitting $\mathrm{BSA}-\mathrm{Cu}$ NCs acted as an internal reference for measuring the PL quenching of APBA-CDs in the presence of dopamine, and a decrease in fluorescence intensity of APBA-CDs could be detected by the naked eye. Wang et $a l .{ }^{39}$ presented a molecular biology technique termed target-cycling strand displacement amplification (TCSDA) to detect adenosine $5^{\prime}$-triphosphate (ATP) in a broad dynamic range from $0.01 \mathrm{nM}$ to $100 \mathrm{nM}$ with a LOD of 5 pM. In the presence of ATP, an oligonucleotide hairpin probe containing an ATP aptamer sequence was structurally switched so that the TCSDA reaction was started by a DNA polymerase Klenow fragment (KF polymerase). This approach could detect ATP in a broad dynamic range from $0.01 \mathrm{nM}$ to $100 \mathrm{nM}$, with a LOD of 5 pM. The PL intensity of PVP-stabilized $\mathrm{Cu}$ NCs was quenched after formation of a $\mathrm{MnO}_{2}-\mathrm{Cu} \mathrm{NC}$ complex through electrostatic interactions with $\mathrm{MnO}_{2}$ nanospheres. GSH was selectively detected by this complex due to its capability of recovering the $\mathrm{PL}$ signal of $\mathrm{Cu}$ NCs (acting as donors) via digesting the $\mathrm{MnO}_{2}$ nanospheres (energy acceptors). This FRETbased biosensor could detect GSH with a LOD of $17 \mu \mathrm{M}^{21}$

In addition to PL properties, the catalytic activity of $\mathrm{Cu}$ NCs was employed for biosensing, as well. $\mathrm{Xu}$ and co-workers ${ }^{241}$ used the advantage of the peroxidase-mimetic activity of $\mathrm{Cu}$ NCs to detect cholesterol with a broad linear range of $0.05-10 \mathrm{mM}$ and LOD of $1.5 \mu \mathrm{M}$. The assay was based on chemiluminescent signals produced by coupling two reactions. The first reaction was the oxidation process of cholesterol catalyzed by cholesterol oxidase enzyme, which produced $\mathrm{H}_{2} \mathrm{O}_{2}$ as a by-product. The second reaction was the luminol oxidation by $\mathrm{H}_{2} \mathrm{O}_{2}$, catalyzed by $\mathrm{Cu}$ NCs.

4.2.5 Enzyme activity detection. Monitoring the activity of enzymes catalyzing biological reactions in living cells is an important task, and metal NCs, including Cu NCs, have been widely employed for enzyme activity biosensing. ${ }^{24,40,242-246}$ Two common strategies were utilized, including in situ synthesis of $\mathrm{Cu}$ NCs leading to the appearance of a fluorescence signal, especially for nucleic acid related enzymes, and the aggregationinduced emission (AIE). ${ }^{247}$ Qing et al. ${ }^{248}$ used micrococcal nuclease (MNase), a nucleic acid degrading enzyme, for detecting Staphylococcus aureus. They showed that in the absence of MNase, dsDNA with the aid of sodium ascorbate served as a template for the formation of $\mathrm{Cu}$ NCs with excitation/emission peaks located at $340 / 570 \mathrm{~nm}$. The fluorescence turn-on strategy based on DNA-templated synthesis of Cu NCs was also used for the activity detection of enzymes like T4 polynucleotide kinase phosphatase $^{43}$ DNA polymerase ${ }^{231}$ and uracil-DNA glycosylase (UDG). ${ }^{46}$ Both dsDNA and ssDNA can act as a template for the synthesis of $\mathrm{Cu}$ NCs. The UDG activity was detected through the 
production of $\mathrm{Cu}$ NCs in a poly(T) tail ssDNA produced by a template-free DNA extension of terminal deoxynucleotidyl transferase. ${ }^{46}$ UDG can remove uracil from the uracil-containing stem-loop DNA substrate with $3^{\prime}$-end block by $2^{\prime}, 3^{\prime}$-dideoxycytosine (ddC), providing sensitive UDG detection with a LOD of $50 \mu \mathrm{U} \mathrm{mL} \mathrm{m}^{-1}$. The sensing scheme could be further improved via a branched amplification with the addition of an abasic sitecontained poly(A) oligonucleotide, which was cleaved by endonuclease and its 3 '-OH end was extended by TdT (Fig. 6B). The UDG enzyme activity has also been detected using the fluorescence approach, based on the $4^{\prime}, 6$-diamidino-2-phenylindole (DAPI, $\lambda_{\mathrm{em}}=452 \mathrm{~nm}$ ) and poly(T) ssDNA templated $\mathrm{Cu}$ NCs $\left(\lambda_{\mathrm{em}}=602 \mathrm{~nm}\right) .{ }^{41}$ In the presence of UDG, three uracil-containing dsDNA substrates denatured, and one of ssDNA was partially hybridized with a helper dsDNA, which triggered exonuclease III digestion. The LOD of this sensor was reported to be $50 \mu \mathrm{U} \mathrm{mL}^{-1}$.

The AIE effect is yet another common strategy that has been used for the activity detection of pyrophosphatase (PPi) by GSHcapped Cu NCs. ${ }^{249,250}$ In the presence of $\mathrm{Al}^{3+}$, the aggregation of $\mathrm{Cu}$ NCs occurred, leading to the PL enhancement due to AIE, providing a sensitive probe with a LOD of $1.3 \mathrm{mU} \mathrm{mL}^{-1}$. Zhao et al. ${ }^{68}$ prepared stable $\mathrm{Cu}$ NCs with improved AIE properties by employing a hydrophobic capping agent (4-methylthiophenol) during synthesis. The as-synthesized $\mathrm{Cu}$ NCs exhibited a weak emission due to their hydrophobic protecting ligands, but through subsequent processing, they were self-assembled into highly red emissive particles. Addition of a hydrophobic electron acceptor molecule (4-nitrophenol) could quench the emission of these $\mathrm{Cu}$ NCs by about $80 \%$. Through this quenching strategy and using 4-nitrophenyl- $\beta$-D-galactopyranoside (NPGal) as the synthetic substrate for $\beta$-galactosidase enzyme, the enzymatic activity of $\beta$-galactosidase in serum could be measured with a LOD of $0.9 \mathrm{U} \mathrm{L}^{-1}$ in the linear range of 2.5-212.0 $\mathrm{U} \mathrm{L}^{-1}$. Huang et $a .^{105}$ used a similar strategy to monitor the $\beta$-galactosidase activity. They employed aluminum cations to self-assemble GSH-capped $\mathrm{Cu}$ NCs into so-called $\mathrm{Cu}$ NC dots with strong PL intensity, which was quenched upon enzymatic release of 4-nitrophenol from 4-nitrophenyl- $\beta$-D-galactopyranoside (Fig. 6C). The same PL-off or PL-on switching mechanism was used for the real-time monitoring of acid phosphatase activity, in which after hydrolyzing the bond between 4-nitrophenol and the phosphate group in p-nitrophenyl phosphate disodium, the PL quenching occurred. $^{251}$ In another study, ${ }^{67}$ the acid phosphatase (ACP) enzyme activity was measured by redox-responsive emission of $\mathrm{Cu}$ NC aggregates. It was shown that D-penicillamine-capped $\mathrm{Cu}$ NCs with $\mathrm{pH}$ and temperature responsiveness could aggregate to form particles with stronger red luminescence. The existence of oxidant species such as free ferric ions $\left(\mathrm{Fe}^{3+}\right)$ could quench the PL intensity of CNC aggregates by $80 \%$ due to oxidation of copper atoms, providing an assay with $0.8 \mathrm{U} \mathrm{L}^{-1} \mathrm{LOD}$ and a broad linear scope of up to $100 \mathrm{U} \mathrm{L}^{-1}$. This strategy also was applied for ACP activity measurement in diluted serum samples as complex medium. $^{67}$

Wang et $a .^{24}$ have introduced a novel assay for protein kinase A (PKA) activity based on the overlap of the emission of PEI-capped $\mathrm{Cu}$ NCs (with an emission peak around $515 \mathrm{~nm}$ ) and the UV-Vis absorption spectrum of Au NPs. The already mentioned inner-filter effect (IFE) could quench PL of PEI-Cu NCs up to 59\%. Peptide-functionalized Au NPs after phosphorylation by PKA enzyme with the assistance of adenosine $5^{\prime}$-triphosphate (ATP) molecules tend to aggregate in the presence of multivalent $\mathrm{Zr}^{4+}$ cations. This fluorescent biosensor for PKA activity measurement with a linear range of 0.1-6.0 $\mathrm{U} \mathrm{mL}^{-1}$ and LOD of $0.038 \mathrm{U} \mathrm{mL}^{-1}$ also was employed for measuring the cellular kinase activity in HepG-2 cell lysates. In another study, ${ }^{40}$ a biosensor for the PKA activity was developed based on the quenching effect of graphene oxide (GO) plates on dsDNA-Cu NCs through fluorescence resonant energy transfer (FRET) (Fig. 6D). Two-domain oligonucleotides including an ATP aptamer sequence were hybridized with a shorter complementary sequence as a template for $\mathrm{Cu}$ NC formation. Binding ATP molecules to aptamer sequences and folding ssDNA inhibited proximity between GO and dsDNA-Cu NCs and kept $\mathrm{Cu}$ NCs fluorescent. ATP hydrolysis to ADP by the PKA enzyme made the ATP domain of the oligonucleotide to be single-stranded, which could adsorb on GO via electrostatic and $\pi-\pi$ stacking leading to PL quenching of dsDNA-Cu NCs. The linear range and LOD of this assay were $0.1-5.0 \mathrm{U} \mathrm{mL}^{-1}$ and $0.039 \mathrm{U} \mathrm{mL}^{-1}$, respectively. A poly(AT-TA) dsDNA with a restriction site for EcoRI endonuclease was also used for endonuclease activity detection. ${ }^{245}$ In the presence of the enzyme, dsDNA was cut even in the presence of reducing agent AA to affect the fluorescence intensity. This assay could detect

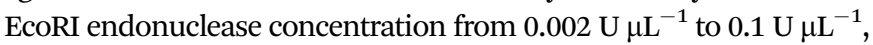
with a LOD of $0.00087 \mathrm{U}^{-1}$.

4.2.6. Temperature and $\mathbf{p H}$ sensing. In many chemical and biological processes, both temperature and $\mathrm{pH}$ are factors which can significantly affect the kinetics and the reaction pathways. In biological, biomedical and pharmaceutical research, monitoring the fluctuations in temperature and $\mathrm{pH}$ during cellular metabolism and cell organelle functions plays an important role. Therefore, plenty of studies focused on the identification of fluorescent nanomaterials with $\mathrm{pH}$ or temperature responsive behavior, ${ }^{252,253}$ and some of them have employed Cu NCs. Zhang et al. ${ }^{31}$ prepared a blueemitting silk fibroin/Cu NC composite, using it as a nanometersized $\mathrm{pH}$ sensor with a linear $\mathrm{pH}$ range from 6.08 to 10.05 . The direct relationship between $\mathrm{pH}$ and $\mathrm{PL}$ intensity in different buffers such as BR, PBS, Tris-HCl and HEPES was demonstrated. The sensor behaved reversibly at least for 5 cycles, independent of the ionic strength and presence of a large number of cations. Xiaoqing et al. ${ }^{254}$ used BSA-capped Cu NCs to detect the intracellular $\mathrm{pH}$ of $\mathrm{RBL}-2 \mathrm{H} 3$ cells and natural water. Their nano-pH meter exhibited a reversible response to $\mathrm{pH}$ up to 6 cycles in the $\mathrm{pH}$ range of 3.01 to 11.13.

Nano-thermometers have plenty of applications, especially in monitoring the temperature within biological cells and microfluidic devices. ${ }^{255,256}$ Shi et al. ${ }^{20}$ synthesized stable, blue-emitting $\mathrm{Cu}$ NCs with a PLQY of $12 \%$ and have shown that their fluorescence signal linearly decreased by $73 \%$ with increasing temperature from 20 to $75{ }^{\circ} \mathrm{C}$, without any shifts of the emission peak (425 nm). Only 5\% deviation was recorded after 10 cycles of heating and cooling between 20 and $75{ }^{\circ} \mathrm{C}$. Han et al. ${ }^{66}$ used bimetallic GSH-Cu/Ag NCs for temperature sensing; by introducing $\mathrm{Ag}$ ions during the synthesis of $\mathrm{Cu}$ NCs, 9-fold enhancement of 
fluorescence intensity was attained. These bimetallic NCs with a strong orange-yellow emission and ionic strength stability showed a linear and inverse relationship between fluorescence intensity and temperature changes within $4-55{ }^{\circ} \mathrm{C}$. Reversibility of the thermal response was demonstrated after 7 heatingcooling cycles without a decrease in the luminescence intensity. Bimetallic NCs were employed for confocal fluorescent imaging of HeLa cells after $24 \mathrm{~h}$ of incubation at three different temperatures ( $293 \mathrm{~K}, 303 \mathrm{~K}$, and $313 \mathrm{~K}$ ). The mechanism underlying fluorescence intensity quenching was ascribed to the aggregation of NCs. ${ }^{216}$ Wang et al. ${ }^{98}$ prepared highly fluorescent GSH-protected $\mathrm{Cu}$ NCs with QY 5\% and used them for temperature monitoring and confocal imaging of MC3T3-E1 human cancer cells in the range of $15-45^{\circ} \mathrm{C}$.

\subsection{Bioimaging}

4.3.1. In vitro imaging. $\mathrm{Cu}$ NCs have been recognized as potential fluorescent probes for bioimaging, because of the features such as reasonably high PLQY, ultra-small size, flexible surface chemistry, and biocompatibility. By using different types of ligands and scaffolds, different kinds of $\mathrm{Cu}$ NCs for bioimaging have been prepared. Blue emitting Cu NCs (at $450 \mathrm{~nm}$ ) were synthesized in lysozyme bed with a PLQY of $18 \%$, and were used for labeling of HeLa cells; ${ }^{152}$ blood compatibility tests confirmed their applicability for bioimaging. Likewise, blue emitting peptide-templated $\mathrm{Cu}$ NCs (with artificial sequence CLEDNN) were applied to HeLa labeling, without inducing any considerable toxicity. ${ }^{155}$ PEI protected $\mathrm{Cu}$ NCs were used for labeling of $293 \mathrm{~T}$ cells, which remained more than $75 \%$ viable after $24 \mathrm{~h}$ at $100 \mu \mathrm{g} \mathrm{mL}{ }^{-1}$ concentration. PEI-capped $\mathrm{Cu}$ NCs were also employed for plasmid DNA condensation, which could be used as a DNA probe and non-viral vector for gene delivery. ${ }^{22}$ Confocal microscopic studies demonstrated that blue emitting GSH-Cu NCs could localize in the membrane of three types of cancerous cells (MDA-MB-231, A549, and HeLa cells). ${ }^{107}$ Tannic acid-stabilized $\mathrm{Cu}$ NCs were sensitive to ferric ions and could detect ferric ions inside A549 cells and serum samples. ${ }^{4}$ BSA-Cu NCs were utilized as a pH probe in living cells by epifluorescence microscopy. ${ }^{254} \mathrm{Cu}$ NCs templated with dopamine were used for fluorescence painting and coding. ${ }^{257}$

Since UV irradiation necessary to excite blue emitting $\mathrm{Cu}$ NCs may damage the cells upon imaging, and induce the autofluorescence of the tissue, red emitting $\mathrm{Cu}$ NCs emerged as alternative probes. Wang and co-workers ${ }^{13}$ used BSA-Cu NCs for low energy excitation at $524 \mathrm{~nm}$ and imaged $24 \mathrm{~h}$-incubated CAL-27 cells at the peak emission of $625 \mathrm{~nm}$. Kailasa's group ${ }^{72}$ synthesized egg white supported $\mathrm{Cu}$ NCs with two emission wavelengths; confocal laser microscopy revealed a blue signal when excited by a $405 \mathrm{~nm}$ laser, and a green signal when excited by a $488 \mathrm{~nm}$ laser in Bacillus subtilis. When HeLa cells were treated with PEG-capped Cu NCs, confocal microscopy showed the ability of these $\mathrm{Cu}$ NCs to stain the nuclei through cellular uptake by membrane crossing without endocytosis. ${ }^{5}$ In another study, transferrin (Tf) receptors were targeted by red emitting Trf-Cu NCs. ${ }^{258}$ High expression of the Tf receptor on HeLa cells caused higher uptake of $\mathrm{Tf}-\mathrm{Cu}$ NCs in comparison to $3 \mathrm{~T} 3$ cells.
Temperature changes could be related to some unfavorable biological pathways of alive cells, ${ }^{259,260}$ making temperature measurements combined with the cellular imaging quite important. Intracellular synthesis of $\mathrm{Cu}$ NCs has been performed for determination of temperature in living cells; $\mathrm{Cu}$ NCs with sizes of $2.4 \pm 0.4 \mathrm{~nm}$ and red emission at $610 \mathrm{~nm}$ could be synthesized in malignant cell lines such as MDA-MB-231 via a specific biomolecular process. ${ }^{73}$ Notably, this cannot be done in healthy cells, e.g. L02. Accumulation of these NCs in the target cells was efficient, and sensitivity of the fluorescence signal to the physiological temperature was high; the calibration curve for MDA-MB-231 cells showed 3.18\% decrease in PL intensity per $1{ }^{\circ} \mathrm{C}$ temperature elevation. Owing to the critical role of $\mathrm{Ca}^{2+}$ in neurodegeneration and the importance of monitoring of $\mathrm{Ca}^{2+}$ pathways in neurons, Tian's group ${ }^{261}$ developed a $\mathrm{Ca}^{2+}$ sensitive probe via $\mathrm{Ca}^{2+}$ ligand modified PEI templated Cu NCs (Fig. 7A-I). Alexa 660 NHS ester was conjugated to $\mathrm{Cu}$ NCs as a reference (Fig. 7A-II). The intensity of Cu NC PL in neurons was amplified based on the increase of $\mathrm{Ca}^{2+}$ concentration. The signal ratio of $\mathrm{Cu}$ NCs to reference sample could also be calibrated to a high concentration range sensor based on intracellular bioimaging. In another study, non-luminescent cysteine and chitosan protected $\mathrm{Cu}$ NCs were employed to specify cell differentiating at $\mathrm{pH}=7.4$. The kinetics of $\mathrm{Cu} \mathrm{NC}$ aggregation inside different cell lines was dependent on the cell type so that a novel approach for detection of various cell lines could be developed only by green channel monitoring of confocal microscopy (Fig. 7B). ${ }^{75,262}$

4.3.2. In vivo imaging. Lung cancer, a five-year low survival rate disease $(<15 \%)$, places serious threats on the global health, ${ }^{263}$ and its early diagnosis helps to save time for the therapy of suffering patients. In recent years, researchers have paid special attention to positron emission tomography (PET) imaging, due to its unrestricted tissue penetration, higher sensitivity, and temporal resolution. ${ }^{264}$ The progress of PET imaging agents able to target particular molecules is necessary for the advancement of clinically related PET techniques. ${ }^{64} \mathrm{Cu}$ as a PET imaging probe has been present in macrocyclic chelators. To put aside utilization of chelators, radioactive BSA-capped $\mathrm{Cu}$ NCs were synthesized for in vivo PET imaging. LHRH as a tumor target peptide was conjugated to BSA to form Cu NCs@BSA-LHRH,${ }^{76}$ which exhibited high radiolabeling constancy, rapid diffusion into the tumor, and high renal clearance. ${ }^{64} \mathrm{Cu}$ radioactivity measurements demonstrated that tumor uptake of Cu NCs@BSA-LHRH was 4 times greater than that of control Cu NCs@BSA. PET imaging by $\mathrm{Cu}$ NCs@BSA-LHRH as a contrast agent indicated sensitive and early precise diagnosis in a primary (orthotopic) lung cancer model (Fig. 7C).

\subsection{Theranostic applications}

Theranostic agents can be used in therapeutics and diagnostics at the same time. ${ }^{8}$ Ghosh et al. ${ }^{143}$ developed a hydrogel-based anticancer carrier containing $\mathrm{Cu}$ NCs and Cisplatin, using red fluorescent $\mathrm{Cu}$ NCs synthesized in an aqueous environment by using poly(vinylpyrrolidone) (PVP) stabilizer and dihydrolipoic acid. Composite fluorescent particles were sensitive to $\mathrm{pH}$ variations and exhibited emission changes from red to orange 

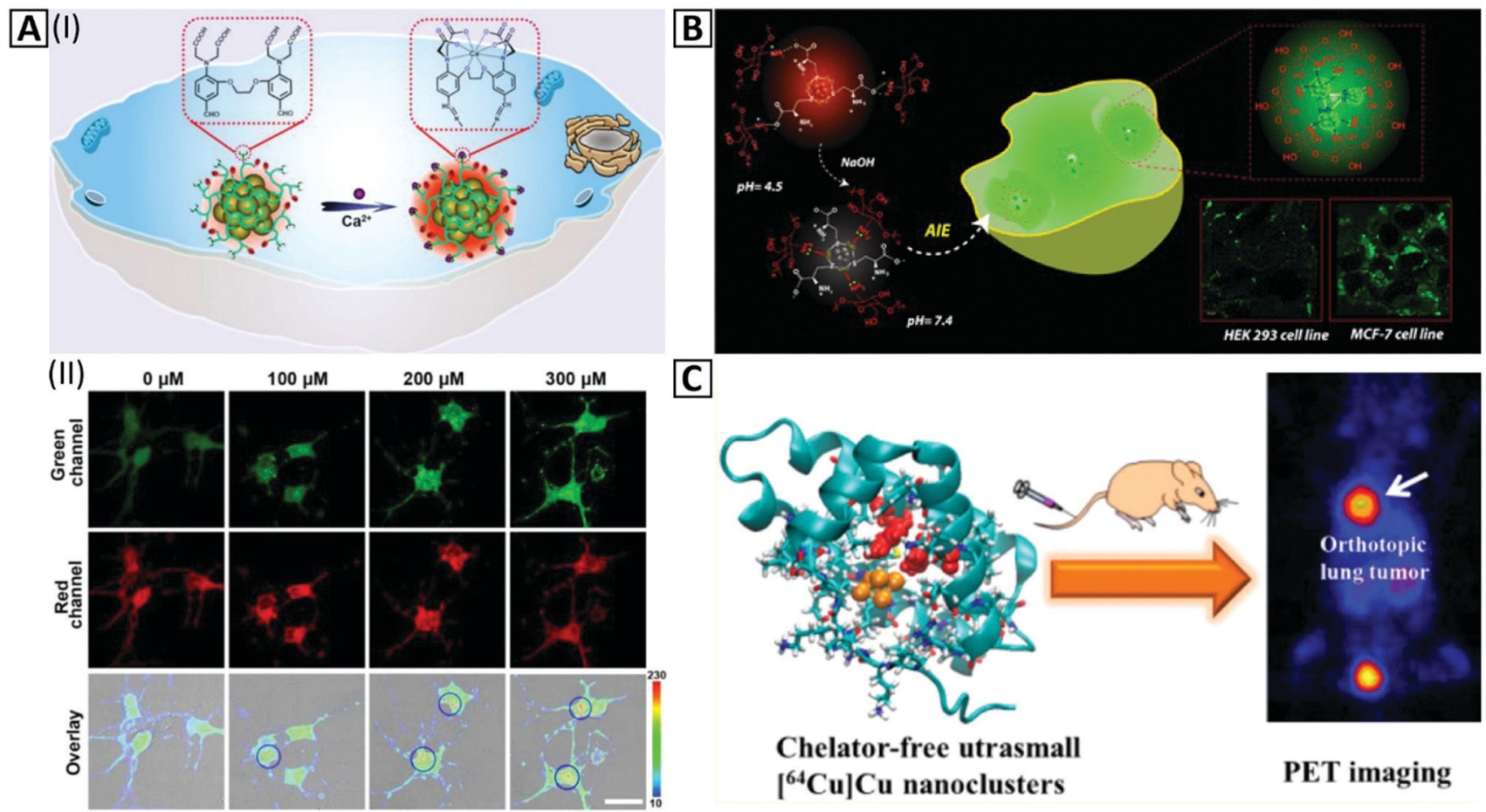

PET imaging

Fig. 7 (A-I) Schematic illustration of in vitro imaging based on the amplification of the PL intensity of the Cu NC(aAlexa660 probe in the presence of $\mathrm{Ca}^{2+}$. (A-II). Fluorescence confocal imaging exhibits amplification of the green channel intensity ratio to the constant signal intensity of the red channel inside neurons via an increase of $\mathrm{Ca}^{2+}$ concentration from 0-300 $\mu \mathrm{M}$ in the presence of $90 \mu \mathrm{g} \mathrm{mL}^{-1}$ of the Cu NC@Alexa660 probe. Adapted with permission from ref. 261, Copyright 2019, ACS. (B) Schematic illustration of in vitro imaging of HEK 293 and MCF-7 cells by red-emitting Cu NCs at $\mathrm{pH}=4.5$, which change their color to green at $\mathrm{pH}=7.4$ via the AIE effect inside the cell cytoplasm. Adapted with permission from ref. $75, \mathrm{Copyright} 2018$, ACS. (C) In vivo PET imaging and organ distribution study after $2 \mathrm{~h}$ intravenous injection of Cu NCs (aBSA-LHRH. Adapted with permission from ref. 76, Copyright 2015, ACS.

through adjustment of the $\mathrm{pH}$ in the range of 4 to 8.5. Fluorescence microscopy showed how this kind of nanocarrier can be used for mammalian cell uptake monitoring; synergetic anticancer activity was attained by coupling the therapeutic effect of Cisplatin alongside with the ability of $\mathrm{Cu}$ NCs in killing cancerous cells through generation of reactive oxygen species (ROS). Goswami et al. ${ }^{77}$ prepared blue emitting Tf-templated $\mathrm{Cu}$ NCs and combined them with Dox through electrostatic interactions to formulate sphere-shaped Tf-Cu NC-Dox NPs for active theranostics. Due to FRET occurring in this system, Tf-Cu NC-Dox NPs displayed significant red emission, while the release of Dox inside the cytoplasm of Tf receptor overexpressed cancer cells restored the blue emission of $\mathrm{Cu}$ NCs. A synergistic effect of the ROS generation by $\mathrm{Tf}-\mathrm{Cu}$ NCs and the anticancer activity of Dox for the therapy of mouse models has been demonstrated. Another study revealed that temozolomide loaded positron emitting $\mathrm{Cu}$ NCs could upgrade a PET contrast agent to a theranostics agent for glioblastoma. ${ }^{78}$

\subsection{Other bioapplications}

In addition to applications of $\mathrm{Cu}$ NCs considered above, there are a few other emerging areas where they can be of interest. For instance, biological staining is frequently used to mark cells in flow cytometry, and to flag proteins or nucleic acids in gel electrophoresis. ${ }^{265}$ Zhu et al. $^{266}$ developed a method for in situ staining of DNA in a polyacrylamide gel through the formation of $\mathrm{Cu}$ NCs in the presence of a DNA template. $\mathrm{Cu}$ NCs have also been utilized for the detection of single nucleotide polymorphisms, which are responsible for various genetic problems of human health. ${ }^{267}$ Since dsDNA affects the Cu NC environment and thus changes the fluorescence intensity, a "mix-and-measure" strategy has been employed for mismatch detection of dsDNA. Cu NCs can also serve as smart probes opening opportunities for fast and economical bioanalysis. ${ }^{268}$

In recent years, nano-bioelectronics has attracted significant attention as a rapidly expanding interdisciplinary field which utilizes nanomaterials to overcome some current limitations in bioelectronics. $^{269}$ DNA nanowires are promising materials for this purpose, while $\mathrm{Cu}$ NCs with resistance to charge transfer can be employed as the key element for the "ON-OFF" process. To exhibit practical aspects of this phenomena, one end of dsDNA was immobilized on the surface of gold electrodes, and another end was tagged by methylene blue (a redox-active agent). In the presence of $\mathrm{AA}, \mathrm{Cu}^{2+}$ was reduced to $\mathrm{Cu}^{0}$ and deposited on the DNA scaffold, which resulted in a switch-off of the charge transfer path. The process was reversible and repetitive by utilizing oxidants that caused the stripping of $\mathrm{Cu} \mathrm{NCs}^{270}$

The antimicrobial effect of $\mathrm{Cu}$ NCs has recently been explored. ${ }^{110}$ Baghdasaryan et al. showed the dose-dependent bactericidal capability of GSH-capped $\mathrm{Cu}$ NCs: at low cluster 
concentrations the growth of bacteria was slowed down, and at high dosages $\left(\geq 250 \mu \mathrm{g} \mathrm{mL}{ }^{-1}\right)$ the bacterial replication was fully restricted. Antimicrobial action of metal NCs has been ascribed to intracellular ROS generation. ${ }^{271}$ To utilize the high antibacterial performance of metal NCs, Ag, Cu, and Au NCs@Bacitracin were synthesized by Wang and coworkers. ${ }^{272}$ Bacitracin as a peptide antibiotic can damage the bacterial membrane; hence, the synergy of the membrane damage and the ROS generation by different MNCs@Bacitracin clusters could be attained. It was demonstrated that Ag NCs@Bacitracin was the most powerful antibacterial agent against $S$. aureus. Comparative results of zone inhibitions, growth curve, percentage of PI stained bacteria, and relative ROS levels are provided in Fig. 8. Cu NC-doped kanamycin-loaded hydroxyapatite NPs were introduced as an antibiofilm and antibacterial agent. ${ }^{273}$

\subsection{Applications in photovoltaics and optoelectronics}

4.6.1. Light harvesting. Photosynthesis is a classical example of light-harvesting systems based on natural composite materials, on which base a number of photovoltaic and optoelectronic applications have been developed. ${ }^{274}$ Different from numerous studies on $\mathrm{Au} \mathrm{NCs},{ }^{275,276}$ utilizing $\mathrm{Cu}$ NCs in light harvesting and charge transfer nanocomposites has been rather rare, so far. Patra's group ${ }^{79}$ produced a light harvesting nanocomposite by electrostatic interactions between the carboxylate groups of cysteine-capped $\mathrm{Cu}$ NCs and imidazole moieties of functionalized reduced graphene oxide (ImRGO) (Fig. 9A). The absorption spectrum of the nanocomposite was the sum of the $\mathrm{Cu}$ NCs and ImRGO spectra, while PL studies revealed that $87 \%$ quenching of the emission intensity of $\mathrm{Cu}$ NCs occurred, accompanied by a significant decrease of the average PL decay time of the Cu NCs in the composite. The positions of HOMO/LUMO levels signified electron transfer from $\mathrm{Cu}$ NCs to ImRGO, due to the lower lying work function of the latter (Fig. 9B).

4.6.2. Solar cells. $\gamma$-Phase copper iodide $(\gamma$-CuI $)$ is a wellknown p-type semiconductor, but its fabrication using wet chemical methods is challenging. Zheng's group ${ }^{80}$ used $\mathrm{Cu}_{53}$ NCs soluble in ether to deposit them on organolead halide perovskite films, with subsequent iodination to form high-quality $\gamma$-CuI films (Fig. 9C). The energy level diagram of the resulting solar cell device signified the injection of holes from the perovskite to the $\gamma$-CuI film (Fig. 9D), which attained $14.3 \%$ efficiency with a minimal hysteresis. ${ }^{80}$

4.6.3. Light-emitting devices. Light emitting $\mathrm{Cu}$ NCs have been often employed as phosphors in down conversion LED prototypes. Wang et al. ${ }^{144}$ synthesized high PLQY Cu NCs with combined red and green emissions and constructed downconversion white light-emitting devices (WLEDs) with a high color rendering index of 92. First, blue emitting PVP-protected $\mathrm{Cu}$ NCs with a PLQY of $8 \%$ were synthesized in an aqueous phase and treated with GSH to enhance their PLQY to $27 \%$ with a red shift in the emission peak. This enhancement was attained via the metal-chelating capability of thiol motifs of GSH, combined with electron-rich carboxyl and amino functional groups of PVP.

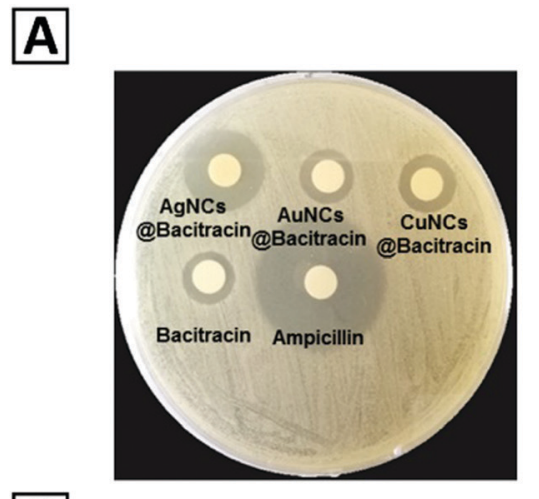

B
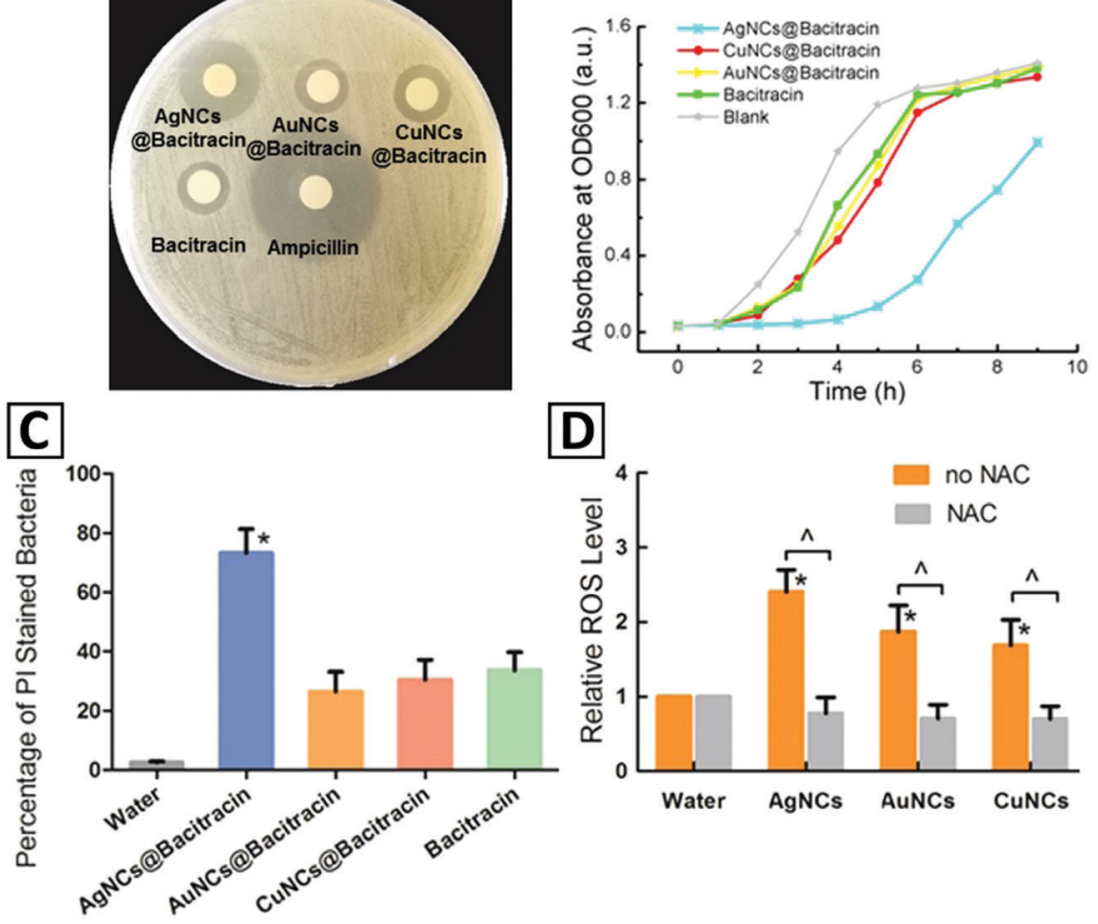

Fig. 8 (A) Zone inhibitions against S. aureus by Ag, Au, Cu NCs@Bacitracin, bacitracin, and ampicillin. (B) S. aureus growth curve in the presence of Ag, $\mathrm{Au}$, and Cu NCs@ Bacitracin. (C) The percentage of stained bacteria cells with PI in the presence of water, Ag, Au, Cu NCs@ Bacitracin, and bacitracin. (D) ROS levels in bacteria cells treated with Ag, Au, and Cu NCs@Bacitracin; ROS levels are for two separate groups treated by water with/out NAC. Adapted with permission from ref. 272, Copyright 2019, ACS. 


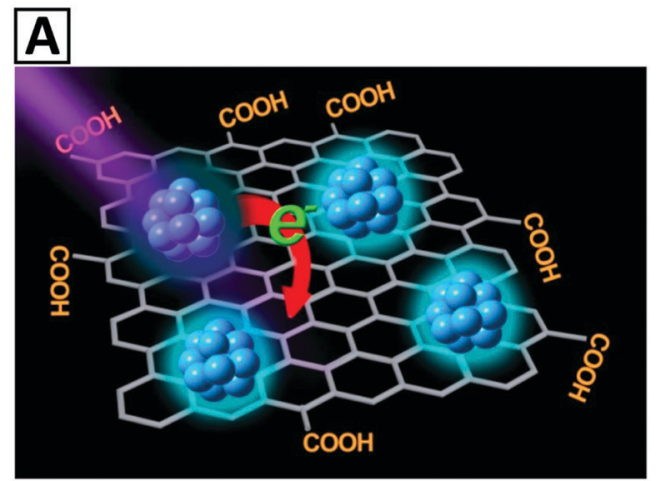

B
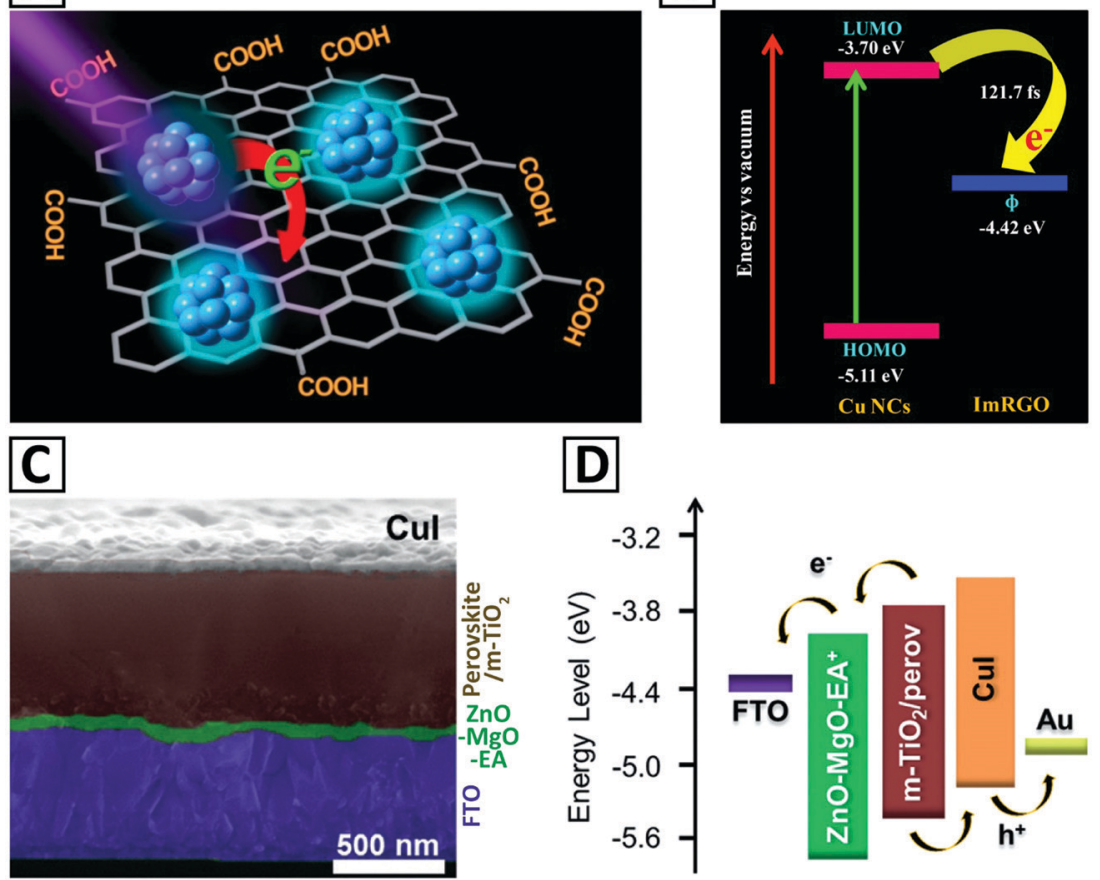

Fig. 9 (A) Schematic illustration of a Cu NCs/ImRGO nanocomposite, and (B) positions of the HOMO-LUMO levels of Cu NCs and work function ( $\phi$ ) of ImRGO. Adapted with permission from ref. 79, Copyright 2018, ACS. (C) Cross-sectional scanning electron microscopy image of a Cul film made from $\mathrm{Cu}_{53} \mathrm{NCs}$ deposited on a lead halide perovskite film through iodization, and (D) energy level diagram of the Cul-based perovskite solar cell. Adapted with permission from ref. 80, Copyright 2019, Wiley- $\mathrm{VCH}$.

Wu et al. ${ }^{81}$ utilized luminescence enhancement of 1-dodecanethiol (DT)-stabilized Cu NCs to fabricate WLEDs. They showed that selfassembly of $\mathrm{Cu}$ NCs to ribbons and sheets resulted in favorable emission changes, amplifying cuprophilic interactions and preventing intramolecular rotation and vibration of the DT stabilizer. This intensified the emission intensity with a blue shift, displaying different thermochromic and mechanochromic luminescence attributes. It was also suggested that surface defects moderately enhanced the ratio of $\mathrm{Cu}^{+}-\mathrm{to}-\mathrm{Cu}^{0}$, which boosted radiative states of excited electrons via the effect on the ligand-to-metal-metal charge transfer (LMMCT). ${ }^{102}$ Blue-green, yellow, and red emitting $\mathrm{Cu}$ NCs were prepared and utilized as phosphors to construct WLEDs. By employing thiophenols with different substitutes as a ligand, the emission color and intensity of self-assembled $\mathrm{Cu} \mathrm{NC}$ nanoribbons could also be tuned $;^{82}$ using this strategy, various types of nanoribbons with high PLQY could be prepared and employed for the fabrication of WLEDs.

Another strategy for tuning fluorescence color is metal doping. ${ }^{277}$ Liu et al. ${ }^{202}$ showed that $\mathrm{Au}^{+}$doping upon preparation of $\mathrm{Cu}$ nanosheets increased their PL intensity with an emission red-shift. The Au doping induced metallophilic interactions of $\mathrm{Au}^{+}-\mathrm{Cu}^{+}$, facilitating excited electrons to experience the radiative relaxation, owing to changes in the ligand-to-metal charge transfer (LMCT) and/or LMMCT. The Au doping also decreased the original $\mathrm{Cu}$-centered triplet energy state inducing an emission red-shift. They revealed that introducing $0.3 \% \mathrm{Au}$ was enough to give rise to 4-fold PL enhancement with a $100 \mathrm{~nm}$ emission red-shift. Such $\mathrm{Au}^{+}$-doped $\mathrm{Cu}$ nanosheets have been applied as phosphors for WLED fabrication.

The AIE effects of luminescent metal NCs have also been utilized for fabrication of WLEDs. ${ }^{101,122,278}$ As already mentioned above, AIE is able to significantly enhance the emission of the $\mathrm{Cu}$ NCs by suppression of the rotation and vibration of their capping ligands. ${ }^{279}$ Wang et al. ${ }^{18}$ used a solvent-induced aggregation method for synthesis of orange emitting aggregated $\mathrm{GSH}$ capped $\mathrm{Cu}$ NCs, which showed PLQY of $24 \%$ and $43 \%$ in solution and solid state, respectively. In parallel, blue emitting Cu NCs@ PVP were synthesized, with a PLQY of 14\%. Both monochrome blue or orange LEDs, and WLEDs were fabricated by depositing respective powders on commercial GaN LED chips providing $370 \mathrm{~nm}$ excitation (Fig. 10). ${ }^{101}$ WLEDs combining blue emitting sulfur QDs with the aggregated orange emitting Cu NCs have been demonstrated, as well. ${ }^{280}$ The same group used in situ aggregation of $\mathrm{Cu}$ NCs in a carboxylated polyurethane matrix to produce remote dual blue/orange emitting composite films, ${ }^{278}$ which were thermally and mechanically stable, and stretchable. The PLQY of the films was as high as $18 \%$ and the CIE chromaticity coordinate was $(0.34,0.29)$. A dehydration-triggered aggregation of GSH capped $\mathrm{Cu}$ NCs occurring in a PVP/poly(vinyl alcohol) matrix resulted in the formation of flexible, large-area polymer composite films with a high PLQY of 30\%, which have been used for fabrication of bright orange LEDs. ${ }^{281}$ A similar dehydration mechanism was used to fabricate protective transparent UV shielding films, ${ }^{282}$ and biocompatible hypromellose-chitosan copolymers with AIE improved the emission of the $\mathrm{Cu}$ NCs reaching $42 \%{ }^{83}$ 

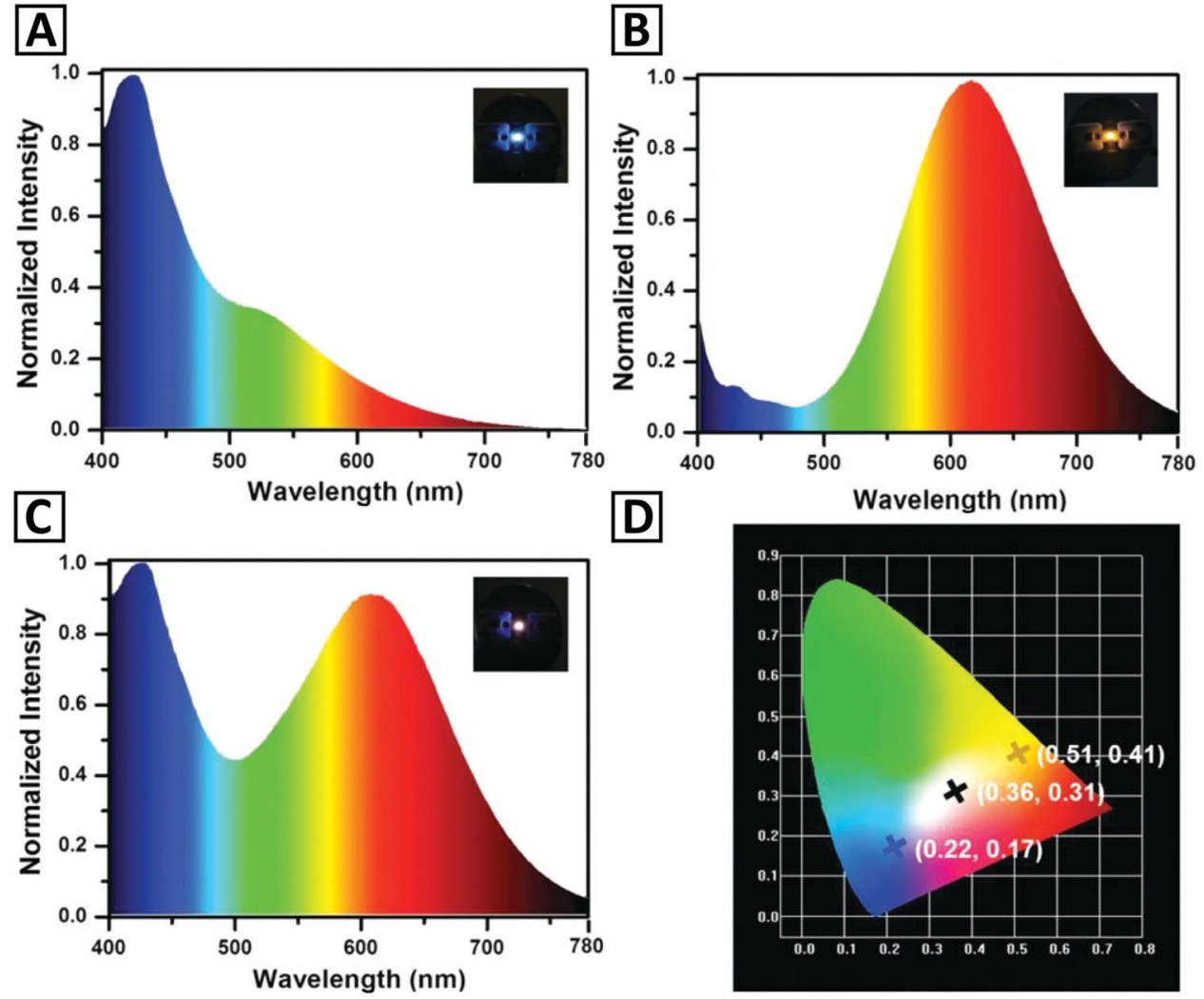

Fig. 10 Emission spectra of monochrome down-conversion LEDs fabricated by using (A) blue emitting Cu NCs and (B) orange emitting Cu NCs. Panel (C) shows an emission spectrum of the WLED fabricated by a combination of these two kinds of Cu NCs. Insets in (A-C) provide photographs of operating blue, orange and white LEDs; while panel (D) shows CIE coordinates of three respective LEDs. Reproduced with permission from ref. 101, Copyright 2016, Wiley-VCH.

\section{Conclusions and outlook}

In this review, rapidly expanding deployment of $\mathrm{Cu}$ NCs in a series of important applications such as catalysis, chemical and biological sensing, bioimaging, theranostics, and fabrication of LEDs is summarized. Extensive up to date research has been carried out on developing viable methods for the synthesis of these promising nanomaterials. One important factor that controls the properties of $\mathrm{Cu}$ NCs is related to the nature of their functional capping agents. Thus, the main thrust in the field of synthesis of Cu NCs is to identify the most appropriate capping agents (ligands) and related templates. Due to the favorable price considerations and availability of precursor materials, practical catalytic applications of $\mathrm{Cu}$ NCs are expected to become widespread as compared to noble metal catalysts, i.e. silver and gold. Also for this application, in order to obtain the desired catalytic activity in appealing reactions e.g. reduction, oxidation, and hydrogen generation, several capping agents/supporting ligands have been investigated. Development of theoretical methods which predict the catalytic performance of $\mathrm{Cu}$ NCs or alloys can facilitate the process of synthesis and introduction of catalysts implemented in some industrial applications in the future. Most of the sensors that have been designed using $\mathrm{Cu}$ NCs exploit their emission (both quenching and enhancement) as the main analytical signal. Capping ligands or stabilizing scaffolds play an important role in the detection mechanism. As in other fluorescent probes, the emission intensity can decrease, increase, or get quenched as a result of interactions with the analyte; thereby, plenty of detection strategies could be employed for different kinds of target molecules. Additionally, combining two or more signal amplification strategies such as molecular biology-based techniques with methods like in situ synthesis of $\mathrm{Cu}$ NCs can enhance the detection capability of the (bio)sensor and significantly lower the detection limits. Non (or low) toxicity, biocompatibility, and low price make $\mathrm{Cu}$ NCs attractive for designing label-free fluorescence sensors. Herein, a variety of analyte classes have successfully been analyzed. There are still drawbacks in this field which are currently inherent to Cu NCs, such as moderate PL QY and higher susceptibility to oxidation; improvement of these aspects has been in the focus of researcher's attention. Using various types of scaffolds, which can be conjugated to targeting agents, $\mathrm{Cu}$ NCs have also been utilized as fluorophores for both in vitro and in vivo bioimaging. Bioimaging can be used to characterize different types of cancer cells, nanothermometry, and estimation of concentration of analytes inside cells. $\mathrm{Cu}$ NCs are able to generate ROS inside eukaryotic and prokaryotic cells and to induce cell death as anticancer and antibacterial agents. ${ }^{64} \mathrm{Cu}$ as a PET imaging probe has been used for the design of new types of PET contrast agents. Recently, $\mathrm{Cu}$ NCs have been also used in photovoltaics, which may provide 
new opportunities for fabrication of solar cells. Light-emitting $\mathrm{Cu}$ NCs were also employed as phosphors in down-conversion LEDs, both monochrome ones, in particular in WLEDs; however, both efficiency and long-term stability of such devices still require massive improvements before their actual practical use.

\section{Conflicts of interest}

There are no conflicts to declare.

\section{Acknowledgements}

We acknowledge financial support from the Iran National Science Foundation (INSF No. 95-S-48740), Sharif University of Technology (Grant No. QA970816), the Research Grant Council of Hong Kong S.A.R. (CityU11305617), and the Science Technology and Innovation Committee of Shenzhen Municipality (JCYJ20170818104224667).

\section{References}

1 J. Wilcoxon and B. L. Abrams, Chem. Soc. Rev., 2006, 35, 1162-1194.

2 X. Hu, T. Liu, Y. Zhuang, W. Wang, Y. Li, W. Fan and Y. Huang, TrAC, Trends Anal. Chem., 2016, 77, 66-75.

3 L. Zhang and E. Wang, Nano Today, 2014, 9, 132-157.

4 H. Cao, Z. Chen, H. Zheng and Y. Huang, Biosens. Bioelectron., 2014, 62, 189-195.

5 M. J. Barthel, I. Angeloni, A. Petrelli, T. Avellini, A. Scarpellini, G. Bertoni, A. Armirotti, I. Moreels and T. Pellegrino, ACS Nano, 2015, 9, 11886-11897.

6 X. Liu and D. Astruc, Coord. Chem. Rev., 2018, 359, 112-126.

7 Z. Wang, B. Chen and A. L. Rogach, Nanoscale Horiz., 2017, 2, 135-146.

8 S. Shahsavari and F. Behroozi, J. Nanomed. Res., 2016, 3, 00069.

9 X. Jia, X. Yang, J. Li, D. Li and E. Wang, Chem. Commun., 2014, 50, 237-239.

10 Z. Wu, Y. Li, J. Liu, Z. Lu, H. Zhang and B. Yang, Angew. Chem., Int. Ed., 2014, 53, 12196-12200.

11 L. D. Pachón, J. H. Van Maarseveen and G. Rothenberg, Adv. Synth. Catal., 2005, 347, 811-815.

12 A. W. Cook, Z. R. Jones, G. Wu, S. L. Scott and T. W. Hayton, J. Am. Chem. Soc., 2017, 140, 394-400.

13 C. Wang, C. Wang, L. Xu, H. Cheng, Q. Lin and C. Zhang, Nanoscale, 2014, 6, 1775-1781.

14 Z. Jin, C. Liu, K. Qi and X. Cui, Sci. Rep., 2017, 7, 39695.

15 R. Cai, P. R. Ellis, J. Yin, J. Liu, C. M. Brown, R. Griffin, G. Chang, D. Yang, J. Ren and K. Cooke, Small, 2018, 14, 1703734.

16 B. Eren, D. Zherebetskyy, L. L. Patera, C. H. Wu, H. Bluhm, C. Africh, L.-W. Wang, G. A. Somorjai and M. Salmeron, Science, 2016, 351, 475-478.

17 B. Sarkar, P. Prajapati, R. Tiwari, R. Tiwari, S. Ghosh, S. S. Acharyya, C. Pendem, R. K. Singha, L. S. Konathala and J. Kumar, Green Chem., 2012, 14, 2600-2606.
18 R. Aparna, J. A. Devi, P. Sachidanandan and S. George, Sens. Actuators, B, 2018, 254, 811-819.

19 Y. Li, L. Feng, W. Yan, I. Hussain, L. Su and B. Tan, Nanoscale, 2019, 11, 1286-1294.

20 Y. E. Shi, S. Luo, X. Ji, F. Liu, X. Chen, Y. Huang, L. Dong and L. Wang, Dalton Trans., 2017, 46, 14251-14255.

21 T. Li, Z. Wang, D. Jiang, H. Wang, W. F. Lai, Y. Lv and Y. Zhai, Sens. Actuators, B, 2019, 290, 535-543.

22 C. Wang, Y. Yao and Q. Song, Colloids Surf., B, 2016, 140, 373-381.

23 J. Yang, N. Song, X. Lv and Q. Jia, Sens. Actuators, B, 2018, 259, 226-232.

24 S. Song, C. Wang, Y. Zhao, T. Hu, X. Zhou, T. Zhao, M. Yang and Q. Lin, Part. Part. Syst. Charact., 2018, 35, 1700471.

25 K. Yang, Y. Wang, C. Lu and X. Yang, J. Lumin., 2018, 196, 181-186.

26 A. Yousefzadeh, J. Hassanzadeh, S. M. J. Mousavi and M. Yousefzadeh, Sens. Actuators, B, 2019, 154-162, 154-162.

27 R. S. Aparna, J. S. Anjali Devi, R. R. Anjana, J. Nebu and S. George, Sens. Actuators, B, 2019, 291, 298-305.

28 G. Zhang, R. Wang, L. Shi, C. Zhang, Y. Zhang, Y. Zhou, C. Dong, G. Li and S. Shuang, Sens. Actuators, B, 2019, 279, 361-368.

29 S. Xu, K. Zhou, D. Fang and L. Ma, Molecules, 2019, 24, 95.

30 Z. Shojaeifard, N. Heidari and B. Hemmateenejad, Spectrochim. Acta, Part A, 2019, 209, 202-208.

31 G. Zhang, T. Xu, H. Du, Y. Qiao, X. Guo, L. Shi, Y. Zhang, S. Shuang, C. Dong and H. Ma, J. Mater. Chem. C, 2016, 4, 3540-3545.

32 R. Rajamanikandan and M. Ilanchelian, Mater. Sci. Eng., C, 2019, 98, 1064-1072.

33 W. He, R. Gui, H. Jin, B. Wang, X. Bu and Y. Fu, Talanta, 2018, 178, 109-115.

34 Y. Wang, T. Chen, Q. Zhuang and Y. Ni, Talanta, 2018, 179, 409-413.

35 R. Aparna, J. A. Devi, R. Anjana, J. Nebu and S. George, Analyst, 2019, 144, 1799-1808.

36 X. Li, X. Wu, F. Zhang, B. Zhao and Y. Li, Talanta, 2019, 195, 372-380.

37 L.-P. Mei, X.-Y. Jiang, X.-D. Yu, W.-W. Zhao, J.-J. Xu and H.-Y. Chen, Anal. Chem., 2018, 90, 2749-2755.

38 J. Li, W. Fu, J. Bao, Z. Wang and Z. Dai, ACS Appl. Mater. Interfaces, 2018, 10, 6965-6971.

39 Y. M. Wang, J. W. Liu, L. Y. Duan, S. J. Liu and J. H. Jiang, Microchim. Acta, 2017, 184, 4183-4188.

40 M. Wang, Z. Lin, Q. Liu, S. Jiang, H. Liu and X. Su, Anal. Chim. Acta, 2018, 1012, 66-73.

41 Y. Ling, J. Zhou, X. F. Zhang, X. H. Wang, N. B. Li and H. Q. Luo, Sens. Actuators, B, 2019, 286, 46-51.

42 R. Li, Q. Liu, Y. Jin and B. Li, Sens. Actuators, B, 2019, 281, 28-33.

43 X. Zhang, Q. Liu, Y. Jin and B. Li, Microchim. Acta, 2019, 186, 3.

44 F. M. Moghadam and M. Rahaie, Biosens. Bioelectron., 2019, 132, 186-195.

45 J. Cao, W. Wang, B. Bo, X. Mao, K. Wang and X. Zhu, Biosens. Bioelectron., 2017, 90, 534-541. 
46 G. Liu, W. He and C. Liu, Talanta, 2019, 195, 320-326.

47 Y.-S. Borghei, M. Hosseini and M. R. Ganjali, Microchim. Acta, 2017, 184, 2671-2677.

48 Y.-S. Borghei, M. Hosseini, M. R. Ganjali and S. Hosseinkhani, Sens. Actuators, B, 2017, 248, 133-139.

49 S. Singh, M. K. Singh and P. Das, Sens. Actuators, B, 2018, 255, 763-774.

50 Y. Zhou, H. Wang, H. Zhang, Y. Q. Chai and R. Yuan, Anal. Chem., 2018, 90, 3543-3549.

51 Y. Nerthigan, A. K. Sharma, S. Pandey and H.-F. Wu, Microchim. Acta, 2019, 186, 130.

52 A. Hatefi, E. Rahimpour, M. Khoubnasabjafari, M. Edalat, V. Jouyban-Gharamaleki, S. Alvani-Alamdari, A. Nokhodchi, M. H. Pournaghi-Azar and A. Jouyban, Microchim. Acta, 2019, 186, 194.

53 H. Liu, X. Gao, X. Zhuang, C. Tian, Y. Li and A. Rogach, Analyst, 2019, 144, 4425-4431.

54 Y. Ma, Y. Yu, B. Lin, L. Zhang, Y. Cao and M. Guo, Microchim. Acta, 2019, 186, 206.

55 G. Hambarde, S. Bothra, Y. Upadhyay, R. K. Bera and S. K. Sahoo, Microchem. J., 2019, 147, 899-904.

56 S. Han and X. Chen, Spectrochim. Acta, Part A, 2019, 210, 315-320.

57 Z. Shen, C. Zhang, X. Yu, J. Li, B. Liu and Z. Zhang, Microchem. J., 2019, 145, 517-522.

58 Y.-S. Lin, T.-C. Chiu and C.-C. Hu, RSC Adv., 2019, 9, 9228-9234.

59 Z. Wen, S. Song, C. Wang, F. Qu, T. Thomas, T. Hu, P. Wang and M. Yang, Sens. Actuators, B, 2019, 282, 9-15.

60 Y. Cheng, F. Sun and Y. Zhou, J. Lumin., 2018, 197, 376-382.

61 C. Boonmee, V. Promarak, T. Tuntulani and W. Ngeontae, Talanta, 2018, 178, 796-804.

62 J. R. Bhamore, B. Deshmukh, V. Haran, S. Jha, R. K. Singhal, N. Lenka, S. K. Kailasa and Z. V. P. Murthy, New J. Chem., 2018, 42, 1510-1520.

63 L. Kong, X. Chu, C. Wang, H. Zhou, Y. Wu and W. Liu, Nanoscale, 2018, 10, 1631-1640.

64 T. Chen, Z. Zhang, Y. Wang and Y. Ni, Gaodeng Xuexiao Huaxue Xuebao/Chemical Journal of Chinese Universities, 2017, 38, 1737-1741.

65 J. Cang, C. W. Wang, P. C. Chen, Y. J. Lin, Y. C. Li and H. T. Chang, Anal. Methods, 2017, 9, 5254-5259.

66 B. Han, X. Hou, R. Xiang and G. He, Anal. Methods, 2017, 9, 4028-4032.

67 M. Zhao, H. Feng, J. Han, H. Ao and Z. Qian, Anal. Chim. Acta, 2017, 984, 202-210.

68 M. Zhao, Z. Qian, M. Zhong, Z. Chen, H. Ao and H. Feng, ACS Appl. Mater. Interfaces, 2017, 9, 32887-32895.

69 Y. Hu, Y. He, Y. Han, Y. Ge, G. Song and J. Zhou, Microchim. Acta, 2019, 186, 5.

70 S. Gou, Y.-e. Shi, P. Li, H. Wang, T. Li, X. Zhuang, W. Li and Z. Wang, ACS Appl. Mater. Interfaces, 2019, 11, 6561-6567.

71 S. Yang, X. Sun and Y. Chen, Mater. Lett., 2017, 194, 5-8.

72 J. R. Bhamore, S. Jha, A. K. Mungara, R. K. Singhal, D. Sonkeshariya and S. K. Kailasa, Biosens. Bioelectron., 2016, 80, 243-248.
73 J. Ye, X. Dong, H. Jiang and X. Wang, J. Mater. Chem. B, 2017, 5, 691-696.

74 J.-M. Xia, X. Wei, X.-W. Chen, Y. Shu and J.-H. Wang, Microchim. Acta, 2018, 185, 205.

75 A. Dutta, U. Goswami and A. Chattopadhyay, ACS Appl. Mater. Interfaces, 2018, 10, 19459-19472.

76 F. Gao, P. Cai, W. Yang, J. Xue, L. Gao, R. Liu, Y. Wang, Y. Zhao, X. He and L. Zhao, ACS Nano, 2015, 9, 4976-4986.

77 U. Goswami, A. Dutta, A. Raza, R. Kandimalla, S. Kalita, S. S. Ghosh and A. Chattopadhyay, ACS Appl. Mater. Interfaces, 2018, 10, 3282-3294.

78 A. Choksi, X. Zhang, G. S. Heo, H. Luehmann and Y. Liu, J. Nucl. Med., 2018, 59, 1122.

79 S. Maity, D. Bain, K. Bhattacharyya, S. Das, R. Bera, B. Jana, B. Paramanik, A. Datta and A. Patra, J. Phys. Chem. C, 2017, 122, 13354-13362.

80 P. Yuan, R. Chen, X. Zhang, F. Chen, J. Yan, C. Sun, D. Ou, J. Peng, S. Lin and Z. Tang, Angew. Chem., Int. Ed., 2019, 58, 835-839.

81 Z. Wu, J. Liu, Y. Gao, H. Liu, T. Li, H. Zou, Z. Wang, K. Zhang, Y. Wang and H. Zhang, J. Am. Chem. Soc., 2015, 137, 12906-12913.

82 L. Ai, W. Jiang, Z. Liu, J. Liu, Y. Gao, H. Zou, Z. Wu, Z. Wang, Y. Liu and H. Zhang, Nanoscale, 2017, 9, 12618-12627.

83 Z. Wang, Y. e. Shi, X. Yang, Y. Xiong, Y. Li, B. Chen, W. F. Lai and A. L. Rogach, Adv. Funct. Mater., 2018, 28, 1802848.

84 D. Li, G. Wang, L. Cheng, C. Wang and X. Mei, ACS Omega, 2018, 3, 14755-14765.

85 D. Li, G. Wang, Y. Peng, Z. Chen, X. Gao, L. Cheng and X. Mei, Nanoscale Adv., 2019, 1, 1086-1095.

86 J. Li, J.-J. Zhu and K. Xu, TrAC, Trends Anal. Chem., 2014, 58, 90-98.

87 A. C. Bhowal, S. Pandit and S. Kundu, J. Phys. D: Appl. Phys., 2019, 52, 015302.

88 J. Bornacelli, C. Torres-Torres, H. Silva-Pereyra, G. LabradaDelgado, A. Crespo-Sosa, J. Cheang-Wong and A. Oliver, Sci. Rep., 2019, 9, 5699.

89 G. S. Yuvasri, N. Goswami and J. Xie, Principles and Applications of Aggregation-Induced Emission, Springer, 2019, pp. 265-289.

90 G. Wang, T. Huang, R. W. Murray, L. Menard and R. G. Nuzzo, J. Am. Chem. Soc., 2005, 127, 812-813.

91 G. Wang, R. Guo, G. Kalyuzhny, J.-P. Choi and R. W. Murray, J. Phys. Chem. B, 2006, 110, 20282-20289.

92 S. Maity, D. Bain and A. Patra, J. Phys. Chem. C, 2019, 123, 2506-2515.

93 Y. Wang, Y.-e. Shi, T. Li, H. Wang, Y. Li, Y. Xiong, S. Peng and Z. Wang, Nanoscale Adv., 2019, 1, 834-839.

94 R. Jalili and A. Khataee, Microchim. Acta, 2019, 186, 29.

95 Y. Guo, F. Cao, X. Lei, L. Mang, S. Cheng and J. Song, Nanoscale, 2016, 8, 4852-4863.

96 W. Wei, Y. Lu, W. Chen and S. Chen, J. Am. Chem. Soc., 2011, 133, 2060-2063.

97 Z. Qing, X. He, D. He, K. Wang, F. Xu, T. Qing and X. Yang, Angew. Chem., Int. Ed., 2013, 52, 9719-9722. 
98 C. Wang, L. Ling, Y. Yao and Q. Song, Nano Res., 2015, 8, 1975-1986.

99 A. W. Cook and T. W. Hayton, Acc. Chem. Res., 2018, 51, 2456-2464.

100 H.-H. Deng, K.-L. Li, Q.-Q. Zhuang, H.-P. Peng, Q.-Q. Zhuang, A.-L. Liu, X.-H. Xia and W. Chen, Nanoscale, 2018, 10, 6467-6473.

101 Z. Wang, B. Chen, A. S. Susha, W. Wang, C. J. Reckmeier, R. Chen, H. Zhong and A. L. Rogach, Adv. Sci., 2016, 3, 1600182.

102 Z. Wu, H. Liu, T. Li, J. Liu, J. Yin, O. F. Mohammed, O. M. Bakr, Y. Liu, B. Yang and H. Zhang, J. Am. Chem. Soc., 2017, 139, 4318-4321.

103 K. D. M. Weerawardene, H. Häkkinen and C. M. Aikens, Annu. Rev. Phys. Chem., 2018, 69, 205-229.

104 Y. Du, H. Sheng, D. Astruc and M. Zhu, Chem. Rev., 2019, DOI: 10.1021/acs.chemrev.8b00726.

105 Y. Huang, H. Feng, W. Liu, S. Zhang, C. Tang, J. Chen and Z. Qian, J. Mater. Chem. B, 2017, 5, 5120-5127.

106 C. Wang, H. Cheng, Y. Huang, Z. Xu, H. Lin and C. Zhang, Analyst, 2015, 140, 5634-5639.

107 N. K. Das, S. Ghosh, A. Priya, S. Datta and S. Mukherjee, J. Phys. Chem. C, 2015, 119, 24657-24664.

108 H. Huang, H. Li, J.-J. Feng, H. Feng, A.-J. Wang and Z. Qian, Sens. Actuators, B, 2017, 241, 292-297.

109 J. Liu, Q. M. Zhang, Y. Feng, Z. Zhou and K. Shih, ChemPhysChem, 2016, 17, 225-231.

110 A. Baghdasaryan, R. Grillo, S. Roy Bhattacharya, M. Sharma, E. Reginato, H. Theraulaz, I. Dolamic, M. Dadras, S. Rudaz and E. Varesio, ACS Appl. Nano Mater., 2018, 1, 4258-4267.

111 B. Han, X. Hu, M. Yu, T. Peng, Y. Li and G. He, RSC Adv., 2018, 8, 22748-22754.

112 Y. Huang, W. Liu, H. Feng, Y. Ye, C. Tang, H. Ao, M. Zhao, G. Chen, J. Chen and Z. Qian, Anal. Chem., 2016, 88, 7429-7434.

113 H.-Y. Huang, K.-B. Cai, M. J. Talite, W.-C. Chou, P.-W. Chen and C.-T. Yuan, Sci. Rep., 2019, 9, 4053.

114 A. Ganguly, I. Chakraborty, T. Udayabhaskararao and T. Pradeep, J. Nanopart. Res., 2013, 15, 1522.

115 X. Liu, W. Ding, Y. Wu, C. Zeng, Z. Luo and H. Fu, Nanoscale, 2017, 9, 3986-3994.

116 S. M. Lin, S. Geng, N. Li, N. B. Li and H. Q. Luo, Talanta, 2016, 151, 106-113.

117 Y. Du, J. Fang, H. Wang and Y. Yang, ACS Appl. Mater. Interfaces, 2017, 9, 11035-11044.

118 Y.-S. Borghei, M. Hosseini, M. Khoobi and M. R. Ganjali, J. Fluoresc., 2017, 27, 529-536.

119 Y. S. Borghei, M. Hosseini, M. Khoobi and M. R. Ganjali, Luminescence, 2017, 32, 1045-1050.

120 N. Goswami, K. Zheng and J. Xie, Nanoscale, 2014, 6, 13328-13347.

121 X. Su and J. Liu, ACS Appl. Mater. Interfaces, 2017, 9, 3902-3910.

122 K. Khonkayan, S. Sansuk, S. Srijaranai, T. Tuntulani, C. Saiyasombat, W. Busayaporn and W. Ngeontae, Microchim. Acta, 2017, 184, 2965-2974.
123 S. Sharma, K. K. Chakrahari, J.-Y. Saillard and C. Liu, Acc. Chem. Res., 2018, 51, 2475-2483.

124 M. Cui, G. Song, C. Wang and Q. Song, Microchim. Acta, 2015, 182, 1371-1377.

125 T. Zhou, W. Xu, Q. Yao, T. Zhao and X. Chen, Methods Appl. Fluoresc., 2015, 3, 044002.

126 T. Zhou, Q. Yao, T. Zhao and X. Chen, Talanta, 2015, 141, 80-85.

127 Y.-J. Lin, P.-C. Chen, Z. Yuan, J.-Y. Ma and H.-T. Chang, Chem. Commun., 2015, 51, 11983-11986.

128 S. Zhou, Y. Li, F. Wang and C. Wang, RSC Adv., 2016, 6, 38897-38905.

129 K. T. Prakash, N. Singh and V. Venkatesh, Chem. Commun., 2019, 55, 322-325.

130 J.-S. Shen, Y.-L. Chen, Q.-P. Wang, T. Yu, X.-Y. Huang, Y. Yang and H.-W. Zhang, J. Mater. Chem. C, 2013, 1, 2092-2096.

131 X.-J. Zheng, R.-P. Liang, Z.-J. Li, L. Zhang and J.-D. Qiu, Sens. Actuators, B, 2016, 230, 314-319.

132 A. Rotaru, S. Dutta, E. Jentzsch, K. Gothelf and A. Mokhir, Angew. Chem., Int. Ed., 2010, 49, 5665-5667.

133 B. Han, R. Xiang, X. Hou, M. Yu, T. Peng, Y. Li and G. He, Anal. Methods, 2017, 9, 2590-2595.

134 F. Zhou, X. Cui, A. Shang, J. Lian, L. Yang, Y. Jin and B. Li, Microchim. Acta, 2017, 184, 773-779.

135 Q. Song, Y. Shi, D. He, S. Xu and J. Ouyang, Chem. - Eur. J., 2015, 21, 2417-2422.

136 G. Liu, Y. Shao, J. Peng, W. Dai, L. Liu, S. Xu, F. Wu and X. Wu, Nanotechnology, 2013, 24, 345502.

137 Y. Ling, N. Zhang, F. Qu, T. Wen, Z. F. Gao, N. B. Li and H. Q. Luo, Spectrochim. Acta, Part A, 2014, 118, 315-320.

138 J. Feng, Y. Ju, J. Liu, H. Zhang and X. Chen, Anal. Chim. Acta, 2015, 854, 153-160.

139 M. Zhao, L. Sun and R. M. Crooks, J. Am. Chem. Soc., 1998, 120, 4877-4878.

140 N. Vilar-Vidal, J. Rivas and M. A. Lopez-Quintela, ACS Catal., 2012, 2, 1693-1697.

141 L. Balogh and D. A. Tomalia, J. Am. Chem. Soc., 1998, 120, 7355-7356.

142 P. N. Floriano, C. O. Noble IV, J. M. Schoonmaker, E. D. Poliakoff and R. L. McCarley, J. Am. Chem. Soc., 2001, 123, 10545-10553.

143 R. Ghosh, U. Goswami, S. S. Ghosh, A. Paul and A. Chattopadhyay, ACS Appl. Mater. Interfaces, 2014, 7, 209-222.

144 Z. Wang, A. S. Susha, B. Chen, C. Reckmeier, O. Tomanec, R. Zboril, H. Zhong and A. L. Rogach, Nanoscale, 2016, 8, 7197-7202.

145 H. Zhang, X. Huang, L. Li, G. Zhang, I. Hussain, Z. Li and B. Tan, Chem. Commun., 2012, 48, 567-569.

146 Z. Yan, Q. Niu, M. Mou, Y. Wu, X. Liu and S. Liao, J. Nanopart. Res., 2017, 19, 235.

147 L. Xiaoqing, L. Ruiyi, L. Zaijun, S. Xiulan, W. Zhouping and L. Junkang, New J. Chem., 2015, 39, 5240-5248.

148 N. Goswami, A. Giri, M. Bootharaju, P. L. Xavier, T. Pradeep and S. K. Pal, Anal. Chem., 2011, 83, 9676-9680. 
149 M. Chen, W. Li, H. Xiong, W. Wen, X. Zhang and S. Wang, Microchim. Acta, 2017, 1-8.

150 L. Zhao and Z. Ma, Sens. Actuators, B, 2017, 241, 849-854.

151 H. Miao, D. Zhong, Z. Zhou and X. Yang, Nanoscale, 2015, 7, 19066-19072.

152 R. Ghosh, A. K. Sahoo, S. S. Ghosh, A. Paul and A. Chattopadhyay, ACS Appl. Mater. Interfaces, 2014, 6, 3822-3828.

153 L. Jin, Z. Zhang, A. Tang, C. Li and Y. Shen, Biosens. Bioelectron., 2016, 79, 108-113.

154 Y. Wang, Y. Cui, R. Liu, Y. Wei, X. Jiang, H. Zhu, L. Gao, Y. Zhao, Z. Chai and X. Gao, Chem. Commun., 2013, 49, 10724-10726.

155 W. Wang, F. Leng, L. Zhan, Y. Chang, X. X. Yang, J. Lan and C. Z. Huang, Analyst, 2014, 139, 2990-2993.

156 Y. Ding, X. Li, C. Chen, J. Ling, W. Li, Y. Guo, J. Yan, L. Zha and J. Cai, Sci. Rep., 2017, 7, 9638.

157 Y. Qiao, T. Xu, Y. Zhang, C. Zhang, L. Shi, G. Zhang, S. Shuang and C. Dong, Sens. Actuators, B, 2015, 220, 1064-1069.

158 X. Hu, X. Mao, X. Zhang and Y. Huang, Sens. Actuators, B, 2017, 247, 312-318.

159 S. Biswas, J. T. Miller, Y. Li, K. Nandakumar and C. S. Kumar, Small, 2012, 8, 688-698.

160 M. T. Reetz and W. Helbig, J. Am. Chem. Soc., 1994, 116, 7401-7402.

161 N. Vilar-Vidal, M. C. Blanco, M. A. López-Quintela, J. Rivas and C. Serra, J. Phys. Chem. C, 2010, 114, 15924-15930.

162 S. Huseyinova, J. Blanco, F. l. G. Requejo, J. M. RamalloLópez, M. C. Blanco, D. Buceta and M. A. López-Quintela, J. Phys. Chem. C, 2016, 120, 15902-15908.

163 N. Vilar-Vidal, J. R. Rey and M. A. López Quintela, Small, 2014, 10, 3632-3636.

164 X. Jia, J. Li and E. Wang, Small, 2013, 9, 3873-3879.

165 Z. Li, S. Guo and C. Lu, Analyst, 2015, 140, 2719-2725.

166 X. Yuan, Z. Luo, Q. Zhang, X. Zhang, Y. Zheng, J. Y. Lee and J. Xie, ACS Nano, 2011, 5, 8800-8808.

167 C. Vázquez-Vázquez, M. Bañobre-López, A. Mitra, M. A. López-Quintela and J. Rivas, Langmuir, 2009, 25, 8208-8216.

168 R. K. Koninti, S. Satpathi and P. Hazra, J. Phys. Chem. C, 2018, 122, 5742-5752.

169 H. Kawasaki, Y. Kosaka, Y. Myoujin, T. Narushima, T. Yonezawa and R. Arakawa, Chem. Commun., 2011, 47, 7740-7742.

170 C. Toh, X. Liu, P. Ho and J. Chen, IEEE Trans. Magn., 2011, 47, 4003-4006.

171 H. Haberland, M. Karrais, M. Mall and Y. Thurner, J. Vac. Sci. Technol., A, 1992, 10, 3266-3271.

172 J. Chen, C. Tan, S. Chow, B. Liu and G. Chow, J. Appl. Phys., 2005, 98, 064306.

173 S. Pan, X. Zhang, W. Lu and S. F. Yu, J. Mater. Chem. A, 2018, 6, 18687-18693.

174 M. Hyotanishi, Y. Isomura, H. Yamamoto, H. Kawasaki and Y. Obora, Chem. Commun., 2011, 47, 5750-5752.

175 X. Nie, H. Qian, Q. Ge, H. Xu and R. Jin, ACS Nano, 2012, 6, 6014-6022.

176 S. Jalili, C. Mochani, M. Akhavan and J. Schofield, Mol. Phys., 2012, 110, 267-276.
177 M. Liu, X. Qiu, K. Hashimoto and M. Miyauchi, J. Mater. Chem. A, 2014, 2, 13571-13579.

178 M. P. de Lara-Castells, A. W. Hauser, J. M. Ramallo-López, D. Buceta, L. J. Giovanetti, M. A. Lopez-Quintela and F. Requejo, J. Mater. Chem. A, 2019, 7, 7489-7500.

179 B. Beguin, B. Denise and R. Sneeden, J. Organomet. Chem., 1981, 208, C18-C20.

180 Q. Tang, Y. Lee, D.-Y. Li, W. Choi, C. W. Liu, D. Lee and D.-e. Jiang, J. Am. Chem. Soc., 2017, 139, 9728-9736.

181 J. Fang, B. Zhang, Q. Yao, Y. Yang, J. Xie and N. Yan, Coord. Chem. Rev., 2016, 322, 1-29.

182 C. Sun, N. Mammen, S. Kaappa, P. Yuan, G. Deng, C. Zhao, J. Yan, S. Malola, K. Honkala and H. Häkkinen, ACS Nano, 2019, 13, 5975-5986.

183 B. Zhang, A. Sels, G. Salassa, S. Pollitt, V. Truttmann, C. Rameshan, J. Llorca, W. Olszewski, G. Rupprechter and T. Bürgi, ChemCatChem, 2018, 10, 5372-5376.

184 O. Lopez-Acevedo, K. A. Kacprzak, J. Akola and H. Häkkinen, Nat. Chem., 2010, 2, 329-334.

185 W. Chen and S. Chen, Angew. Chem., Int. Ed., 2009, 48, 4386-4389.

186 Y. Lu and W. Chen, J. Power Sources, 2012, 197, 107-110.

187 Y. Lu, W. Wei and W. Chen, Chin. Sci. Bull., 2012, 57, 41-47.

188 W. Wei and W. Chen, Int. J. Smart Nano Mater., 2013, 4, 62-71.

189 Q.-Y. Zhang, Q.-F. Zhao, X.-M. Liang, X.-L. Wang, F.-X. Ma, B.-B. Suo, W.-L. Zou, H.-X. Han, Q. Song and Q. Wu, Int. J. Hydrogen Energy, 2018, 43, 9935-9942.

190 M. Takahashi, H. Koizumi, W.-J. Chun, M. Kori, T. Imaoka and K. Yamamoto, Sci. Adv., 2017, 3, e1700101.

191 L. He, H. Liu, C.-X. Xiao and Y. Kou, Green Chem., 2008, 10, 619-622.

192 B. Sarkar, C. Pendem, L. N. Sivakumar Konathala, R. Tiwari, T. Sasaki and R. Bal, Chem. Commun., 2014, 50, 9707-9710.

193 A. A. Athawale and S. V. Bhagwat, J. Appl. Polym. Sci., 2003, 89, 2412-2417.

194 L. Hu, Y. Yuan, L. Zhang, J. Zhao, S. Majeed and G. Xu, Anal. Chim. Acta, 2013, 762, 83-86.

195 D. Tang and J. Zhang, RSC Adv., 2013, 3, 15225-15236.

196 R. S. Dhayal, H. P. Chen, J. H. Liao, W. E. van Zyl and C. Liu, ChemistrySelect, 2018, 3, 3603-3610.

197 S. S. Tafreshi, A. Roldan and N. H. de Leeuw, J. Phys. Chem. C, 2014, 118, 26103-26114.

198 R. A. Hoyt, M. M. Montemore and E. Kaxiras, J. Phys. Chem. Lett., 2018, 9, 5339-5343.

199 V. V. Rostovtsev, L. G. Green, V. V. Fokin and K. B. Sharpless, Angew. Chem., 2002, 114, 2708-2711.

200 B.-H. Lee, C.-C. Wu, X. Fang, C. Liu and J.-L. Zhu, Catal. Lett., 2013, 143, 572-577.

201 Y. Zhong, Q. Wang, Y. He, Y. Ge and G. Song, Sens. Actuators, B, 2015, 209, 147-153.

202 J. Liu, Z. Wu, Y. Tian, Y. Li, L. Ai, T. Li, H. Zou, Y. Liu, X. Zhang and H. Zhang, ACS Appl. Mater. Interfaces, 2017, 9, 24899-24907.

203 G. Zhang, R. Wang, L. Shi, C. Zhang, Y. Zhang, Y. Zhou, C. Dong, G. Li and S. Shuang, Sens. Actuators, B, 2019, 279, 361-368. 
204 H. Cao, Z. Chen and Y. Huang, Talanta, 2015, 143, 450-456.

205 L. Ruiyi, W. Huiying, Z. Xiaoyan, L. Xiaoqing, S. Xiulan and L. Zaijun, New J. Chem., 2016, 40, 732-739.

206 X. Hu, W. Wang and Y. Huang, Talanta, 2016, 154, 409-415.

207 X. Yang, Y. Feng, S. Zhu, Y. Luo, Y. Zhuo and Y. Dou, Anal. Chim. Acta, 2014, 847, 49-54.

208 D. Li, Z. Chen, Z. Wan, T. Yang, H. Wang and X. Mei, RSC Adv., 2016, 6, 34090-34095.

209 L. Lin, Y. Hu, L. Zhang, Y. Huang and S. Zhao, Biosens. Bioelectron., 2017, 94, 523-529.

210 S. M. Lin, S. Geng, N. Li, S. G. Liu, N. B. Li and H. Q. Luo, Sens. Actuators, B, 2017, 252, 912-918.

211 H. Y. Zou, J. Lan and C. Z. Huang, RSC Adv., 2015, 5, 55832-55838.

212 N. K. Das, S. Ghosh, A. Priya, S. Datta and S. Mukherjee, J. Phys. Chem. C, 2015, 119, 24657-24664.

213 Z. Shojaeifard, N. Heidari and B. Hemmateenejad, Spectrochim. Acta, Part A, 2019, 209, 202-208.

214 J. Liu, B. Wang, M. Xu, L. Wang and Z. Zhou, J. Lumin., 2017, 185, 258-262.

215 D. Q. Feng, W. Zhu, G. Liu and W. Wang, RSC Adv., 2016, 6, 96729-96734.

216 L. Kong, X. Chu, W. Liu, Y. Yao, P. Zhu and X. Ling, New J. Chem., 2016, 40, 4744-4750.

217 Y. S. Lin, T. C. Chiu and C. C. Hu, RSC Adv., 2019, 9, 9228-9234.

218 Z.-C. Liu, J.-W. Qi, C. Hu, L. Zhang, W. Song, R.-P. Liang and J.-D. Qiu, Anal. Chim. Acta, 2015, 895, 95-103.

219 D. Li, B. Li and S. I. Yang, Anal. Methods, 2015, 7, 2278-2282.

220 Z. Shen, C. Zhang, X. Yu, J. Li, B. Liu and Z. Zhang, Microchem. J., 2019, 145, 517-522.

221 Y. Huang, W. Liu, H. Feng, Y. Ye, C. Tang, H. Ao, M. Zhao, G. Chen, J. Chen and Z. Qian, Anal. Chem., 2016, 88, 7429-7434.

222 P.-C. Chen, Y.-C. Li, J.-Y. Ma, J.-Y. Huang, C.-F. Chen and H.-T. Chang, Sci. Rep., 2016, 6, 24882.

223 J. Y. Ma, P. C. Chen and H. T. Chang, Nanotechnology, 2014, 25, 195502.

224 U. Sivasankaran, J. Radecki, H. Radecka and K. Girish Kumar, Luminescence, 2019, 34, 243-248.

225 Z. Wang, C. C. Zhang, J. Gao and Q. Wang, J. Lumin., 2017, 190, 115-122.

226 R. S. Aparna, J. S. Anjali Devi, P. Sachidanandan and S. George, Sens. Actuators, B, 2018, 254, 811-819.

227 Z. Wang, R. Chen, Y. Xiong, K. Cepe, J. Schneider, R. Zboril, C. S. Lee and A. L. Rogach, Part. Part. Syst. Charact., 2017, 34, 1700029.

228 H. Li, J. Chang, T. Hou, L. Ge and F. Li, Talanta, 2016, 160, 475-480.

229 H.-W. Zhu, W.-X. Dai, X.-D. Yu, J.-J. Xu and H.-Y. Chen, Talanta, 2015, 144, 642-647.

230 Y. Nerthigan, A. K. Sharma, S. Pandey and H. F. Wu, Microchim. Acta, 2019, 186(3), 130.

231 X. Zhang, Q. Liu, Y. Jin and B. Li, ChemistrySelect, 2019, 4, 2398-2403.

232 R. Liu, L. Zuo, X. Huang, S. Liu, G. Yang, S. Li and C. Lv, Microchim. Acta, 2019, 186, 250.
233 H. Jiang and X.-M. Wang, Chin. J. Anal. Chem., 2017, 45, 1776-1785.

234 Q. Song, Y. Shi, D. He, S. Xu and J. Ouyang, Chem. - Eur. J., 2015, 21, 2417-2422.

235 L. Zhao and Z. Ma, Sens. Actuators, B, 2017, 241, 849-854.

236 C. Wang, S. Shu, Y. Yao and Q. Song, RSC Adv., 2015, 5, 101599-101606.

237 Y. Zhou, H. Wang, H. Zhang, Y. Chai and R. Yuan, Anal. Chem., 2018, 90, 3543-3549.

238 C. Muñoz-Bustos, A. Tirado-Guízar, F. Paraguay-Delgado and G. Pina-Luis, Sens. Actuators, B, 2017, 244, 922-927.

239 Z. Gao, R. Su, W. Qi, L. Wang and Z. He, Sens. Actuators, B, 2014, 195, 359-364.

240 N. Zhang, F. Qu, H. Q. Luo and N. B. Li, Anal. Chim. Acta, 2013, 791, 46-50.

241 S. Xu, Y. Wang, D. Zhou, M. Kuang, D. Fang, W. Yang, S. Wei and L. Ma, Sci. Rep., 2016, 6, 39157.

242 W. Li, W. Li, Y. Hu, Y. Xia, Q. Shen, Z. Nie, Y. Huang and S. Yao, Biosens. Bioelectron., 2013, 47, 345-349.

243 Y. Hu, Q. Zhang, L. Xu, J. Wang, J. Rao, Z. Guo and S. Wang, Anal. Bioanal. Chem., 2017, 409, 6677-6688.

244 L. Wang, M. Wang, F. Shi, Z. Liu and X. Su, Sens. Actuators, $B, 2017,252,209-214$.

245 H. Zhao, J. Dong, F. Zhou and B. Li, Sens. Actuators, B, 2017, 238, 828-833.

246 Y. Zhang, Y. Li, C. Zhang, Q. Zhang, X. Huang, M. Yang, S. A. Shahzad, K. K.-W. Lo, C. Yu and S. Jiang, Anal. Bioanal. Chem., 2017, 409, 4771-4778.

247 Y. Hong, J. W. Y. Lam and B. Z. Tang, Chem. Soc. Rev., 2011, 40, 5361-5388.

248 T. Qing, C. Long, X. Wang, K. Zhang, P. Zhang and B. Feng, Microchim. Acta, 2019, 186, 248.

249 M. Ye, Y. Yu, B. Lin, Y. Cai, Y. Cao, M. Guo and D. Zhu, Sens. Actuators, B, 2019, 284, 36-44.

250 Q. Liu, Q. Lai, N. Li and X. Su, Microchim. Acta, 2018, $185,182$.

251 Y. Huang, H. Feng, W. Liu, Y. Zhou, C. Tang, H. Ao, M. Zhao, G. Chen, J. Chen and Z. Qian, Anal. Chem., 2016, 88, 11575-11583.

252 X.-d. Wang, O. S. Wolfbeis and R. J. Meier, Chem. Soc. Rev., 2013, 42, 7834-7869.

253 X. Ma, Y. Wang, T. Zhao, Y. Li, L.-C. Su, Z. Wang, G. Huang, B. D. Sumer and J. Gao, J. Am. Chem. Soc., 2014, 136, 11085-11092.

254 L. Xiaoqing, L. Ruiyi, L. Xiaohuan and L. Zaijun, $R S C A d v$, 2015, 5, 48835-48841.

255 S. Uchiyama, Y. Matsumura, A. P. de Silva and K. Iwai, Anal. Chem., 2003, 75, 5926-5935.

256 F. H. C. Wong, D. S. Banks, A. Abu-Arish and C. Fradin, J. Am. Chem. Soc., 2007, 129, 10302-10303.

257 L. Wang, H. Miao, D. Zhong and X. Yang, Anal. Methods, 2016, 8, 40-44.

258 T. Zhao, X.-W. He, W.-Y. Li and Y.-K. Zhang, J. Mater. Chem. $B, 2015,3,2388-2394$.

259 M. Karimi, P. Sahandi Zangabad, A. Ghasemi, M. Amiri, M. Bahrami, H. Malekzad, H. Ghahramanzadeh Asl, 
Z. Mahdieh, M. Bozorgomid and A. Ghasemi, ACS Appl. Mater. Interfaces, 2016, 8, 21107-21133.

260 P. S. Zangabad, S. Mirkiani, S. Shahsavari, B. Masoudi, M. Masroor, H. Hamed, Z. Jafari, Y. D. Taghipour, H. Hashemi and M. Karimi, Nanotechnol. Rev., 2018, 7, 95-122.

261 Z. Liu, X. Jin, S. Zhang and Y. Tian, Anal. Chem., 2019, 91, 2488-2497.

262 S. Shahsavari, J. Nanomed. Res., 2017, 5, 000101.

263 R. Siegel, D. Naishadham and A. Jemal, Ca-Cancer J. Clin., 2013, 63, 11-30.

264 M. Shokeen and C. J. Anderson, Acc. Chem. Res., 2009, 42, 832-841.

265 H. Lyon, Biotech. Histochem., 2002, 77, 57-80.

266 X. Zhu, H. Shi, Y. Shen, B. Zhang, J. Zhao and G. Li, Nano Res., 2015, 8, 2714-2720.

267 K. Nakatani, ChemBioChem, 2004, 5, 1623-1633.

268 X. Jia, J. Li, L. Han, J. Ren, X. Yang and E. Wang, ACS Nano, 2012, 6, 3311-3317.

269 A. Abi and E. E. Ferapontova, J. Am. Chem. Soc., 2012, 134, 14499-14507.

270 X. Zhu, S. Liu, J. Cao, X. Mao and G. Li, Sci. Rep., 2016, 6, 19515.

271 K. Zheng, M. I. Setyawati, D. T. Leong and J. Xie, ACS Nano, 2017, 11, 6904-6910.
272 S. Wang, Y. Wang, Y. Peng and X. Yang, ACS Appl. Mater. Interfaces, 2019, 11, 8461-8469.

273 A. T. Simon, D. Dutta, A. Chattopadhyay and S. S. Ghosh, ACS Omega, 2019, 4, 4697-4706.

274 S. Kundu and A. Patra, Chem. Rev., 2016, 117, 712-757.

275 H. Choi, Y.-S. Chen, K. G. Stamplecoskie and P. V. Kamat, J. Phys. Chem. Lett., 2014, 6, 217-223.

276 K. G. Stamplecoskie and P. V. Kamat, J. Am. Chem. Soc., 2014, 136, 11093-11099.

277 S. C. Erwin, L. Zu, M. I. Haftel, A. L. Efros, T. A. Kennedy and D. J. Norris, Nature, 2005, 436, 91-94.

278 Z. Wang, B. Chen, M. Zhu, S. V. Kershaw, C. Zhi, H. Zhong and A. L. Rogach, ACS Appl. Mater. Interfaces, 2016, 8, 33993-33998.

279 Y. Liu, D. Yao and H. Zhang, ACS Appl. Mater. Interfaces, 2017, 10, 12071-12080.

280 H. Wang, Z. Wang, Y. Xiong, S. V. Kershaw, T. Li, Y. Wang, Y. Zhai and A. L. Rogach, Angew. Chem., Int. Ed., 2019, 58, 7040-7044.

281 Z. Wang, Y. Xiong, S. V. Kershaw, B. Chen, X. Yang, N. Goswami, W.-F. Lai, J. Xie and A. L. Rogach, Chem. Mater., 2017, 29, 10206-10211.

282 Y. e. Shi, X. Zhuang, L. Cao, S. Gou, Y. Xiong, W. F. Lai, Z. Wang and A. L. Rogach, ChemNanoMat, 2019, 5, 110-115. 